University of Louisville

ThinkIR: The University of Louisville's Institutional Repository

Electronic Theses and Dissertations

$5-2021$

\title{
The lived experience of women with head \& neck cancer and the impact on close relationships.
}

Georgia Anderson

University of Louisville

Follow this and additional works at: https://ir.library.louisville.edu/etd

Part of the Social Work Commons

\section{Recommended Citation}

Anderson, Georgia, "The lived experience of women with head \& neck cancer and the impact on close relationships." (2021). Electronic Theses and Dissertations. Paper 3646.

https://doi.org/10.18297/etd/3646

This Doctoral Dissertation is brought to you for free and open access by ThinkIR: The University of Louisville's Institutional Repository. It has been accepted for inclusion in Electronic Theses and Dissertations by an authorized administrator of ThinkIR: The University of Louisville's Institutional Repository. This title appears here courtesy of the author, who has retained all other copyrights. For more information, please contact thinkir@louisville.edu. 
THE LIVED EXPERIENCE OF WOMEN WITH HEAD \& NECK CANCER AND THE IMPACT ON CLOSE RELATIONSHIPS

Georgia Anderson

B.A., Xavier University, 2004

MSW, University of Kentucky, 2007

\begin{abstract}
A Dissertation
Submitted to the Faculty of the Raymond A. Kent School of Social Work of $\mathrm{y}$ of The Universit Louisville In Partial Fulfillment of the

Requirements For the Degree of

Doctor of Philosophy in Social Work

Social Work

University of Louisville

Louisville, KY
\end{abstract}

May 2021 
CCopyright by

Georgia Anderson 



\title{
THE LIVED EXPERIENCE OF WOMEN WITH HEAD \& NECK CANCER AND THE IMPACT ON CLOSE RELATIONSHIPS
}

\author{
By \\ Georgia Anderson \\ B.A., Xavier University, 2004 \\ M.S.W., University of Kentucky, 2007
}

A Dissertation Approved on

April 29, 2021

By the Following Dissertation Committee:

(Karen Kayser) Chair

(Lesley Harris) Co-Chair

(Heehyul Moon)

(Tara Schapmire) 


\section{DEDICATION}

For my family - the ones who are blood and the ones who I chose. 


\section{ACKNOWLEDGMENTS}

There are so many people who were instrumental in my success in the doctoral program. First of all, thank you Dr. Karen Kayser for seeing my potential and encouraging me to pursue my doctoral degree. Your guidance, teaching, mentoring, and support helped me along every step of this journey. Thank you, Dr. Lesley Harris for cochairing my committee and teaching me the intricate world of qualitative research. You pushed me to do my best and cheered me on through my struggles. Dr. Heehyul Moon, thank you for your unwavering attention to detail and clear guidance. Dr. Tara Schapmire, thank you for helping me link my clinical experience with the world of research.

I appreciate the friendships I have made in the doctoral program and admire the intelligence and perseverance of each of my classmates. It has been my honor and privilege to take this journey with you.

Thank you to the faculty of the Kent School of Social Work. Dean Jenkins, Dr. Sar, Dr. Archuleta, Dr. Lawson, Dr. Gattis, and Sharon Sanders, M.S.W. - thank you for your instruction and helping me grow, not only as a scholar and educator, but a person.

My studies have been supported by an American Cancer Society Doctoral Social Work Training grant. This grant provided me with financial resources and mentorship that made my success possible.

Finally, I want to thank my family. To my husband, Don - without your support and encouragement this degree would be nothing more than a dream. You have always been proud of me and stood by my side. To my children, Auggie and Nora - thank you for sharing me with the university. I love you more than you will ever know. To my 
sister Ann - you are my biggest cheerleader and toughest audience. You have encouraged me to never give up and kept me laughing. Dear Kyla - thank you for always wearing your funny pants and being the best niece ever. To my mother, Belinda - you have made me the woman I am today. You always pushed me to be the best and to work hard. Thank you. To my father, John - I am sorry you did not live to see me finish this dissertation. But in the end, you told me you would be with me the whole time, even if you were not on Earth. I know you are watching. To my dear friends, my other brain cells - thank you for letting me lean on you and keeping me sane.

With the completion of this dissertation, I am certain my head is as full as my heart. 


\title{
ABSTRACT \\ THE LIVED EXPERIENCE OF WOMEN WITH HEAD \& NECK CANCER AND THE IMPACT ON CLOSE RELATIONSHIPS
}

\author{
Georgia Anderson
}

April 28, 2021

Background: Head and neck cancer (HNC) is emotionally and physically burdensome to people who are diagnosed with this disease. In the United States, nearly $30 \%$ of people diagnosed with HNC are women. Studies about depression and anxiety in this population have been conducted for decades; however, there are no studies that specifically examine the psychosocial implications of this disease from the perspective of women. Method: Women diagnosed with HNC were recruited from two academic medical centers in the Ohio-Kentucky-Indiana tri-state area to explore the lived experience of women with HNC and how this disease impacts their close relationships. Semistructured interviews were conducted with 10 women. Using grounded theory analysis techniques, themes emerged from the interviews to describe the experience of women living with HNC. 
Results: Women describe tremendous physical challenges throughout the treatment process and side effects lasting years after completing treatment. The women also experienced a range of emotions and employed various strategies to cope with their

disease. Many experienced increased closeness in their relationships with loved ones and described social support as one of the most valuable assets in their cancer journey. Conclusion: The experience of $\mathrm{HNC}$ is physically and emotionally difficult for women who are diagnosed with the disease. Women must adjust to changes in their appearance and lifestyle but are able to manage with increased closeness that develops in their close relationships. 


\section{TABLE OF CONTENTS}

PAGE

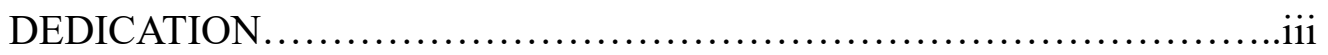

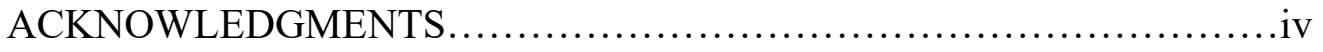

ABSTRACT ............................................................

CHAPTER I: INTRODUCTION.....................................

CHAPTER II: LITERATURE REVIEW................................ 9

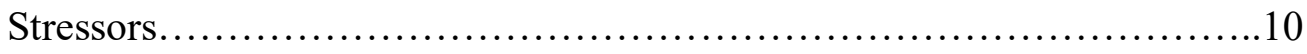

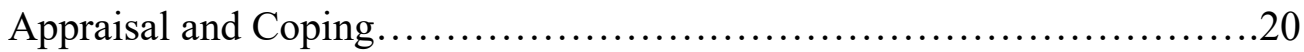

Theoretical Framework..................................................

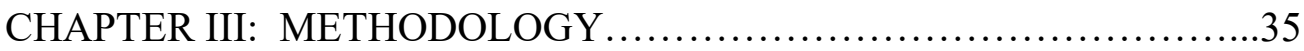

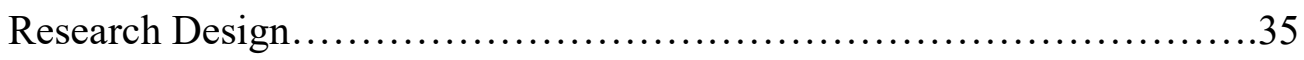

Philosophical Assumptions..............................................

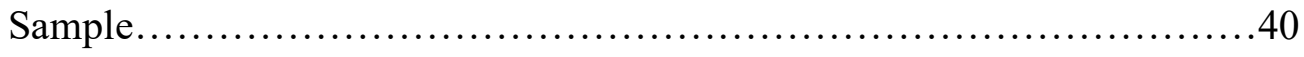

Ethical Considerations..............................................43

Data Collection........................................................ 43

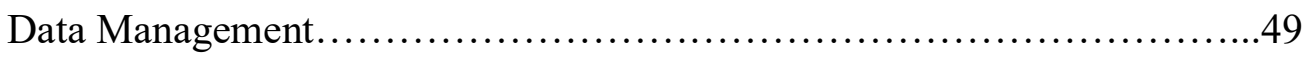

Data Analysis........................................................ 49 


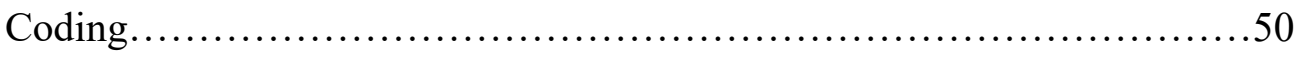

Memo Writing ..................................................... 52

Saturation and Sufficiency..........................................52

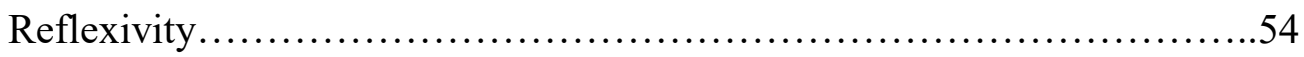

Trustworthiness and Rigor.......................................... 58

Writing and Dissemination............................................. 61

Representation....................................................... 61

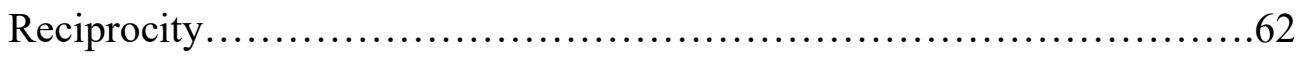

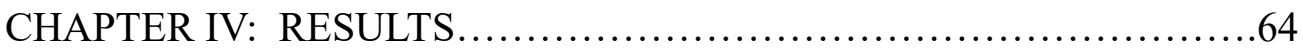

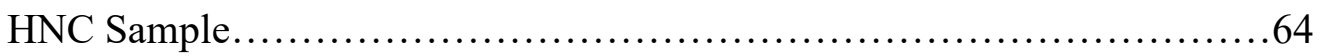

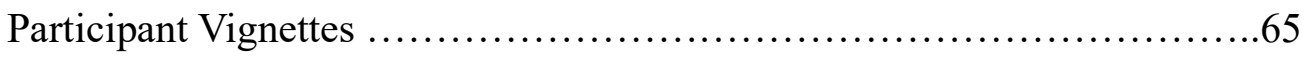

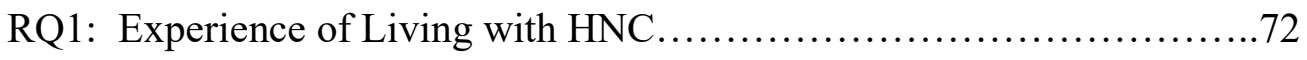

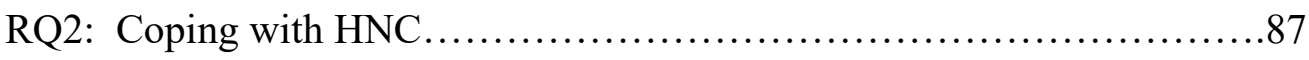

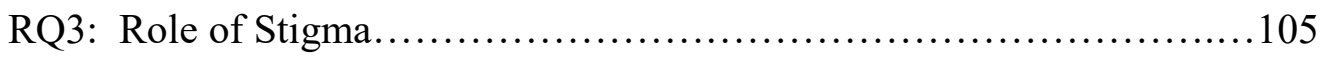

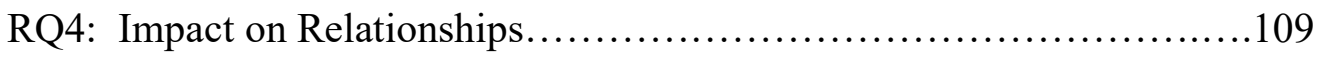

CHAPTER V: DISCUSSION AND IMPLICATIONS.....................116

Stressors Related to Living with HNC .................................117

Coping, Support and Close Relationships...............................123

Living with HNC during the Covid-19 Pandemic.........................126

Limitations and Future Direction for Research...........................128

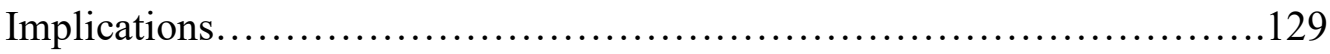

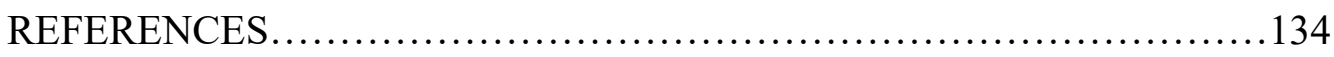

APPENDIX A: INTERVIEW GUIDE .................................. 153 
APPENDIX B: CONSENT ........................................ 155

APPENDIX C: FIELD NOTES TEMPLATE .........................158

APPENDIX D: PARTICIPANT INFORMATION SHEET .................160

APPENDIX E: INCLUSION CRITERION...........................161

APPENDIX F: HADS ............................................... 162

APPENDIX G: FACT-HN....................................... 163

APPENDIX H: FACT-HN SCORING ................................. 166

APPENDIX I: UNIVERSITY OF LOUISVILLE IRB..................168

APPENDIX J: UNIVERSITY OF CINCINNATI IRB..................171

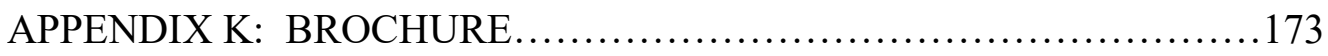

APPENDIX L: SAMPLE MEMO.................................. 175

APPENDIX M: CODING SAMPLE $-1^{\text {ST }}$ ITERATION ................... 177

APPENDIX N: CODING SAMPLE - $2^{\text {ND }}$ ITERATION .................. 179

APPENDIX O: CODING SAMPLE - $3^{\text {RD }}$ ITERATION ................. 180

APPENDIX P: PARENT/CHILD CODES........................... 181

CURRICULUM VITAE ............................................... 183 


\section{CHAPTER I: INTRODUCTION}

According to the Centers for Disease Control and Prevention (CDCP), women are diagnosed with head and neck cancer (HNC) at a rate of 6.4 per 100,000 compared to men at 17.6 (CDCP, 2018). The rate of women diagnosed with HNC has remained steady over the past twenty years (www.cancer.net), yet little research has been conducted on the psychosocial adjustment of woman with this disease. Most existing studies that report on the experience of psychosocial factors in HNC include a predominately male study population and in studies that include women with $\mathrm{HNC}$, there is no reporting of psychosocial factors by gender. To address the psychosocial needs of women with HNC with evidence-based interventions, oncology social workers need to understand how women live with this disease and identify any unique stresses and coping strategies that may exist for women with HNC. 
Worldwide, $\mathrm{HNC}$ accounts for $3 \%$ of all cancers, making it the eighth most common diagnosis (Garfield, et. al 2020). According to the Global Cancer Statistics, 929,931 new HNC diagnoses were made in 2020, with 467,125 people dying of $\mathrm{HNC}$ (Sung et. al, 2020). Global data shows that across all cancer diagnoses, men are more likely to be stricken. Men represent 10 million new diagnoses compared to 9.2 million women (Sung, et. al, 2020). Mortality is also higher for men at 5.5 million versus 4.4 million women (Sung, et. al, 2020). While it is true that men are more likely to get this disease, there are a large number of women living with HNC. The experience of those women with $\mathrm{HNC}$ is missing from the literature.

Looking at $\mathrm{HNC}$ rates in comparison to the ten most common cancers globally provides some perspective on this disease. Internationally, the ten most diagnosed cancers are (in order of most to least common): female breast, lung, prostate, nonmelanoma skin, colon, stomach, head \& neck, liver, rectum, and cervix uteri (Sung, et. al, 2020). Calculating the rate of mortality rate of each kind of cancer by dividing the number of deaths by the number of new cases in the year 2020, HNC was the fifth most deadly cancer. The most lethal cancers in order are: liver ( $92 \%$ death rate), cervix uteri (90\%), lung (81\%), stomach (71\%), HNC (50.23\%), colon (50.22\%), rectum (46\%), breast (30\%), and prostate (27\%). HNC may not be diagnosed as often as other types of cancer, but with such a high mortality rate (Sung, et al., 2020), addressing the needs of people with this disease is important.

In an annual report of cancer statistics published by the American Cancer Society, head and neck cancers, including those of the oral cavity, pharynx and larynx, account for 118,890 new diagnoses and 25,250 deaths during 2020 in the United States (Siegel, 
Miller, \& Jemal, 2020). Out of those incidents, 32,310 women were diagnosed and 6,730 died. The rate of diagnosis in women has remained steady for the past twenty years, but the mortality rate for women has increased $1.9 \%$ per year compared to $1.0 \%$ for men. In fact, oral cavity and pharyngeal cancers have the second most increased rate of mortality of all cancers in women (www.seer.cancer.gov/report to nation/). This is alarming when considering the mortality of all cancer sites in women has dropped $1.4 \%$ (www.seer.cancer.gov/report to nation/).

There are a variety of causes of head and neck cancer. According to the National Cancer Institute (NCI) the most common cause of these cancers are the use of alcohol and tobacco, which accounts for $75 \%$ of HNC diagnoses. People who use both alcohol and tobacco are at an increased risk (www.cancer.gov/types/head-and-neck-factsheet\#what-causes-cancers-of-the-head-and-neck). The next most common risk factor for $\mathrm{HNC}$ is being infected with the human papilloma virus (HPV). Other risk factors identified by NCI include the use of Paan (betel quid, commonly chewed in southeast Asia), poor oral health, occupational exposure (wood and nickel dust, formaldehyde, asbestos, and other construction related materials such as ceramic, textile and metal), radiation exposure, Epstein-Barr virus, and Asian ancestry (particularly Chinese heritage).

According to the CDCP, physical symptoms of $\mathrm{HNC}$ can present in a variety of ways depending on the location of the disease and the stage. Cancers inside the mouth may cause sores, unusual pain, swelling, bleeding, or lumps (www.cdc.gov/cancer/headneck/index.htm). Problems with chewing, swallowing, breathing, speaking, and pain in the throat or ears are symptoms of pharyngeal cancers. 
Laryngeal cancer presents with pain in the ears and when swallowing. Facial pain, nose bleeds, headaches, sinus infections that will not heal, swelling around the eyes, and upper tooth pain are common symptoms of cancers in the sinuses and nasal cavity (www.cdc.gov/cancer/headneck/index.htm).

Psychosocial symptoms include cognitive and behavioral changes in people with HNC. This includes neuropsychiatric symptoms, such as loss of appetite, changes in behaviors at night, less alertness, poor concentration, and slowed reactions. Depression, anxiety, irritability and avoidant attitudes such as apathy or indifference, are common symptoms (Bond, Hawkins, \& Murphy, 2014). Issues concerning eating, communication in couples, and fear of reoccurrence present significant challenges for those living with HNC (Ghazali et al., 2013; Hodges \& Humphris, 2009; Locher et al., 2010; Maguire et al., 2017; Mayre-Chilton, et al., 2011; Nund et al., 2015).

\section{Problem}

The experience of women with $\mathrm{HNC}$ is largely absent from the literature, which may lead to unnecessary suffering in this population. This suffering may include unmanaged depression, anxiety, or poor understanding of the disease trajectory and treatment side effects. As cited earlier, there are more men with HNC than women and the existing studies were conducted with a mostly male population. In studies that had women as participants, the results were not reported out by gender. This ambiguity makes the well-being of women with $\mathrm{HNC}$ unclear. As discussed in the theory section of this paper, relational-cultural theory suggests that women cope with stress within the context of relationships (Kayser, et al., 1999), which may be different from male coping. Otherwise, the literature provides minimal understanding about the experience of the 
disease, considering the patient's sex. In at least 17 studies reviewed for this dissertation (Table 1, chapter 2), when women are considered on the psychosocial aspects of HNC patients, it is often in the role of caregiver for a man with HNC. It is difficult to ascertain a clear picture of the experience of women with $\mathrm{HNC}$ because of a lack of voice and in the literature. This certainly leaves room for further exploration of the female perception of living with cancer in the United States.

Women are virtually absent in the psychosocial literature, with only a few studies reporting the rates of depression and anxiety by gender (Locher et. al, 2010; Moubayed et. al, 2015; Onakoya et al, 2006; and Schenck, 2002). These studies report symptomology for a total of 92 women who live across the globe (Canada, Nigeria, and the United States). Compared to the 9.2 million women diagnosed with $\mathrm{HNC}$ internationally in 2020 , these studies represent $0.001 \%$ of women in this population. The information known about women with $\mathrm{HNC}$ is miniscule, with only the Nigerian study reporting that women report more suffering than men on every metric, except for pain (Onakoya et. al, 2006).

\section{Purpose of the Study}

The purpose of this study is to gain an understanding of how women's lives are impacted by HNC. At this time, little is known about the psychosocial impact of HNC on women. In the entire HNC population, the literature states that those with the diagnosis have a $16-44 \%$ rate of depression (Chan, et. al, 2011). Suicide is markedly higher in the HNC population $(50.5$ per 100,000) compared to all other cancers (36 per $100,000)$ and the general population (12 per 100,000) (Zeller, 2006). Due to the fact that most people who have $\mathrm{HNC}$ are men, it is unclear how women experience $\mathrm{HNC}$. Based 
upon a study conducted by Chan and colleagues, when all other variables are controlled, having HNC is a strong predictor of depressive symptoms (Chan et al, 2011). The same study, which include men and women, found an 11 times greater risk of suicide in HNC patients who manifested depressive symptoms.

Comparative studies of coping and psychological symptomology between males and females have been conducted in other cancer populations. Lung and colorectal cancers have been examined in men and women with a range of results. In a longitudinal study of people with colorectal cancer, women reported more, long-lasting side effects from treatment than men (McCaughan, et. al, 2012). The men were more likely to deny any physical effects of having cancer and treatment, which was found to be linked to gender stereotypes. Differences between how men and woman cope with cancer have also been conducted. One such study found that men tend to engage in task-oriented, while women were more likely to utilize avoidance-oriented, emotion-oriented, and distraction-oriented coping (Michalowska, et. al, 2019). Patients who engaged in emotion-oriented coping displayed the highest levels of anxiety in this study (Michalowska, et. al, 2019). Given this information, it is reasonable to question how women with $\mathrm{HNC}$ are coping and if the level of suffering mirrors that of the HNC population that has been studied.

There is also a deficiency in what is understood about how women and their close relationships change and grow through the $\mathrm{HNC}$ journey. Women have been found to be more open to expressing the emotional aspects of coping with cancer than men and are more likely to demonstrate symptoms of Post-traumatic stress disorder (PTSD) than men (Hampton \& Frombach, 2000). By ascertaining an elementary understanding of the 
overarching experience of women with $\mathrm{HNC}$ and the functioning of their close relationships, future studies will have a foundation on which to build additional knowledge.

\section{Significance of the Study}

Establishing a research foundation can inform the development of psychosocial interventions to provide support for women with this disease. Not only is this information important for social workers, but it may also allow other medical professionals to be more aware of the challenges faced by their patients. Better understanding of how women live with their illness and treatment effects can help medical providers better prepare women for treatment and recovery after being diagnosed with HNC. Additionally, patients may be better informed when making treatment decisions and giving consent for treatment.

The significance of this study primarily impacts the head and neck oncology community. The absence of women's voices in the existing HNC researcher is notable. Social workers and other medical professionals are missing critical knowledge to inform social work practice with women with HNC. Psychosocial care is rarely a "one-size-fitsall" endeavor. The difficult physical and emotional nature of $\mathrm{HNC}$ is more complicated than any other cancer (Gil, et. al, 2012) and deserves a more robust understanding. This study adds to the broader psychosocial oncology and women's health literature.

The National Association of Social Work Code of Ethics dictates that social workers honor the dignity, inherent worth, and right to self-determination of those who are served (NASW, 2017). The code also states that social workers should "continually 
strive to increase their professional knowledge and skills and to apply them in practice." This study provides knowledge to inform the practice of social workers.

\section{Research Questions}

The goal of any qualitative descriptive study is to provide a rich description of a

phenomenon. This study seeks to understand what it is like to be woman living with head and neck cancer and how the diagnosis impacts close relationships. To meet this goal, four research questions were posed.

1. How do women describe their experience of living with HNC?

2. How do women describe their coping with cancer?

3. What role does stigma play in their experience?

4. What do women perceive to be the impact of the $\mathrm{HNC}$ on their close relationships?

\section{Research Design}

This study uses a qualitative descriptive method to capture a rich description of the experience of women living with $\mathrm{HNC}$ and how it impacts their relationships. Women were interviewed twice, two to three weeks apart, to gather a full description of their experience.

\section{Summary}

Studying the lived experience of women with head and neck cancer provides a basic understanding of this phenomenon. Women may be suffering with no representation in the literature about how they live with this disease. The next chapters will discuss the existing literature about $\mathrm{HNC}$, the methodology for this study, and the results. Finally, a full discussion about the findings and implications for practice will complete this study. 


\section{CHAPTER II: LITERATURE REVIEW}

This chapter will provide a general overview of the existing literature about HNC. Due to the lack of studies about the psychosocial impact of HNC on women, studies of other stigmatized cancers are included because the limited information know about women with HNC. Supplemental studies about other stigmatized cancers, such as lung and colon, will be used to explain what is known about women living with cancer. Finally, this chapter will examine literature about the impacts of cancer on caregivers, to give context for the emotional and physical environment that may impact the loved ones of women with cancer.

The combination of extensive physical and emotional challenges that come with HNC set the stage for it to be considered one of the most "traumatic" of cancer diagnoses (Björklund, et. al, 2010). This literature review will provide an overview of the physical and psychosocial challenges for people with HNC and caregivers because this study is 
specifically examining the experience of living with $\mathrm{HNC}$ and the impact on close relationships. To understand the impact on relationships, this review will define caregiving, close relationships, and typical coping in relationships affected by cancer.

\section{Stressors}

\section{Physical Stressors}

Communication challenges are common and frustrating in the general $\mathrm{HNC}$ population. The physical impact on communication includes changes in tone, volume, rate of speech, and increase in mouth dryness after treatment. Hearing is impacted by non-glottic head and neck cancers, which makes it difficult for patients to fully comprehend conversations happening around them (Nund et al., 2015). People with $\mathrm{HNC}$ often feel excluded from conversations due to a lack of understanding from others

about the patient's communication challenges (Nund et al., 2015). People with HNC may institute a self-imposed restriction on activities that include speaking, such as reading to their children or attending social functions, because of difficulties with speech (Nund et al., 2015).

Most notably, people with $\mathrm{HNC}$ often lose their ability to speak or have significant impairment in the ability to speak clearly. Studies have found between 60$80 \%$ of people with $\mathrm{HNC}$ have vocal problems after treatment (Hutcheson et. al, 2012; Kraaiijenja, et. al, 2015; Ouyoung, et. al, 2015). People who speak more extensively for their professions are more likely to notice differences in their vocal abilities (Ebersole et. al, 2018). All HNC and treatments can cause dysphonia, but laryngectomy most directly impacts speech. A recent study found that approximately $70 \%$ of people who have undergone laryngectomy procedures have communication issues. Women under the age 
of 60 years report a greater burden than older women and all men with $\mathrm{HNC}$, with $75 \%$ of those studied having challenges (Leemans et. al, 2019).

Not only do people with HNC experience challenges with speaking, but many are also faced with problems with eating. Studies about eating after HNC diagnosis and treatment highlight the psychosocial challenges. Sharing meals is often an event shared between the person with cancer and a loved one. One study explored how food preparation is viewed as an act of caring and how the changes in eating abilities impacts the relationship between the patient and caregiver (Locher et al., 2010). Struggles with roles within the relationship and gender-based responsibilities surfaced in in-depth interviews with thirty patients and their caregivers. They described their feelings of frustration, inadequacy, or guilt about the level of their participation in meal planning, preparation, and presentation of food (Locher et al., 2010). Caregivers voiced a greater level of distress about the feeding-tube, reporting stress about providing care for a medical intervention for which they had limited training, as well as the overall increased demand for caregiving created by the need for tube-feeding (Mayre-Chilton et al., 2011). On the other hand, patients reported feelings of higher self-efficacy as they mastered their tube-feed care and usage, as well as a reduction in distress because of weight loss (Mayre-Chilton et al., 2011). Both patients and caregivers could articulate the benefits of having a feeding-tube and appreciate the stress of the situation (Mayre-Chilton et al., 2011).

\section{Medical Complexity in Women with $\mathrm{HNC}$}

From a medical perspective, there are noted differences in how men and women experience the physical stressors related to HNC. As early as 1983, an increase in the 
rates of women with HNC was noted (McGuirt, 1983). In early studies on the rates of HNC among women, it was thought that increased rates were attributed to smoking and heavy alcohol consumption. Since that time multiple other risk factors have been identified in women. Women are commonly employed in job that pose occupational hazards for the development of HNC. It was found that squamous cell carcinoma was linked to women being exposed to perchloroethylene or trichloroethylene, both are chlorinated solvents. The women in these studies were most commonly in dry cleaning and laundering jobs, making shoes or leather goods, rubber and plastics workers, welders, and electronics workers. (Carton, et. al, 2016).

Oral health has also been associated with increased risk of HNC. A study in Vietnam found that women who rated their oral health poorly were more likely to also have human papilloma virus (HPV), a known risk factor for HNC (Cong Bui, et. al, 2015). This demonstrates that while the women may have been unaware of their HPV status, they were aware of deficiencies in their oral health.

Finally, hormones may play a part in the risk of women developing HNC. Studies have been conducted that indicate that fluctuating hormones during pregnancy and postmenopause have been linked to some incidents of HNC (Le Guevelou, et. al, 2019; Harshim, et. al, 2017). While neither of these studies found hormonal changes to be the definitive cause of $\mathrm{HNC}$, there was an observance of etiologic markers that raise suspicion. In the case of $\mathrm{HNC}$ in pregnant women, most were diagnosed with cancers of the oral cavity. These women were also noted to have the presence of "oncogenic viruses" and changes in their immune systems during pregnancy (Le Guevelou, et. al, 2019). This study documents beginning investigation of this link to HNC and advocates 
for ongoing study. The other study found that women who took hormone replacement therapy (HRT) had lower rates of $\mathrm{HNC}$, indicated another unexplored connection between this cancer and hormones (Hashim, et. al, 2017).

Two more studies found links to $\mathrm{HNC}$ in women with cervical and ovarian illnesses (Gaudet, et. al, 2014; Cannon, et. al, 2012). Women who had been diagnosed with certain strains of Cervical Intraepithelial Neoplasia (CIN2 and CIN3) and were HPV positive were discovered to be more at risk for anal cancer and $\mathrm{HNC}$ than cervical cancer (Gaudet, et. al, 2014). Other women who had been diagnosed with ovarian cancer were documented to have increased risk of $\mathrm{HNC}$ (Cannon, et. al, 2012). This study found it was not the ovarian cancer or an HPV infection that increased the risk of HNC, but rather the chemotherapy agent, pegylated liposomal doxorubicin (PDL), used to treat the ovarian cancer (Cannon, et. al, 2012). This study indicated further studies would be conducted and, in the meantime, women undergoing treatment with PDL would be advised to participate in monitoring for signs of oral cancer. These studies suggest that there are still unknown factors that contribute to the development of $\mathrm{HNC}$ in women.

\section{Treatment Disparities Between Men and Women}

Despite women with HNC being a relatively rare population, there are studies revealing treatment disparities between men and women (Joseph, et. al, 2015; Loupatatzi, et. al, 2014; and Park, et. al, 2019). Access to medical care, surgical complications, and overly conservative treatment plans for women are brought to light in these studies, adding to the need for more complete information about how women experience HNC.

Women were found to have higher mortality rates from HNC than men (Joseph, et al, 2015; Park, et al, 2019). There are a couple of reasons for a higher rate of mortality in 
women. First of all, it appears that there are delays in diagnosing $\mathrm{HNC}$ in women, especially among Black women (Joseph, et. al, 2015). In those who sought diagnosis and treatment of $\mathrm{HNC}$, women were less likely than men to be given platinum-based chemotherapies, which results in greater mortality (Park, et. al, 2019). Another treatment disparity documented in the literature involves surgical intervention. Free flap surgery involves the grafting of muscle, tissue, and vascular structures from an area such as the leg or arm, to reconstruct areas of the mouth that must be removed because of HNC. In a Greek study of people with free flap surgeries, women are more likely to have complications than men (Loupatatzi, et. al, 2014). The study examined many variables including, co-morbidities, alcohol use, time under anesthesia, history of radiation therapy, demographics, and physical status. Three of the variables were found to increase likelihood of complications: length of operation, having radiation therapy, and being a woman. Most notably, being a woman was the only variable that was statistically significant and occurred in conjunction with higher incidences and severity of complications (Loupatatzi, et. al, 2014). These studies certainly point to discrepancies in outcomes for women with $\mathrm{HNC}$ but raise questions about how women seek healthcare for potential HNC and how the medical community advises women who do seek care.

\section{Emotional Stressors}

Head and neck cancer affects not only the physical body, but also the mental health and emotional well-being of those who are diagnosed. Not only is the suffering in this population prolific, but it also often goes unnoticed by the medical team and unreported by patients (Moore, et. al, 2003). Many people with HNC fear that disclosing emotional suffering will lead to being prescribed medications that patients fear will lead 
them to addiction, such as anti-depressants, and exacerbating feelings of loss of control (Moore, et. al, 2003).

Worries about body image is a concern that appears frequently in the literature (Fingeret et al., 2012; Konradsen, et al., 2012; Konradsen, et al., 2009). Male and female patients have reported feeling embarrassed by their appearance, with as many as $75 \%$ of participants in one study citing this experience (Fingeret et al., 2012). The participants talked about the difficulty of being newly disfigured and how other people reacted to the disfigurement after leaving the hospital. They talked about coping with their own feelings about their appearance, as well as being mindful of how their looks impacted their loved ones (Konradsen et al., 2012). Not only were loved ones affected by the changes in appearance, but the patient's perceived their relationship with healthcare professionals also suffered. In another qualitative study, participants reported discomfort in discussing their body image concerns because they felt dismissed by nurses (Konradsen et al., 2009). The themes that emerged in the interviews with patients included, "minimizing disfigurement, disfigurement is a luxurious problem, and another time, another place" (meaning nurses did not bring up the subject unless the patient started the conversation or being unsure of what to say) (Konradsen et al., 2009). Body image had far-reaching consequences, including being a risk factor for depression in men and women (Fingeret et al., 2012).

Self-concept perceptions of people with HNC contribute to the experience of stigma. The idea of being a "survivor" and viewing this concept positively has been discussed in the breast cancer literature (Helgeson, 2011). However, the HNC literature, has identified that there are people who did not want to be described as a "cancer 
patient", because this lends to a negative self-view (Wong et. al, 2013). Distancing from this persona is deemed a way to avoid negative stereotypes of the disease and causes of the disease. Interestingly, the same study found that as symptom or disease burden increased, there was less feeling of stigma around being identified as a cancer patient (Wong et. al, 2013). Lung cancer and HNC have both been associated with the experience of stigma by people with these diagnoses. Societal views of lung cancer and $\mathrm{HNC}$ tend to blame people for getting sick, because smoking is the leading cause of both diseases (Hamann et. al, 2013; Lebel et. al, 2013; Brown \& Cataldo, 2012). People who smoke have been judged most harshly in studies of attitudes toward lung cancer (Hamann et. al, 2013). Smokers who have been diagnosed with lung cancer report feeling stigmatized and that "if you get lung cancer, you have it because you smoked and if you were that dumb you deserve to die..." (Brown \& Cataldo, 2012, pp.357). In fact, it is often assumed by medical professionals and the public that one must have been a smoker to have been diagnosed with cancer (Brown \& Cataldo, 2012). This assumption contributes to the sense of self-stigma and social stigma. Stigma has been studied among people with lung or $\mathrm{HNC}$, and was found to be most prevalent in men, people with lung cancer, and people who had been disfigured by their disease (Lebel et. al, 2013). Studies have found that people who are disfigured experience increased distress and more stigma than people with other kinds of cancer (Hagedoorn \& Molleman, 2006). Worry of the opinion of others, being treated inappropriately by others, social isolation, and feeling shame are all parts of the stigma experienced in people with HNC (Hagedoorn \& Molleman, 2006). Women are particularly subjected to stigma when they are disfigured, because the changes in their appearance are often more noticeable than men (Lebel et. al, 
2013). The influence of being diagnosed with HPV has been studied and has been found to minimally increase feelings of stigma (Baxi, et al, 2012; Dodd, et al., 2018). In these studies, patients were more concerned with spreading HPV to their partners. Patients expressed experiencing more stress about having cancer than the cause of the disease.

\section{Quality of Life of HNC Survivors}

People with HNC experience mental health challenges at a rate much higher than the general population and oncology population. Those living with $\mathrm{HNC}$ have been documented to have a depression rate of $16-44 \%$ (Chan et. al, 2011), compared to the general population at $16-21 \%$ (www.cdc.gov). The HNC population also experiences suicide at strikingly higher rates than other groups. Suicide occurs in the HNC population at a rate of 50.5 per 100,000 , compared to all other cancers (36 per 100,000) and the general population (12 per 100,000) (Zeller, 2006). Although not universally true for all people with head and neck cancer, many experience risk factors for depressive symptomology such as heavy drinking, smoking, and substance abuse (Zeller, 2006).

People in the HNC population who report high levels of distress have also been found to meet diagnostic criterion for anxiety and depression. Those people undergoing curative treatment were found to have the highest correlation of anxiety and depression (Pandey et. al, 2007). The psychosocial hardship of living with head and neck cancer was shown to decrease in a qualitative study of people 24-30 months after diagnosis (Isaksson, et al., 2016). The participants in this study reported physical and psychological changes in their lives because of having cancer. Some confirmed that symptoms of depression and social isolation decrease as time passed, but other stated that despite the physical burden lessening, the psychological stress persisted (Isaksson et al., 2016). 
Twenty of the study's 56 participants reported overall their lives were worse than before the disease and were not able to identify a lessening of suffering (Isaksson et al., 2016).

Depression is reported at a higher rate in people with head and neck cancer than any other kind of cancer diagnosis (Chan et al., 2011; Zeller, 2006). Pre-existing depression before a diagnosis of head and neck cancer has been shown to be a risk factor for increased incidence and severity of depression after being diagnosed (Chan et al., 2011; Chiou et al., 2013; Howren, et al., 2010). People were found to have higher rates of depression and depression that lasted after cancer treatment in a study of predictors of depression. Predictive factors included being diagnosed with stage III or stage IV disease, drinking more than 14 alcoholic drinks per week, having three or more medications, and smoking at the time of diagnosis (Moubayed et al., 2015). These studies do not address whether having pre-existing depression may have contributed to high-risk health behaviors, such as increased alcohol or drug use, that ultimately may have played a role in being diagnosed with head and neck cancer.

In people who do not report depressive symptoms prior to being diagnosed with head and neck cancer, depression is still reported in rates higher than the general population and among other types of cancer (Zeller, 2006). Decreased physical health, increased body image concerns, and social isolation are among several risk factors that contribute to the increase in depression (Chan et al., 2011; Fingeret et al., 2012; Perry, et al., 2015). A correlation between depression and cancer and an increase in morbidity and mortality have been documented (Archer et. al, 2007; Lazure et. al, 2008). People with higher instances of depression were found to have died sooner than others. 
Many types of treatment for head and neck cancer appear to have an impact on overall well-being in people with head and neck cancer. There is no singular treatment found to be most arduous for people with HNC. Those who undergo laryngectomy surgery experience difficulty with speech, eating, and body image, all of which contribute to increased depression (Perry et al., 2015). Increased rates of fatigue and depression are linked to radiation therapy in patients with head and neck cancer (Sawada et al., 2012). These symptoms were found to influence patients with HNC to feel less inclined to participate in social and recreational activities, a risk factor for depression (Chan et al., 2011). Having a large social network to provide connection and support are valuable in decreasing depression (De Leeuw et al., 2000). Marital status was also found to influence incidence of depression (Chan et al., 2011). Patients who were single and divorced had higher rates of depression than married people, with those who were divorced having the most severe depression (Chan et al., 2011).

Another significant psychosocial stressor identified by HNC survivors is the fear of reoccurrence. In a study by Ghazali and colleagues, (2013), half of the sample reported the concern of reoccurrence. In particular, those who were younger, had higher levels of anxiety at the onset of disease, experienced higher rates of loneliness, and had less invasive treatment for the disease reported higher levels of fear (Ghazali et al., 2013; Maguire et al., 2017). One study found fear of reoccurrence declined over the passage of time for patients and caregivers; however, caregivers had more fear of reoccurrence at all points of study (Hodges \& Humphris, 2009). Clinical characteristics of the disease showed little effect on levels of fear (Ghazali et al., 2013).

\section{Table 2.1}




\begin{tabular}{|c|c|c|c|c|}
\hline Author & Year & $\begin{array}{l}\text { Participants } \\
\text { (Female/Male) }\end{array}$ & $\begin{array}{c}\text { Report } \\
\text { Symptoms by } \\
\text { Sex }\end{array}$ & Country \\
\hline $\begin{array}{l}\text { Bond, Hawkins } \\
\text { \& Murphy }\end{array}$ & 2014 & $3 / 20$ & No & USA \\
\hline Chan, et. al & 2011 & $18 / 59$ & No & USA \\
\hline Chiou, et. al $^{*}$ & 2013 & $7 / 66$ & No & Taiwan \\
\hline DeLeeuw, et. al & 2000 & $39 / 158$ & No & Netherlands \\
\hline Fingeret, et. al & 2012 & $101 / 179$ & No & USA \\
\hline Ghazail, et. al & 2013 & $68 / 121$ & No & UK \\
\hline $\begin{array}{c}\text { Harding, } \\
\text { Sanipour \&Moss }\end{array}$ & 2014 & $212 / 34$ & No & UK \\
\hline $\begin{array}{l}\text { Hodges \& } \\
\text { Humphris }\end{array}$ & 2009 & $29 / 72$ & No & UK \\
\hline Howeren, et. al & 2010 & $114 / 192$ & No & USA \\
\hline Isaksson, et. al & 2016 & 56 total & No & Denmark \\
\hline Konradsen, et. al & 2009 & 14 total & No & $\begin{array}{c}\text { Denmark \& New } \\
\text { Zealand }\end{array}$ \\
\hline Konradsen, et. al & 2012 & $6 / 9$ & No & USA \\
\hline Locher, et. al* & 2010 & $17 / 13$ & Yes & USA \\
\hline $\begin{array}{l}\text { Mayre-Chilton, } \\
\text { Talwar \& Goff }\end{array}$ & 2011 & $2 / 6$ & No & UK \\
\hline Moubayed, et. al & 2015 & $56 / 153$ & $\begin{array}{l}\text { Only depression } \\
\text { reported by sex }\end{array}$ & Canada \\
\hline Nund, et. al & 2015 & $2 / 12$ & No & Australia \\
\hline Onakoya, et. al & 2006 & $18 / 32$ & Yes & Nigeria \\
\hline $\begin{array}{l}\text { Perry, Casey \& } \\
\text { Cotton }\end{array}$ & 2015 & $13 / 70$ & $\begin{array}{c}\text { Physical } \\
\text { symptoms } \\
\text { reported by sex, } \\
\text { but not mental } \\
\text { health }\end{array}$ & Australia \\
\hline Sawada, et. al & 2011 & $6 / 35$ & No & Brazil \\
\hline Schenck, D. P. & 2002 & $1 / 1$ & Yes & USA \\
\hline
\end{tabular}

*Study included people with pancreatic, colon, breast, lymphoma, skin, and head \& neck cancers.

\section{Appraisal and Coping}

\section{Individual Appraisal and Coping in People with HNC}

Despite the struggles of people with HNC, studies show the existence of effective methods of coping and adjusting to the illness. Some patients are able to find meaning in 
the experience of having had head and neck cancer, also known as post-traumatic growth (PTG) (Harding, et al., 2014). Studies have found several factors that contribute to benefit finding. These factors include being married or living with a significant other, having higher income, being younger, having emotional support, and being an already optimistic person (Harding et al., 2014; Sharp, et. al, 2018). Perhaps most important for this study, women were found to most often demonstrate PTG (Sharp, et. al, 2018). People who reported greater levels of depression and anxiety during diagnosis and treatment reported the highest levels of benefit finding after cancer (Harding et al., 2014). People with advanced stages of disease and higher experience of pain were less likely to experience post-traumatic growth after cancer (Harding et al., 2014). The burdens of HNC disrupt the daily lives of those who are diagnosed. People with HNC must continually process how their cancer influences their lives and futures (Lang, et. al, 2013). This may be a silver lining in the head and neck cancer experience, given the high levels of depression that are reported in this population.

There are differences in how individuals cope with having cancer. Two international studies (Japan and the Netherlands) examined coping styles and quality of life in people with HNC (Ichikura, et. al, 2017; Derks, et. al, 2005). These studies examined the differences in feelings of locus of control and coping styles between people with HNC. Quality of life scores did not vary based upon age or sex; however, it was clear that different coping styles were more characteristic of certain age groups and that some coping styles were more inclined to report depressive symptomology. The Japanese study defined three coping styles: resigned coping, problem-focused coping, and dependent coping (Ichikura, et. al, 2017). The other found that certain age groups 
gravitated to certain coping styles; younger people using more active coping and older people using religious coping (Derks, et. al, 2005). Both studies found higher rates of depression and less sense of internal control in people who utilized more passive coping styles. Those individuals who employed coping strategies that required action directly from the patient reported better quality of life and more feelings of self-efficacy.

\section{The Role of Gender in Coping with HNC}

While there are several studies that explore the differences between men and women in their ways of coping with cancer, HNC literature does not specify if there are differences in coping based on gender. Without studies about the HNC population, the existing oncology literature provides some indication of how gender influences coping with cancer.

The role of gender in $\mathrm{HNC}$ was first studied in a Canadian study in the early 2000's. In this rare comparative study of women and men, the variables of gender, social support, and disfigurement were examined (Katz, et. al, 2003). Prior to this study, the literature did not have a clear picture of whether gender mattered in terms of quality of life, the role of social support, or the reaction to disfigurement. Instead, gender was viewed as a moderator to other variables or interact with other variables to influence outcomes (Katz, et. al, 2003). The participants in this Canadian study were given a battery of questionnaires to rate quality of life, disfigurement, social desirability, medical variables, social support, and demographic data. The findings determined that women experience $\mathrm{HNC}$ differently than men and suggested that in many ways, women fare worse (Katz, et. al, 2003). Women reported significantly lower happiness with their lives. It was noted that women, even those with high social support were unhappier than 
men. However, social support was shown to reduce discontent with disfigurement and improve feelings of well-being (Katz, et. al, 2003). Women were also more inclined to depressive symptoms, anxiety, and psychosocial complaints. For the women in the study, supportive family and friends were key in feelings of well-being, whereas men preferred support from professionals (Katz, et. al, 2003). Other studies have found no statistically significant differences between how men and women perceive cancer-related distress or cope with cancer (Espie, et. al, 1989; D'Antonio, et. al, 1998; Morton, RP, 1995; de Graeff, et al., 2000); however, differences in perception of quality of life and need for information between the genders have been identified (Egestad \& Emaus, 2014; Faller, et. al, 2016).

From the literature that does exist, there is evidence of women suffering. This limited evidence leaves room to learn more about the lives of women with this disease.

\section{Caregivers}

For this study, it is important to understand caregiving, because this study seeks to understand how relationships are impacted when a woman has HNC. A great number of studies document the experience of men with $\mathrm{HNC}$ with female caregivers. A literature review conducted as an independent study found no articles that spoke specifically to females with $\mathrm{HNC}$, but rather highlighted that most women in the literature on this topic are the caregivers (wives or significant others of male patients). Out of twelve studies with a total of 1,201 participants, nine studies reported the gender of the participants. Only one compared the quality of life for female and male patients, finding that overall mean scores for all variables were higher for women (Onakoya,et al., 2006). That study came out of Nigeria and had 18 female participants, compared to 32 males. One study 
had no female participants (Maguire, 2017) and three studies did not report the gender of the participants (Konradsen, 2009; Konradsen, 2012; Issakson et. al, 2016). Many of the articles reviewed were conducted in countries other than the United States ( 8 of 12) including: Canada, Taiwan, UK, Denmark, New Zealand, Australia, Nigeria, and Brazil. There may be cultural considerations to be accounted for in the documented HNC population, such as gender roles and what constitutes a stigmatized situation.

Additionally, there has been a lack of consistency in quantitative instruments and how the scales were administered to evaluate quality of life and psychological well-being. For example, instruments used in the studies included: Neuropsychiatric Inventory Questionnaire, Beck Depression Inventory Fast-Screen, University of Washington Quality of Life, Voice Handicap Index, MD Anderson Dysphagia Inventory, Social Support List Interaction, Inventory of Socially Supportive Behaviors, and the Social Provisions Scale (Bond, et al., 2014; Chan, et al., 2011; DeLeeuw, et al., 2000), just to name a few. Another challenge in the existing literature is the low reliability of measures reported because the instrument used have been validated in a variety of settings, but not necessarily validated in the $\mathrm{HNC}$ population (Bond, 2014).

Many caregivers represented in the literature (between $52.8 \%$ and $82.5 \%$ ) are female (Bernard \& Guarnaccia, 2003; Bowman, et al., 2006; Cormio et al., 2014; Lee, et al., 2016; Levesque \& Maybery, 2012; Levesque \& Maybery, 2014; Strawbridge et al., 1997). This is also true in several studies that used data collected from the American Cancer Society (ACS) Quality of Life Survey of Caregivers (Kim, et al.,, 2007; Kim, et al., 2006; Kim, et al., 2013; Kim, et al., 2007). Although each of the ACS studies examined a different aspect of caregiving and had varying numbers of participants, the 
vast number were women. Because many of the studies survey women as caregivers of $\mathrm{HNC}$ patients, the present study is unique in exploring the experience of women as patients. Although the aim of the present study is not to compare female patients with female caregivers of HNC patients, I speculate that there may be some similarities in how women in each role address the challenges of cancer.

\section{Appraisal and Coping in Caregivers}

Family and friends of people living with cancer are deeply impacted by the disease (Palos, et al., 2011). Many caregivers provide support, including physical, financial, and emotional, with little or no training. In some instances, this means providing physical care, such as bathing and toileting. Other times, it means that a caregiver is assisting with preparing meals and doing housework or helping financially. Spending time together and providing emotional support can also be considered caregiving. (Noonan \& Tennstedt, 1997; Strawbridge et al., 1997). Whatever the duties included in caregiving, finding an element of meaning making is possible based upon the emotional and cognitive experiences of caregiving (Noonan \& Tennstedt, 1997). In a qualitative study of 48 caregivers, the themes that arose from the interviews: "gratification and satisfaction", "friendship and company", "improved relationship", and "personal growth" mirrored the concepts measured in the Post Traumatic Growth (PTG) Inventory (Noonan et al., 1996). Based upon this finding, it is possible that the very nature of the caregiving experience may cultivate the potential for post-traumatic growth. Adding the intensity of a cancer diagnosis within the caregiving relationship also lends to the potential for PTG, as it is the most stressful situations that seem to generate positive growth (Kissil et al., 2010; Tedeschi \& Calhoun, 1996). 


\section{Post-Traumatic Growth in Caregiving}

Post-traumatic growth is experienced by people with cancer and their caregivers. More post-traumatic growth was identified in caregivers than patients, although there was a significant association in PTG between patients and caregivers (Cormio et al., 2014), meaning that caregivers reported more PTG in proportion to the patients' report of more existential growth as a result of the cancer experience. Caregivers with more social support demonstrated higher levels of PTG (Kim, et al., 2007; Lee et al., 2016), as did those who utilized religious coping measures (Kim, et al., 2007). The implication in this finding is that for caregivers who have other people helping with the responsibilities of caregiving or emotional support for themselves could process the experience on an emotional and psychological level that may not be possible for caregivers who lack support. For those caregivers without support, there may be less time and energy to focus their efforts on anything other than the tasks of caregiving.

Existential experience may commonly be thought of in terms of religious or spiritual experience of a situation. The literature found that religious coping was identified as a factor that contributes to higher levels of depressive symptoms. In addition to greater religious coping, other factors that were reported to contribute to more frequent depression and anxiety are caregiver stress, financial worries, and patients' higher symptom burden (Kim, et al., 2007; Lee et al., 2016; Mosher \& Danoff-Burg, 2005). The search for meaning in the cancer experience and life, in general, was cited in various ways throughout this review, including worries about a parent dying "before they were ready" (Mosher \& Danoff-Burg, 2005), developing a great appreciation for life (Cormio et al., 2014; Kim, et al., 2007; Mosher \& Danoff-Burg, 2005) and the 
development of stronger relationships with other people (Cormio et al., 2014; Levesque \& Maybery, 2012). The duration of illness and the outcome of treatment appear to function as moderators of the experience of PTG (Cormio et al., 2014; Levesque \& Maybery, 2014). During the initial period of diagnosis and treatment, there is very low occurrence of PTG, but after the passage of time, the likelihood of reporting PTG increases significantly (Cormio et al., 2014). In agreement with the assumption that the greater the stress from an event, the stronger the experience of PTG, when the caregivers experienced the death of a parent from cancer, they reported more incidents of PTG than those caregivers whose loved one recovered after cancer treatment (Levesque \& Maybery, 2014).

The realization of self-efficacy is another manifestation of PTG experienced by caregivers. Many caregivers reported increased awareness of his or her own person strength and ability to cope with difficult situations because of living with their parent's cancer (Kissil et al., 2010; McPhail, et al., 2017; Mosher \& Danoff-Burg, 2005). An increased feeling of personal ability, coupled with a deeper appreciation of relationships demonstrates the nature of PTG and is shown in the literature.

\section{Relational Coping}

This study is interested in the experience of women with HNC and the impact of the diagnosis on their close relationships. Understanding how women and their friends or partners cope as a pair is important. Dyadic coping can be defined as a process by which the coping of each individual is intertwined with the other (Bodemann, et. al, 2011). There is a shared experience and coping is based upon interaction within the relationship. The dyad is invested in the relationship and has common goals and concerns 
(Bodenmann, 1995). There are several types of coping that have been defined in the dyadic literature including: common dyadic coping, supportive dyadic coping, delegated coping, mutual responsiveness, and disengaged avoidance (Bodenman, et. al, 2011; Kayser, 2007).

The literature explores dyadic coping in the context of several types of cancer, including colorectal, lung, and HNC (Kayser, et. al, 2018; Ellis, et. al, 2012; Kim, et. al, 2015; Manne \& Badr, 2010; Foxwell \& Scott, 2011; Mouschopoulou, et. al, 2018). Openly sharing concerns and problem-solving solutions increases feelings of well-being and closeness in relationships (Kayser, et. al, 2018; Ellis, et. al, 2013). Talking frankly about cancer worries, such as managing care needs of a tracheostomy, end of life concerns, or daily challenges is beneficial for dyads (Nakarada-Kordic, et. al, 2018; Foxwell \& Scott, 2011; Manne \& Badr, 2010). Another strategy found to be helpful in dyadic coping is adopting an attitude of acceptance, not to be confused with surrendering to the illness which is viewed negatively. Instead, framing the cancer experience in the wider world and taking things as they come describes acceptance (Foxwell \& Scott, 2011).

Specifically, in HNC, maintaining an appearance of strength, confidence and positivity while hiding more difficult emotions, such a sadness, was found to be common (Foxwell \& Scott, 2011). Maintaining a strong persona appears to bolster feelings of control and protecting loved ones in the context of HNC. This avoidant type of coping also includes distraction with other activities that are unrelated to cancer and minimizing one's own challenges in light of other's difficulties was documented in people with HNC (Foxwell \& Scott, 2011). This type of avoidant or distracted type of coping is only 
helpful when there is a highly supportive relationship. In partnerships with low support, this strategy is considered more detrimental (Kayser, et. al, 2018). Regardless of coping strategy, dyads that feel they are working together, sharing their worries and experience reciprocity in the relationship cope better with HNC (Foxwell \& Scott, 2011).

Even in strong partnerships with health coping skills, there is evidence of posttraumatic stress disorder (PTSD) and post-traumatic stress symptoms (PTSS) in people with HNC and their caregivers. In a study by Moschopoulou and colleagues (2018) fear of reoccurrence was the most common manifestation of PTSS and up to six years after treatment, both patients and caregivers demonstrated this symptom.

\section{Gaps in the Literature}

The experience of women with $\mathrm{HNC}$ is largely absent from the literature, which may lead to unnecessary suffering in this population. The gap is likely a result of women being a smaller portion of the overall HNC population. The prior evidence of differences in medical care and poorer psychosocial functioning in women may also indicate that women simply do not feel well enough to participate in research studies. As discussed in the theory section of this paper, relational-cultural theory suggests that women cope with stress within the context of relationships, which may be different from male coping. Otherwise, the literature provides minimal understanding about the differences in the experience of the disease, considering gender.

A great number of studies document the experience of male patients with female caregivers. A literature review that I conducted as an independent study found no articles that spoke specifically to females with head and neck cancer, but rather highlighted that most women in the literature on this topic are the caregivers (wives or significant others 
of male patients) (Anderson, 2018). Most of the articles reviewed were conducted internationally (Canada, Taiwan, Netherlands, UK, Denmark, New Zealand, Nigeria, Australia, and Brazil). Four of the twelve studies were conducted in the United States. There may be cultural considerations to be accounted for in the documented $\mathrm{HNC}$ population, such as gender roles and what constitutes a stigmatized situation. It is difficult to ascertain a clear picture of the experience of women with $\mathrm{HNC}$ because of a lack of voice and inconsistent measurement in the literature. This certainly leaves room for further exploration of the female experience of living with cancer in the United States.

\section{Theoretical Framework}

Three theories provide the framework for this study: transactional stress and coping theory, relational-cultural theory, and stigma theory. Each of these define how a person experiences a situation and themselves within that situation. However, the theories have distinctive differences, when combined provide a foundation to understand the lived experience of women with HNC. This foundation provides a lens to view how women view themselves and their illness in the context of their relationships with others.

\section{Lazarus and Folkman's Transactional Stress and Coping Model}

Lazarus and Folkman define coping as "A person's constantly changing cognitive and behavioral efforts to manage specific external and/or internal demands that are appraised as taxing or exceeding the person's resources." (Folkman \& Greer, 2000; Lazarus \& Folkman, 1987). The two main components of this framework are cognitive appraisal and contextual consideration of the situation. The primary appraisal of the situation is defined as the cognitive appraisal. In this initial phase of coping an individual assesses a situation and decides if it is pertinent to his/her well-being or personal interests 
(Folkman \& Greer, 2000; Lazarus \& Folkman, 1987). To conduct this appraisal, the individual takes into account past experience and behaviors to guide the decision about what action to pursue in the current situation. The context of the current situation must also be considered in this secondary phase of appraisal. The person must evaluate whether past actions can be applied to address the current issue and evaluate the costs and benefits of each potential action (Folkman \& Greer, 2000; Lazarus \& Folkman, 1987). Within this framework, coping is a strategy to help a person regulate emotions (emotionfocused coping) or make changes in the situation to alleviate stress (problem-focused coping). There is no value judgement of coping as "bad" or "good", but instead serves as a snapshot of the person and their resources for addressing a stressor (Lazarus \& Folkman, 1987).

The appraisal of the cancer experience by people with a head and neck diagnosis, includes the current situation and any prior experience with cancer (either in themselves or a loved one). Those experiences in combination with how the person feels about his or her ability to manage the symptoms and treatment may influence the incidence of anxiety and depression. The theory operates on the premise that coping with an adverse situation requires evaluation of the events and a decision, whether unconsciously/consciously, of the action to take based upon prior behavior and experiences. This is helpful in working with people diagnosed with head and neck cancer and their loved ones, because it is important to treat each patient as an individual to improve health outcomes and quality of life (Gourin, 2014). Healthcare choices can be tailored to meet the goals of care for patients when there is an understanding of prior experiences with the medical system, cancer, treatment, and one's ability to cope with a challenge. 
The appraisal of one's self-efficacy and existing resources provides a lens through which women can view their needs for support and information.

\section{Relational-Cultural Theory}

Relational-cultural theory views human development through a feminist lens. This theory posits that a woman's sense of identity is formed through relationships with others (Miller, 1984; Jordan et al., 1991). Women tend to base the view of self upon how they act in relation to important people in their lives (Miller, 1984; Jordan et al. 1991). Relationships alone are not the only influencing factor in women's definition of self, but more importantly, the exchange of mutual regard with others is the cornerstone of this theory. Women's psychological needs are best met within the context of relationships that are mutually satisfying (Jordan et al, 1991). This mutuality is defined as a reciprocity of actions, ideas, and feelings between the individuals (Genero, et al., 1992). The drawback to this kind of "village" mindset is that women may not attend to their own needs or feelings if this action is viewed as detrimental to the other people in her life. This is called the "silencing of self" schema (Jack, 1991). An example of this schema is a woman who may not share her fears about beginning chemotherapy with her spouse, for fear of stressing the spouse, which in turn may cause upset in her children. According to this framework, women may tailor her coping style to be least disruptive to their support network. Relational coping also suggests that feeling a sense of mutuality is important for women to manage the strain of chronic illness, meaning that it is important to feel that the person with cancer is contributing to the support to their loved ones, as well as receiving support (Kayser, et al., 1999). This theory is well-suited to studying women with $\mathrm{HNC}$, because just as many studies of human development and coping have focused 
on male subjects, most studies of HNC focus on the male experience or simply exclude a strictly female reference. It will be important to consider the ways women's coping styles differ from men to get a clearer picture of what it is like to live with HNC.

\section{Stigma Theory}

The third theoretical pillar in this study is stigma theory. Pioneered by Goffman's Stigma: Notes on the Management of Spoiled Identity in 1963, stigma has been studied in a variety of contexts over the past decades. Stigma will be defined as the experience of being "other" or differing from the commonly accepted norm in a group or society. Goffman outlines four types of stigma in this work including, social stigma, self-stigma, stigma by association, and structural stigma. For this study, the two kinds of stigma that are most applicable are self-stigma and social stigma. Self-stigma is how an individual's social functioning and psychological well-being are impacted by possessing a stigmatizing condition (Goffman, 1963). Social stigma is focused on the psychological and social reaction of the non-stigmatized group to someone perceived as possessing a stigmatizing quality (Goffman, 1963). People with cancer have been found to experience certain kinds of stigma, particularly those diagnoses that are perceived to have been caused by poor lifestyle choices, such as lung cancer which is associated with smoking or cervical cancer which is associated with the sexually transmitted HPV virus (Lebel \& Devins, 2008). Head and neck cancers have been linked to drinking, smoking, and some strains of HPV. So, it is reasonable to hypothesize that persons with HNC will share similar stigmas as these other types of cancer.

These theories can work together to explain how a woman may experience a diagnosis of HNC. Women may be judged because of societal views about drinking, 
smoking, and perceived sexual misbehavior. By experiencing this social stigma, woman may experience self-stigma, having feelings of shame which may in turn underlie the way a woman discloses her experience of cancer with others. Stigma does not occur in isolation within an individual, but rather in a social context. This is consistent with relational theory wherein feelings about one's identity is defined as self-in relation. 


\section{CHAPTER III: METHODOLOGY}

This chapter details the methodology of the study and discusses the research design including the epistemology and theoretical underpinnings, study population and sample, and ethical considerations. An in-depth presentation of the procedures for participant selection, data collection, and data analysis are included in this chapter. The following research questions have been posed:

1. How do women describe their experience of living with HNC?

2. How do women describe their coping with cancer?

3. What role does stigma play in their experience?

4. What do women perceive to be the impact of the $\mathrm{HNC}$ on their close relationships?

\section{Research Design}

\section{Overview}

This study was conducted using qualitative description (QD). Qualitative description is utilized to identify a phenomenon and establish understanding of what happens, to whom, and how (Caellli et al., 1998; Sandelowski, 2000). This approach is employed in healthcare research to gain practical knowledge used to inform policies and develop health care practices (Sandelowski, 2000). In QD, the researcher seeks to 
provide precise description of the data. This includes, allowing the voices of the participants (i.e., their literal words) to tell the story of the phenomenon (Bradshaw, et al., 2017; Latifnejad Roudsari, 2019). For this study, a description of the overall experience was created, as well as a description of each of the participants using brief vignettes. The combination individual and collective experiences of the women studied provide the data for deep description. A description of being a woman with $\mathrm{HNC}$ is accomplished by the researcher staying close to the data in the description and using straight-forward language, rather than figurative interpretation of the transcripts. This method works well to inform intervention development (Bradshaw, et al., 2017). The knowledge acquired by this study will spotlight how women with HNC live with the disease and the inventions that may be helpful in addressing the stressors experienced by the women.

\section{Philosophical Assumptions}

Philosophy is defined as "the study of the fundamental nature of knowledge, reality, and existence, especially when considered as an academic discipline" (Oxford English Dictionary, 2021). Creswell defines philosophy as "the use of abstract ideas and beliefs that inform our research" (Creswell, 2013, pp.16). In other words, philosophy is examining how we know what we know and how do we build upon that knowledge. There are four philosophical assumptions in qualitative research: ontological, epistemological, axiological, and methodological (Creswell, 2013).

\section{Ontological Assumptions}

To conduct research inquiry, the researcher must explore the paradigms, or personal ideas of the world, society, and themselves (Creswell, 2013: Guba, 1990, p.17). In qualitative research, there is a relationship between the participants and the researcher, because of 
the interaction during data collection. This is unlike quantitative research, where the participant may never meet the researcher. Because the qualitative researcher is part of the research, it is of utmost importance for the researcher to understand their own views and how those influence the research process (Bradshaw, et al., 2017). The shared experience is unavoidable, because of the interactive process that is required of qualitative research.

Qualitative work is a form of naturalistic inquiry, which means it illustrates a phenomenon by using the meanings given to it by the study participants (Bradshaw, et al., 2017). The language used by the participants is important because it demonstrates how the phenomenon was experienced (Frowe, 2001). In QD, not only is it important to make note of the language used, but to use similar language when sharing these data or disseminating to larger audiences (Bradshaw, et al., 2017).

Because each participant will have a personal vocabulary and understanding of their own experience of a phenomenon, QD can be understood through the lens of relativism. Simply stated, relativism means that there is no single reality. Instead, each person experiences their own reality; therefore, making reality subjective (Parahoo, 2014). QD looks for the meaning given to a phenomenon by the way it is described (Sandelowski, 2010). Relativism fits well with the epistemological assumptions of QD.

\section{Epistemological Assumptions}

Epistemology is the theory of knowledge. Knowledge is subjective and viewed as an interaction between the world and the learner (Denzin \& Lincoln, 2011). The theory of knowledge that best applies to QD is social constructivism. Vygotsky asserts that not only is learning relative to the perspective of the learner but also a product of the 
interactions between the learner and other people within the environment (Vygotsky, 1978). This interaction exists between the researcher, participants, and the social environment in QD. This perspective acknowledges that the participant's experience is unique, true, and valid. Vygotsky emphasizes the importance of shared language to understand experience and asserts that language has a communal function (Vygotsky, 1978). Both the ontology and epistemology of QD consider person in the environment and the importance of language to understand experience. Not only does this framework harmonize with the social work value of considering the worth of all people and examining person in the context of environment, but it is also demonstrated in this study through the lens of the three theories: Lazarus \& Folkman Transactional Stress and Coping, Relational-Cultural, and Stigma. This study is interested in not only how women experience their cancer journey, but how it impacts their close relationships. Cancer does not impact only the person who has been diagnosed, but also their loved ones.

Similar to social constructivism, all three of these theories explain coping and self-concept in relationship with others, rather than through isolation as an individual. Social constructivism works in the same way. For example, the name Transactional Stress and Coping sets the stage for the coping process to occur within interaction with others. In the case of $\mathrm{HNC}$, women who have experienced other hardships in life understand their capacity for overcoming adversity because they have done it in the past. In exchange for living through stressors, such as domestic violence or divorce, the women understand that they can cope with hard things. Similarly, Relational-Cultural theory posits that women define their identities in the context of the relationships they have with others. One would not define herself as a mother or wife, if not for the existing 
relationship with another person. Wife and mother can both be considered a social construct, because there is common language to describe this phenomenon and a societal acceptance of that meaning. Finally, social constructivism can be seen in action in stigma theory. One does not feel shame or being ostracized by other people in a vacuum. The concept of stigma comes from the opinions of others being projected on an individual. In the case of women with HNC, feeling self-conscious about physical appearance would be non-existent without the expectations of traditional female beauty and the negative reactions from others about their appearance. All three of the theories used to frame this study are bound in social constructivism, because none of them exist without an interaction between the individual and others.

\section{Axiological Assumptions}

Axiology is defined by the Encyclopedia Britannica as "the philosophical study of goodness, or value, in the widest sense of these terms". In terms of research, it is understood that there are many biases, and the researcher must acknowledge these. In qualitative research, when the researcher identifies and explains their own values as it relates to the research topic, this is called positioning themselves in the study (Creswell, 2013). Positionality allows the researcher to be part of the research process, being part of the social constructivism, while simultaneously learning from the participants' experiences.

My ideas about HNC from my personal and professional background influence my approach to this study. My knowledge and feelings about HNC serve to feel part of the community I am studying, as well as eliminate any fear about the topic that may exist 
for someone with no prior knowledge of this experience. This positionality will be explored later in the chapter through my explanation of reflexivity.

\section{Methodological Assumptions}

The purpose of QD is to generate a deep description of a phenomenon (Bradshaw, et al., 2017). To do this, qualitative descriptive researchers use an inductive process to examine the details of the data, describing those details and ultimately make generalizations (Bradshaw, et al., 2017). This is an iterative process that requires the researcher to continually revisit the data while gathering additional data from the field, further describing the details and grouping the details to allow for broader themes to emerge.

When can you say enough is enough? I mean, if I was not awake, and it looked like this might be forever and ever, amen, go ahead and put me away.

\section{Sample}

The exploratory nature and descriptive qualitative design of the study called for the use of purposive sampling methods. Purposive sampling is commonly used in studies that aim to explore detailed information about a specific situation (Glaser \& Strauss, 1967). For this study, the inclusion criteria were quite broad to allow for a variety of women to be recruited due to the complex nature of HNC. Head and neck cancer diagnoses included in this study were cancers of the oral cavity, tongue, pharynx (throat), larynx (voice box), salivary glands, nasal and paranasal sinuses, and nasopharynx. The women included in the study must have been diagnosed within the past one to five years. The first year of HNC diagnosis and treatment can be exhausting and therefore difficult to obtain participants. After five years, it may be difficult for participants to recall the 
details of their diagnosis and treatment. Most medical professionals consider a person with cancer to be a survivor after the five-year mark. The selected time period allowed for most women to have completed the course of treatment and be living as a survivor of HNC. The women may have been diagnosed with any stage of disease (I, II, III, or IV), any prognosis, undergone any treatment modality (surgery, radiation, chemotherapy, or any combination therein). Women receiving no curative treatment were also eligible for the study. Participants had to be able to participate in oral or written communication in English and able to speak with the researcher by telephone, video meeting (Microsoft Teams), or in person utilizing Covid-19 precautions (social distancing of at least six feet, wearing a mask). Cancers of the brain, thyroid and esophagus were excluded based upon the American Cancer Society's explanation of the wide difference in treatment modalities and symptomology of these types of cancer (www.cancer.org).

\section{Setting and Recruitment Process}

Participants were recruited from University of Louisville Brown Cancer Center in Louisville, Kentucky and University of Cincinnati Cancer Institute in Cincinnati, Ohio through collaboration between nurse navigators, social workers, physicians, and the researcher. Potential participants were identified by either a nurse navigator or social worker (herein referred to as staff) in the clinic. Staff were provided the study criteria and reviewed the weekly clinic schedule for women and their medical records for patients who met the requirements. Staff would get approval from the attending physician to refer potential participants to the researcher. There were two avenues by which the researcher was given referrals. 
The first was used for patients attending clinic visits in person. After obtaining approval, the researcher was notified via encrypted email including their names and appointment dates. The researcher then attended the clinic and was introduced to potential participants by the physician. During this meeting, the researcher explained the study, requirements of the study, time commitment, and incentive for participation. Those women who agreed to participate completed the consent process at that time. The researcher explained the consent sheet and provided a copy to the participant, along with a brochure that described the study and gave the researcher's contact information. Participants were given a survey to complete that included Hospital Anxiety and Depression Scale (HADS) Functional Assessment of Cancer Treatment Head and Neck (FACT-HN) and a demographics sheet. At the conclusion of the visit, the researcher set up the first interview which was scheduled within the following week.

Due to the COVID-19 pandemic, some participants who would be appropriate for the study were not scheduled for in-person appointments at the clinic. For those women, staff would call and give a brief overview of the study using a phone script provided by the researcher. Women who were interested in participating were referred to the researcher via encrypted email. The researcher then called the women and explained the study, requirements of the study, time commitment, and incentive for participation. For those who agreed to participant, the researcher explained the consent sheet and provided a copy to the participant via email. In addition to the consent form, the participants were sent a brochure that described the study, the researcher's contact information, HADS questionnaire, FACT-HN questionnaire and demographics sheet. The women were asked to return the completed documents electronically, either by email or by taking a picture 
and texting each page to the researcher. The first interview was scheduled within the following week.

\section{Ethical Considerations}

People with $\mathrm{HNC}$ are a vulnerable population within the cancer community, experiencing depression at greater rates than any other kind of cancer (Chan et al., 2011; Zeller, 2006) and have a suicide rate of more than four times that of the general population and other people with cancer (CDCP; Zeller, 2006). Safeguards were employed to protect participants in the study. The researcher reviewed the consent form with each participant and provided ample opportunity for questions and concerns to be expressed. Part of the consent discussion included clear explanation that participants were free to withdraw from the study at any time without penalty and could decline to answer any questions that were uncomfortable. A cancer diagnosis and treatment have the potential to induce psychological, emotional, or physical trauma. Participants were informed that telling the story of their cancer experience may stir up these feelings. In the event of this retraumatization, the researcher was prepared to refer participants who experienced distress to their oncologist or a mental health provider, if they were connected to one.

In addition to a thorough informed consent procedure, this study was reviewed and granted approval by the University of Louisville Internal Review Board (IRB) and University of Cincinnati IRB (see Appendix). There were no conflicts of interest in this study, nor did any participants report distress during or after participation in the study.

\section{Data Collection}


Data was collected in two ways. Data collection began once consent was obtained. Participants were asked to complete a short 10-minute survey which included the following items: participant demographic sheet, HADSand FACT-HN uestionnaires. The survey was intended to collect descriptive information about the women.

Data were collected through semi-structured interviews with the participants between October 2020 and February 2021. The women were interviewed twice, with two to three weeks between each. The first interview lasted an average of an hour and the follow-up interview lasted between 20-60 minutes. All the interviews were conducted by the researcher, who is the principal investigator.

Five of the women were interviewed using Microsoft Teams video conferencing. The video interviews were recorded in the Teams platform. Two of the women preferred to meet in person and invited the researcher to their homes for both interviews. These interviews were recorded using Rev Recorder, a smart phone application on the researcher's password protected iPhone. The other three women were interviewed by phone. The calls were recorded using Rev Call Recorder, another smart phone application. During one of the video interviews, there were problems with internet connectivity and some sections of the recording are indecipherable. The researcher was able to clarify the missing information during the second interview with that participant.

All the interviews were sent to Rev, an online transcription company, for transcription. The transcripts were reviewed by the researcher for accuracy and edited accordingly. The transcripts were saved on a password protected computer and to Cardbox, a secure, cloud-based storage service, provided by the University of Louisville. Transcripts were also loaded in Dedoose ${ }^{\mathrm{TM}}$ Version 8.3.47 for coding and analysis. 
The interview guide was used to elicit the conversation (See appendix). A slight deviation was taken from the methods protocol to include asking the women about how the Covid-19 pandemic was affecting them as a person living with cancer. This question emerged because the Covid-19 pandemic was at the forefront of the participants' minds. The interviews took place during the second wave of widespread infections in the US.

\section{Guiding Interview Questions}

The semi-structured interview was conducted using an interview guide. The interview guide questions were formulated using the theories of Lazarus \& Folkman's Transactional Stress and Coping, Relational-Cultural Theory, and Stigma Theory as sensitizing concepts. The researcher used the interview guide to understand the following pieces of the HNC experience: background of the illness, identity, impact on close relationships, support, and coping (See Appendix X).

\section{First Interview Procedures}

The day before the first interview, the researcher sent a confirmation email or text message. Women who agreed to an online meeting also received a link for a MS Teams video conference. All the women were at their homes during the interviews and spoke with the researcher either by phone, video conference, or in person. At the beginning of the first interview, the researcher reiterated the study information and obtained permission to record the conversation. Phone calls were recorded using Rev Call Recorder and in person meetings were recorded using Rev Recorder. Both Rev products are apps installed on the researcher's smart phone.

At the beginning of the interview, participants were asked to choose a nickname by which they would be called throughout the process to protect their real identities. 
Using a semi-structured interview guide, the researcher conducted an interview that lasted approximately 60 minutes (see Appendix). The interview questions were developed based on the research questions and theories used to support the study. Participants were given the opportunity to add any information that was not directly asked about during the interview. At the conclusion of the interview, the second interview was scheduled for two weeks later.

Immediately following the interview, the researcher completed field notes that documented the date, time, duration, and location of the interview, as well as notations about current events. The field notes included detailed impressions of the participant, participant reactions to the researcher, analytic and theoretical notes, methodological notes, and technical notes. Finally, the notes included a reflexive section to keep account of the personal reactions of the researcher. The recording was sent for transcription within a week of the interview.

\section{Second Interview Procedures}

The process for the second interview was like that of the first interview. The interview was confirmed the day before it was scheduled to occur. The researcher reviewed the transcript from the first interview prior to the second interview to identify gaps in information or points needing clarification. Follow-up questions were posed during the second interview based upon this review. For example, one participant described the experience of getting divorced during her $\mathrm{HNC}$ treatment. The researcher followed up in the second interview by asking if the treatment team had been aware of her social situation. This was asked to ascertain the amount of support the participants was comfortable getting from her treatment team. Another participant had shared that she 
had experienced significant depression during her surgical hospitalization, so much in fact that she was screened for suicidal ideation. During the second interview, the researcher asked if the participant had been referred for mental health care and if she had gone for any such care since her surgery. It was important to understand the resources that were offered to the participant, as well as her willingness to utilize those resources. Second interviews lasted between 15-60 minutes. At the conclusion of the second interview, the researcher provided an opportunity for the participants to debrief about their experience. The same process for gathering field notes was utilized after the second interview as the first and recordings were sent for transcription. Participants were given a $\$ 40.00$ gift card as a token of appreciation for their time. The gift card was emailed to the women after the second interview.

\section{Survey}

A questionnaire including a demographic sheet, the HADS, and FACT-HN was given to participants with the intention to gather descriptive information the women (See appendix). The HADS and FACT-HN questionnaires are easy to administer and score; therefore, informing the researcher's selection of these instruments.

The HADS was developed for use in outpatient medical settings and has been validated in multiple languages (Stern, 2014). It is a 14-question, self-assessment that most patients can complete easily in less than five minutes, except in case when the patient is unable to read. The seven questions for each domain, depression, and anxiety, are rated on a $0-3$ scale. It is easily calculated, and the results are equally easy to interpret. The higher the number, the more intense the experience of the symptom. This measure has sensitivity and specificity balance between the two subscales for anxiety and 
depression, with caseness scoring higher than 8 . The two subscales have correlations of .40 to .74 . The HADS-anxiety has a Cronbach's alpha between .68 to.93, (.83 mean) and the HADS-depression has .67 to .90 (.82 mean) (Bjelland et al., 2002). Persons taking the assessment are asked to answer the questions based upon their function in the past two weeks.

The FACT-HN was developed as a quality-of-life measure for people with HNC and validated in 1996 (List, et al, 1996). This disease specific measure was developed based upon the general quality of life measure, the FACT-G (Cella, et al, 1993). The researcher received approval to use this measure from the authors. The FACT-HN is a self-assessment consisting of 39 items, scored with a 0-4 Likert scale, in five domains (physical well-being, social/family well-being, emotional well-being, functional wellbeing, and $\mathrm{HNC}$ sub-scale). The scoring guidelines are easy to follow, as seen in table 3.2. The measure was determined to be sensitive to a variety of performance statuses in people with $\mathrm{HNC}$ and the Cronbach's alpha for the FACT-HN was between .75 and .90 for reliability and validity (List, et al., 1996).

\section{Figure 3.3}

FACT-HN Scoring List, et al., 1996

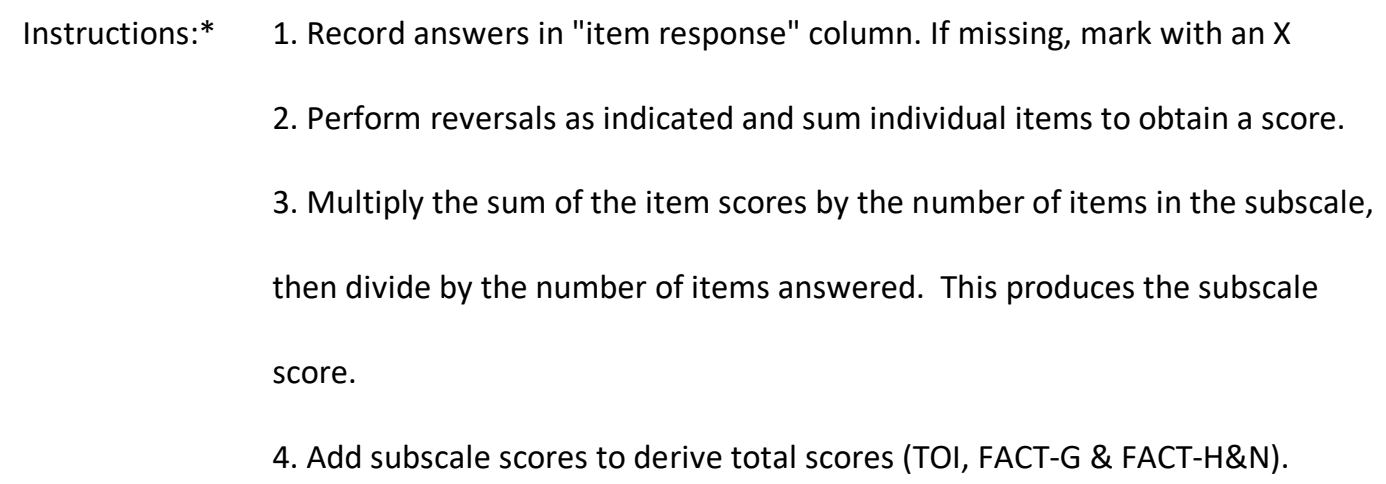




\section{Data Management}

The researcher recorded in-person and telephone interviews using smartphone apps by Rev, an IRB approved transcription service. The phone was password protected and utilized facial recognition for security of the data. Video conferences took place using Microsoft Teams and recorded within that platform. The computer used for these conferences was password protected. All the recordings were saved to a universitybased, password protected web-based storage platform (Cardbox). Each participant had a confidential file to hold questionnaires, demographics sheets and handwritten field notes. These files were kept in a locked file cabinet until all the information was converted to electronic files. Data from the questionnaires and demographic sheet were entered into IBM Statistical Package for the Social Sciences ${ }^{\mathrm{TM}}$ (SPSS) Version 27.

All interviews were transcribed by Rev and were reviewed for accuracy by researcher. Recordings from Rev Call Recorder and Rev Recorder were directly uploaded to Rev for transcription. Video conference interviews that were recorded on MS Teams were uploaded to Rev.com via secure website. Any conversation not related to the topic, such as small talk at the being of the interview to build rapport, was deleted from the transcripts. The researcher reviewed the completed transcriptions of the first and second interviews for accuracy and combined into a single transcript for each participant. The transcripts were saved to the researcher's laptop and to Cardbox.

\section{Data Analysis}

The goal of the analysis was to provide rich description of the phenomenon (Bradshaw, et al., 2017; Sandelowski, 2000). The experience of HNC was described by 
the individuals and analyzed using inductive processes to identify themes among the women and their loved ones.

Questionnaire data was entered into SPSS. Descriptive statistics were run on the demographic information. The HAD-S and FACT-HN questionnaires were manually scored and then recorded in the same SPSS data set.

Qualitative data analysis was conducted using grounded theory analysis coding strategies, including initial coding, focused coding, and memo writing (Charmaz, 2014). The interviews provided narrative data of the women's experience of having HNC. Field notes and memos written by the researcher also constitute data collected for this study.

\section{Coding}

First, the researcher read each transcript in its entirety to gain understanding of the overall situation. Giorgi describes this as reading "for a sense of the whole." This means that before themes can emerge, the researcher must be familiar with the full story. Then, initial coding was completed in Microsoft Word. Line by line coding methods were used to create gerunds. Gerunds or action words were applied to describe the physical or emotional action in each line of the transcript (Charmaz, 2014). After all transcripts had undergone initial coding, the gerunds were entered in an Excel spreadsheet. This spreadsheet included the following columns: interview number (chronologic order of interview), participant code name, and gerunds. When this spreadsheet was complete it contained 2,056 entries and was sent to the coding partner for review. The researcher and coding partner held a meeting to discuss the gerunds and identify common themes. Next, one-to-three-page excerpts from the transcripts of all ten participants were sent to the coding partner. Both researchers conducted initial coding using the common themes that 
were identified. The researchers then met again to compare the excerpt coding, with widespread agreement. To show agreement, the both coded transcripts were combined into one document to allow the codes of both researchers to appear side-by-side. Once the basic themes were identified in that step, the researcher grouped the gerunds according to theme and color coded the newly established code groups. The researcher then reviewed each of the 36 code groups. At this point, the researcher listed out the code groups into "parent and child codes" meaning that the broader, more abstract themes were identified as the parent codes, and more specific themes which were embedded within the parent code were identified as the child codes. Eventually, the codebook was created with eight parent codes and 51 child codes to create a codebook .

\section{Table 3.1}

Parent-Child Codes

\begin{tabular}{|c|c|c|c|}
\hline Emotional Impact & Adverse Life Events & Control & Coping \\
\hline Gratitude & Divorce & Self-advocacy & Mental Health therapy \\
\hline Facing mortality & Death of a child & Planning & Maintaining normalcy \\
\hline $\begin{array}{c}\text { Fear of } \\
\text { reoccurrence }\end{array}$ & Death of a parent & $\begin{array}{c}\text { Making treatment } \\
\text { decisions }\end{array}$ & Managing expectations \\
\hline Being stronger & COVID-19 & Self-care & Medication \\
\hline Stigma/shame & Domestic violence & & Activities \\
\hline Worry/anxiety & Other medical diagnosis & & Personality traits \\
\hline Depression & & & Range of Emotions \\
\hline Adjustment & Grieving & Physical Impact & Support \\
\hline Looking different & Loss of former appearance & Oral changes & Material assistance \\
\hline Eating & Fertility & Dental problems & Increased closeness \\
\hline Intimacy & Distancing in relationship & Fatigue & Emotional support \\
\hline $\begin{array}{c}\text { Changes in } \\
\text { lifestyle }\end{array}$ & Loss of former life & Nausea & Physical care \\
\hline Personal style & Unmet needs & Commication problems & $\begin{array}{c}\text { Relationship with } \\
\text { treatment team }\end{array}$ \\
\hline Role change & & Pain & \\
\hline Seeking normalcy & & Treatment & \\
\hline \multicolumn{2}{|c|}{} & Weight loss & \\
\hline & & Skin problems & \\
\hline
\end{tabular}


*Areas shaded green indicate Parent Codes.

After the codebook was established, the codes and transcripts were uploaded to Dedoose $^{\mathrm{TM}}$ (Version 8.3.47) for the final analysis. Dedoose $\mathrm{T}^{\mathrm{TM}}$ is a data analysis software used to organize data and manage the coding (Sociocultural Research Consultants, LLC, 2021). The researcher and coding partner met to review the codes and code definitions. Once the coding partner understood the codes and definitions, an interrater reliability test was created in Dedoose ${ }^{\mathrm{TM}}$, wherein the researcher selected transcript passages to be coded. The interrater reliability test was run to establish a pooled Cohen's Kappa score, which is considered a reliable and valid test in qualitative research (Landis \& Koch, 1977). The pooled Cohen's Kappa score was .71, which demonstrates "good" agreement between the two coders (Cohen, 1960).

\section{Memo Writing}

Field notes were kept by the researcher and included in the analysis and included content related to observational notes, theoretical notes, and methodological notes (Creswell, 2013). Observational notes describe what happened in the interview. As the researcher reflected on the experiences and began to derive meaning in the data, analytic notes were written. The process of the interviews was documented in the methodological notes. This included critiques and instructions for the researcher to observe in upcoming interviews. Analytical memos serve as a summary of these data and include progress made within the study.

\section{Sufficiency and Saturation}

The number of participants necessary for qualitative studies are typically small, ranging from as few as two to 10 (Boyd, 2001; Creswell, 1998; Glaser \& Strauss, 1967), 
particularly with hard-to-reach populations such as people living with HNC. It is recommended that the sample size be balanced with the number and length of the interviews. Interviewing participants more than once is conducive to gathering a greater depth of data and increasing credibility (Lincoln \& Guba, 1985). It is widely accepted that code saturation can be obtained with a minimal number of participants; however, meaning saturation is more likely to occur with a greater number of participants (Dukes, 1984; Hennick et. al, 2017; Moustakas, 1994; Polkinghorne, 1989; Starks and Trinidad, 2007; Wertz, 2005). Based upon these standards, this study was designed with a target of 12-15 participants, each being interviewed twice. Based on the ample amount of data collected in the first 10 participants, it was determined that saturation was reached. This was determined by fact checking that was conducted with each participant during the second interview to ensure the researcher had accurately understood the first interview. The researcher has extensive clinical experience which allowed for the member checking inquiries to flow as part of the conversation. It was clear that there were no new codes or themes emerging in the latter interviews. The distribution of codes by participant can be seen in Figure 3.1. Finally, the researcher spent between 60-120 minutes. Hence, this study was concluded with 10 participants. 
Figure 3.1

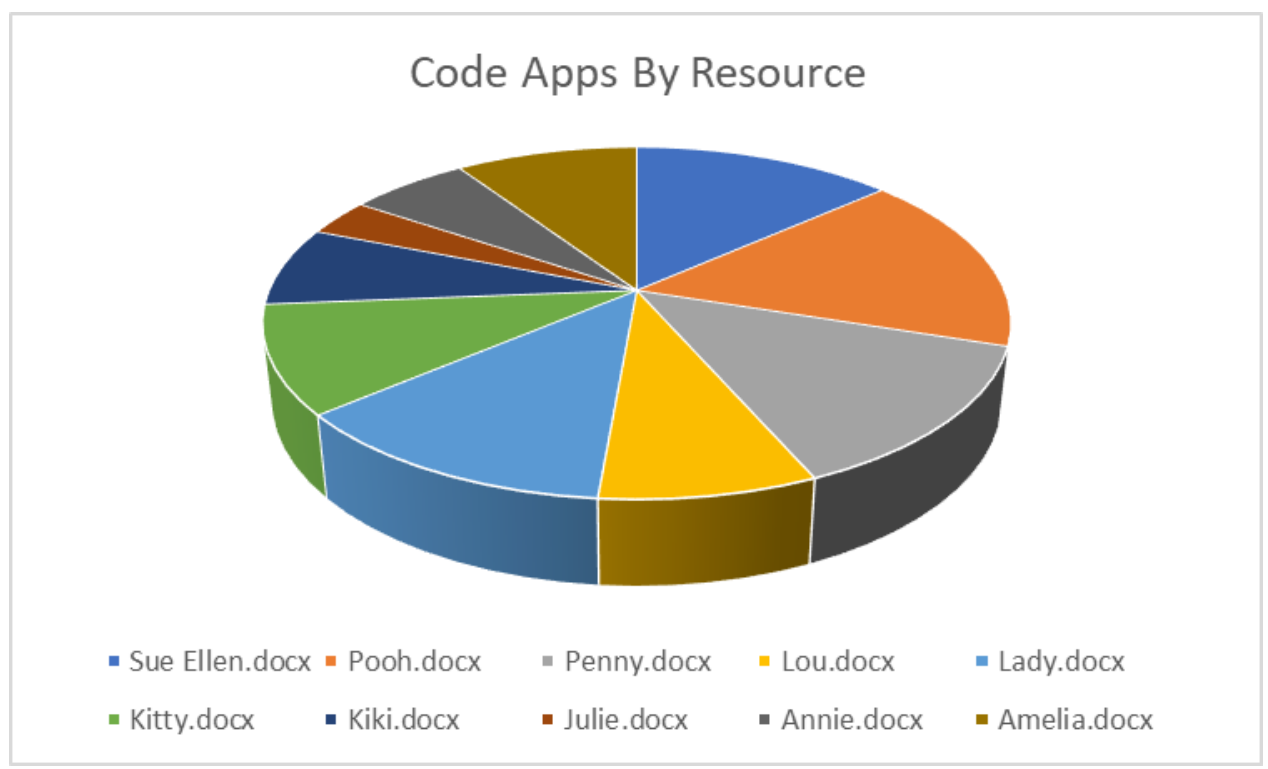

\section{Reflexivity}

The researcher was actively involved in every step of the study. The researcher provided education about the study, obtained consent from all participants, and conducted all interviews in this study. Every transcript was reviewed and edited by the researcher. Professionally, the researcher has experience with the head and neck cancer population in two capacities: clinical social worker practicing extensively with this population and as family member of a person with head and neck cancer. The researcher's interest in working with people with cancer stems from the experience of having three grandparents die of cancer - most specifically her paternal grandmother who died of laryngeal cancer. These professional and personal experiences absolutely influenced the choice of dissertation topic, particularly the interest in women with HNC.

The reasons for choosing to study women with $\mathrm{HNC}$ are both personally and professionally motivated. My paternal grandmother, Ruth, died at age 57 from laryngeal 
cancer. She was a vivacious woman with a big laugh and even bigger heart. She had eight children, my father being the oldest. My grandmother not only ran her large family, but she also owned and operated a small restaurant. She had been a smoker for most of her life. Every weekend, my family would go to my grandparents' house. Visits were always fun times filled with great home cooking and lively conversation. I do not remember exactly when I realized something was different about Grandma, but it was before her laryngectomy. The family would talk in hushed tones about Grandma being sick, but never anything more. It was after her surgery, when she lost her ability to speak and her big laugh, that my mother told me "the cancer is in her throat and lungs." I was so scared. Grandma had a stoma and an electrolarynx. She had chemotherapy, which made her lose her hair. She wore a turban and was noticeably unhappy about it. She wore little crocheted collars over her stoma that would often be stained brown from secretions. I remember seeing her use long cotton swabs to clean her stoma when she thought no one was watching. Eventually, she stayed in the hospital bed that had been brought into the living room. This was a stark change from her buzzing around the kitchen or dealing the occasional game of poker with my uncles. She slept all the time. Our family did not go to her house for several weeks. Then my parents told me that she had died.

Fast forward 23 years and I was working at The Barrett Cancer Center in Cincinnati, Ohio. I was the only social worker in the outpatient oncology service. The physicians working with head and neck cancer patients requested more social work services for their patients. This request was motivated by extended hospitalizations for this population after surgery. The patients had many psychosocial needs. The patients 
and their families were understandably nervous about the tremendous amount of care needed to recover from surgery, the physical disfigurement, and increased likelihood of the patient needing a short term stay in a skilled nursing facility (SNF) after surgery. In conjunction with the medical team, I developed a pre-surgery psychosocial assessment to better understand the patients and their families, as well as prepare them for the long road ahead. The assessment identified the support systems, barriers to care (lack of insurance, substance use, mental illness), and health literacy of the patients. In ideal circumstances, the assessment would include input from caregivers. After the implementation of the assessment, hospital stays were shorter. Patients and families had a better understanding of the surgery and recovery requirements. The people I met while conducting the assessments were open to telling me their life stories, no matter how unconventional. Many had been drinkers and smokers. There were complicated family histories.

During the formulation of this study, the researcher expected that some of the participants would have experienced stigma, because the most common causes of HNC are drinking, smoking, and the sexually transmitted HPV virus, all of which could be considered to contradict traditional female stereotypes. Under this stereotype, women who engage in these sorts of behaviors are subject to being stigmatized. Practice experience led the researcher to expect a large portion of the sample to have a history of drinking and smoking behaviors.

To suspend these biases and increase study rigor, the researcher used bracketing. The technique of bracketing is described by Moustakas as epoche, which means the researcher must suspend previously held knowledge or beliefs about the study subject. This does not eliminate the existence of the knowledge or beliefs but forces the 
researcher to be aware of those "natural attitudes" (Moustakas, 1994) and use bracketing as a mental shelf on which to place them. This bracketing process is like the skills required of social workers in clinical practice wherein personal attitudes must be held outside of professional interactions with clients. To do this, the researcher kept a journal that included thought and feelings about the subject of women with HNC before beginning data collection.

The researcher has personal experience with a family member dying of $\mathrm{HNC}$. The loss of the researcher's grandmother and subsequent witnessing of changes in the extended family dynamics certainly colored the researcher's view. During the same year as data collection, the researcher's father died of leukemia, thus influencing the researcher's ideas about family caregiving and adjustment. To bracket these experiences out of the data analysis, the researcher made detailed field notes before and after each interview. These field notes included details of the setting, current events, duration of the interaction, and activities involved with each interview. The researcher's impression of the interview process and participants were documented in the field notes. Memos were also written as part of the researcher's journal to process the researcher's feelings from bearing witness to the trauma undergone by the participants. To further employ bracketing during the data analysis, a code specific to adult children was used. During adjudication meetings with the coding partner, the researcher was able to identify how many of the instances of that code were better suited to other categories. The coding partner was able to assist the researcher with further bracketing of personal sentiments about the experience of cancer. 
The structure of qualitative interviewing incorporates the researcher as an instrument of the study that cannot be removed from the overall picture. This reflexivity is managed using field notes and memos to allow the researcher to bracketed out of the descriptive research findings (Creswell, 2013).

\section{Trustworthiness and Rigor}

The results of this study are credible, transferable, dependable, and confirmable as defined by Lincoln \& Guba (1985), and these criteria are further explained below.

\section{Credibility}

The researcher took steps to ensure the credibility of the study. This aspect of trustworthiness was demonstrated in a few different ways. First, the researcher made an effort to establish rapport with the women, rather than diving right into the interviews. Reflective listening and paraphrasing back to the participants throughout the interviews demonstrated both the researcher's attention and empathy. There was extended interaction in the field by lengthy engagement with the participants. The researcher conducted two interviews, each lasting between 30 and 80 minutes, with each participant. This gave the researcher between 60-120 minutes of engagement, which allowed the women to become more comfortable and open in their communication. The researcher used reflective listening skills to conduct member checking. In many instances, member checking was important not only for meaning, but to confirm the actual content of the participants' responses due to speech impairment from their cancer.

Negative Case Study. An instance of additional rigor can be demonstrated through a negative case presentation. By having a participant who provides information 
that is different from the other participants demonstrates that the process was trustworthy and researcher bias did not only find positive case examples (Lincoln \& Guba, 1985).

This study contains one negative case study provided by participant, Julie. Her story did not provide details that contributed to the formation of many of the themes in the study. Julie is a 64-year-old, retired teacher. Her story documents lifelong, chronic illness that began for her as an infant. She has had two kidney transplants and is required to take medication to keep her body from rejecting her transplanted organs. One of the side effects of this anti-rejection medication is cancer, more specifically skin and oral cancer. Julie has lived through multiple occurrences of both cancers. Her skin cancer has been more prolific than oral cancer; however, she has had three instances of oral cancer. She reports being very aware of her health and immediately seeking medical attention when she discovered sores in her mouth. All three oral cancers were removed by local surgery. Julie did not have chemotherapy, immunotherapy, or radiation. She reports that her physical appearance is not changed because of her oral cancer. She stated her young students did not notice a difference, so she believes there is no impact on her speech. During the interview, the researcher did not note any speech impairment. Julie reported having more pressing health concerns than her oral cancer. She is currently experiencing kidney failure and is on dialysis. Because of her multiple instances of skin and oral cancer, she has been declined consideration for a future transplant. She is grieving this change in her health but does not attribute her grief specifically to cancer. In the broader context of her life, Julie felt cancer contributes to her current decline in health but views it as a symptom of her other ailments. 
Understanding gained from this study of the experience of women with $\mathrm{HNC}$ and their relationships may have commonalities with other psychosocial oncology studies and populations. While it is true that not all people with cancer are the same, there are common threads woven throughout this study that may mesh well with other populations. It is important to consider the participants, as well as their psychological and geographic positions, before making blanket assumptions about women with HNC. However, this study sets the stage for further study of the experience of women with HNC.

\section{Transferability}

Transferability refers to the presence of a clear research process that would allow for the replication of the study by a different researcher (Lincoln \& Guba, 1985). The researcher employed purposeful sampling to be sure the study population was able to address the research questions. The researcher also kept a journal throughout the study and noted details in field notes after each interview to help provide additional context to the interviews. The interviews were reviewed verbatim to allow the results to richly descriptive. Future studies could be conducted following the same procedures to examine the same phenomenon to obtain similar findings.

\section{Dependability}

An in-depth description of the steps taken to conduct this inquiry is detailed earlier in this chapter, creating an audit trail (Lincoln \& Guba, 1985). The research followed the detailed research procedure to ensure dependability.

\section{Confirmability}


Measures were taken to safeguard the study from personal bias. All data was coded by the researcher, with a coding partner serving as the "critical other" (Giorgi, 2009) to increase the rigor of the study. The researcher and coding partner are trained in qualitative interview procedures and methods as established by Charmaz (Charmaz, 2014) and passed a doctoral level course in qualitative studies and methodology. Both the researcher and coding partner have at least 15 years of experience as clinical social workers. Both have worked in mental health and medical settings throughout their careers. The researcher has experience working on several qualitative projects throughout the doctoral program, including conducting and coding focus groups, and serving as a coding partner on several projects. By writing in a journal, memo writing, field notes, and bracketing exercises (both independent and in conjunction with a coding partner) the researcher took steps to name and understand potential biases. Throughout the study, the researcher evaluated the data and personal insights. This was an ongoing process that allowed the researcher to not only be aware of biases, but also adjust her viewpoint to create more depth in the research inquiries and analysis.

\section{Writing and Dissemination}

Writing is part of the iterative process of qualitative studies. Just as data collection, coding, and analysis lead to the final ideas in QD, writing serves as part of the analysis process that allows the researcher to sort through their thoughts and the data (Glaser, 1978).

\section{Representation}

In all research it is important to be mindful of the attitudes of the participants as the "subjects" of studies, and not dehumanize their experience for the sake of the 
advancement of knowledge (Vargas-Cetina, 2013). As in any social work endeavor, the dignity and worth of the person is important to honor and research is no exception. For this study, it was important to accurately represent the details of the participants, while still honoring their privacy. To do this, the researcher provided many direct quotes throughout the manuscript. These detailed quotes allow the participants to tell their story in the fullest possible way, rather than the researcher interpreting the information.

\section{Reciprocity}

In this study, it was important for the researcher to be mindful of the power dynamics in the relationship with the participants. Typically, the researcher has more to gain from the study than the participants (Seidman, 1991). However, in this study many of the participants shared that they felt an emotional weight lifted after sharing their stories with the researcher. Several of the women cried when describing the cathartic feelings they experienced by participating in the study and thanked the researcher for the opportunity. The researcher experienced tender feelings toward the participants because of their willingness to share their difficult stories. The women were vocal about wishing the researcher well in her doctoral program and voicing their happiness at being able to help other women with HNC. At the conclusion of the second interview, the researcher openly shared her personal connection to HNC because of her grandmother's illness, as well as hopes for future research based upon this study. The participants were offered access to the final study product (Rubin \& Babbie, 2016). Nearly all stated they were curious about the results and would love a copy.

To further the work that has begun with this dissertation, the researcher has plans for follow up. Many of the participants commented they had never met another woman 
with $\mathrm{HNC}$ and asked questions about the other participants. Because of this, the researcher is interested in facilitating a follow up focus group with the participants to allow them to share their experiences with each other. To disseminate the knowledge gained in this study, the researcher is planning to accept speaking engagements in the social work and medical fields. The researcher has been invited to present Grand Rounds for the otolaryngology department at University of Cincinnati Medical Center. Finally, the researcher plans to share this study through conference presentations and publications.

\section{Summary}

The methods of this study were designed to meet three research aims: (1) to distill the essence of the lived experience of women with head and neck cancer (2) to understand how women cope with head and neck cancer (3) to understand how a diagnosis of head and neck cancer impacts relationship function in the close relationships of women patients. The research design, study population and sample, and ethical considerations, as well as detailed procedures for participant selection, data collection, and data analysis were included in this chapter. A clear understanding of the study design and methods leads to a discussion in the next chapter of the results and findings. 


\section{CHAPTER IV: RESULTS}

In Chapter 4 research findings of this study will be presented along with an explanation of how these understood through a qualitative descriptive lens. In this chapter, brief profiles of each of the participants, along with the demographic and clinical description of the study sample, will set the stage for the findings of the women's lived experience with HNC. Their experiences with living with HNC are organized around the four research questions: 1) how do women describe their experience of living with HNC? 2) how do women describe their coping with cancer? 3) what role does stigma play in their experience? 4) what do women perceive to be the impact of HNC on their close relationships?

\section{HNC Patient Sample}

The lived experience of being a woman with HNC and the impact on close relationships was shared by ten women. All participants were Caucasian. The women were between the ages of 28 and 81 years of age, with a mean age of 62.9 years. Six of the women had never been smokers and the remaining four had quit ( 3 before diagnosis, 1 after diagnosis). Eight of the women were diagnosed with tongue cancer, one with cancer of the sinus, and one with oral cavity cancer. Four of the women were nondrinkers, and another four reported social drinking. The other two woman reported being 
heavy drinkers in their younger years but had since quit or cut back on their drinking. Only one woman reported a history of recreational drug use, with the others reported they had never used drugs. The women live in a variety of locations: three in rural Kentucky, one in rural Ohio, four in suburban Ohio, one in rural Indiana, and one in suburban Indiana. Four of the women are retired, two are homemakers, three are professionals, and one was working an unskilled labor job at the time of her diagnosis. Half of the women are married, three are divorced, one is widowed, and one is in a committed relationship. All but one of the women have children. One has a child under the age of five and the rest of the woman have adult children.

The women were asked to complete the Hospital and Anxiety Scale (HADS) and the Functional Assessment of Cancer Treatment- Head and Neck (FACT-HN). Eight of the ten completed the questionnaires. The scores of the HADS reflect a moderate amount of depression and normal to moderate range of anxiety. Four of the women were within normal range for depression, two scored in the borderline abnormal range and two were in the top of the range for depression. In the anxiety domain, four scored within normal range, three were within borderline limits, and one scored high for anxiety. The FACT$\mathrm{HN}$ scoring is less specific, stating that a higher score indicates a higher quality of life, with a maximum score of 148. Half of the participants had scores less than 100. The other four had scores between 111 and 136. Tables 4.1 and 4.2 present details about each participant.

The study participants were open to sharing their experience as women with HNC. Many thanked the researcher for giving them the opportunity to share their story and found the experience to be cathartic. To better understand the essence of their 
experience, the following vignettes provide a brief description of each individual. The quotes were selected based upon the strength of their description of their feelings about the cancer experience.

\section{Participant Vignettes}

The goal of this study is to describe the collective experience of women with HNC. However, it is important to give voice to their individual stories to give context to the whole story. Positioning the women as individuals helps to illustrate the details of their lives.

\section{Sue Ellen}

\section{"I'm scared that he thinks I look like Frankenstein."}

Sue Ellen is a 28-year-old woman who is married and has a 3-year-old son. She is employed as a nurse. Due to a genetic disorder, she was predisposed to HNC and was aware of this possibility since her early childhood. She has lived through three occurrences of her cancer and undergone increasingly invasive surgeries each time. Her speech and ability to eat have improved since her treatment and extensive rehabilitation. She has extensive family support and a large network of people to help her and her family. She struggles to adjust to the changes in her appearance, but reports she is becoming less self-conscious.

\section{Annie}

"I'm proud of myself. I think that beating this as I consider I have done so far has given me a feeling of wellbeing and a pride that I went through it without falling apart."

Annie is an 81-year woman who lives alone. She divorced her husband after her cancer diagnosis, due to his abusive behavior and threatening her children. She has been 
able to recover from her cancer and treatment with a great amount of support from one of her daughters, who lives in the same neighborhood. She is very matter of fact in her description of her cancer experience and treats it as just another part of life.

\section{Amelia}

\section{"Being alone I was just petrified."}

Amelia is a 64-year-old woman who lives alone. Her best friend lives next door. She has one adult daughter who has provided support to her throughout her cancer experience. Amelia describes herself as an independent person who had difficulty accepting that she needed help to get through her diagnosis and treatment. It was important to her to not be a burden on her only daughter, who had a new baby. She has an extensive network of friends who worked together to help her get to treatment and to recover. Amelia noted that one of the best things about her cancer experience was reconciling with her brother, from whom she had been estranged.

\section{Julie}

\section{"I knew something was wrong. And having all these problems health-wise, I've kind of learned to, even if it's nothing, you should go check it out."}

Julie is 64 years old and a retired teacher. She lives with her husband, whom she describes as her greatest support and advocate. Julie has been chronically ill since birth and undergone two kidney transplants. The anti-rejection medication she takes to manage her transplants are the cause of her cancer. She has had three surgeries to remove cancerous spots in her mouth and numerous bouts of skin cancer. Julie is an excellent advocate for her medical care and treats her cancer as a challenge that she will manage. 
She has recently learned that her kidneys are failing again, but she is not a candidate for another transplant because of having cancer.

\section{Penny}

"I feel like a part of me is missing. She'll never come back from that. I hope I'm wrong."

Penny is a married 57-year-old woman. She describes her relationship with her children as strained, more as a result of divorcing their father several years ago because of domestic violence than her cancer. She reports a history of bipolar disorder, but currently struggles more with depression. Penny is very insightful into her emotions and has strong coping skills. She sees a therapist and uses art and writing to cope. Her husband is an excellent caregiver and provides her with physical and emotional support.

\section{Kiki}

"To me, war is a willful act, you make a choice and that somehow you have control in the outcome. But cancer doesn't feel like you have control of the outcome. You can certainly do all the things that we know medically can help, but you can't necessarily control the outcome."

Kiki is 72 years old and lives with her partner of 30 years. She was married three times before meeting her current partner. She has 4 adult daughters, who live across the country. She describes herself as a spiritual person who has embraced complementary medicine since the 1960 's. She shared a story about seeing a news report about HNC shortly before her diagnosis and was not surprised by her cancer diagnosis because of the information she learned in that report. Kiki had severe complications during her treatment that resulted in extended hospitalization and a stay in a long-term acute care facility. She took part in an immunotherapy clinical trial and is currently showing no evidence of disease. 


\section{Lou}

\section{"It's not fun. It's not something I wanted. But this is my journey."}

Lou is a 68-year-old woman who is married to a funeral director and is the mother of two grown sons. She had nearly all of her tongue removed and depends on a feeding tube that is surgically implanted for all of her nutrition. She reports the inability to eat by mouth has been a difficult adjustment but makes the best of it by continuing to cook and join her family at the table. She credits her Christian faith and relationship with God for getting through her cancer diagnosis and treatment.

\section{Pooh}

"It was months before I saw the light at the end of the tunnel. And I wondered if I made the right decision."

Pooh is a married 64-year-old woman. She lives with her husband and their 38year old son, who she describes as having "mental disabilities." She has two other adult children who live out of the home. Pooh describes a difficult course of treatment and reports being assessed for suicidal ideation when she was recovering in the hospital from her surgery. She has had difficulty getting the emotional support she needs but is hopeful she will eventually feel better. She had a large portion of her tongue removed and continues to struggle with communicating clearly and eating.

\section{Lady}

\section{"All I can say is that I have regained confidence and been able to speak. I just accepted what I sound like now, even though I wish I could be better."}

Lady is a divorced 63-year-old woman who lives alone. She has worked as an architect and is very engaged in her community. Lady had surgical removal of leukoplakia, a skin condition that includes patches of thick, white mucus on the inside of 
the mouth (www.mayoclinic.org) several times since the late 1990's. The surgeon who performed these removals died a couple of years before her diagnosis and she wonders if her cancer developed in that time frame. She was most worried about her ability to communicate clearly because she often speaks at professional conferences. After ongoing speech therapy, she is proud of her progress. Her three daughters have provided physical and emotional support throughout her cancer journey. Despite having some difficulty eating, Lady feels her life is relatively normal now.

\section{Kitty}

\section{"Yeah, because a day don't go by that I still worry about getting cancer. Because I pray every night for the Lord not to give it back to me."}

Kitty is a 68-year-old, woman who was widowed several years ago. Her only son died a few years ago. She shared that she struggled with depression since her son's death and when she was diagnosed with cancer, she wondered if she was meant to die to be with her son. Kitty did get treatment and despite a tumultuous relationship with her oncologist, made great strides toward recovery. She was frustrated with the exhaustion and other physical side effects she experienced during radiation therapy and felt the treatment team did not adequately prepare her for the side effects of treatment. Much like another participant, Kitty reconciled her relationship with her estranged brother, who has become her primary support person. 
Table 4.1

Description of Participants

\begin{tabular}{|c|c|c|c|c|c|c|c|c|}
\hline Participant & Age & job & location & $\begin{array}{c}\text { Cancer } \\
\text { Type }\end{array}$ & $\begin{array}{l}\text { Marital } \\
\text { Status }\end{array}$ & Parenthood & $\begin{array}{c}\text { Smoking } \\
\mathrm{Hx}\end{array}$ & $\begin{array}{c}\text { Drinking } \\
\mathrm{Hx}\end{array}$ \\
\hline Sue Ellen & 28 & professional & $\begin{array}{c}\text { suburban } \\
\text { IN }\end{array}$ & tongue & married & Child under 18 & $\begin{array}{c}\text { non- } \\
\text { smoker }\end{array}$ & social \\
\hline Annie & 81 & retired & $\begin{array}{c}\text { suburban } \\
\mathrm{OH}\end{array}$ & tongue & divorced & 3 adult & $\begin{array}{l}\text { former } \\
\text { smoker }\end{array}$ & social \\
\hline Amelia & 64 & retired & $\begin{array}{c}\text { suburban } \\
\mathrm{OH}\end{array}$ & tongue & divorced & 1 adult & $\begin{array}{c}\text { non- } \\
\text { smoker }\end{array}$ & $\begin{array}{l}\text { non- } \\
\text { drinker }\end{array}$ \\
\hline Julie & 64 & retired & Rural KY & tongue & married & None & $\begin{array}{c}\text { non- } \\
\text { smoker }\end{array}$ & $\begin{array}{c}\text { non- } \\
\text { drinker }\end{array}$ \\
\hline Penny & 57 & $\begin{array}{l}\text { unskilled } \\
\text { labor }\end{array}$ & $\begin{array}{c}\text { suburban } \\
\mathrm{OH}\end{array}$ & tongue & married & 3 adult & $\begin{array}{l}\text { former } \\
\text { smoker }\end{array}$ & $\begin{array}{l}\text { former } \\
\text { heavy } \\
\text { drinker }\end{array}$ \\
\hline Kiki & 72 & professional & Rural KY & tongue & partnered & 4 adult & $\begin{array}{l}\text { former } \\
\text { smoker }\end{array}$ & social \\
\hline Lou & 68 & homemaker & Rural OH & tongue & married & 2 adult & $\begin{array}{c}\text { non- } \\
\text { smoker }\end{array}$ & $\begin{array}{c}\text { non- } \\
\text { drinker }\end{array}$ \\
\hline Pooh & 64 & homemaker & Rural IN & tongue & married & 3 adult & $\begin{array}{c}\text { non- } \\
\text { smoker }\end{array}$ & $\begin{array}{c}\text { non- } \\
\text { drinker }\end{array}$ \\
\hline Lady & 63 & professional & Rural KY & $\begin{array}{l}\text { other } \\
\text { HNC }\end{array}$ & divorced & 3 adult & $\begin{array}{l}\text { non- } \\
\text { smoker }\end{array}$ & social \\
\hline Kitty & 68 & retired & Rural KY & $\begin{array}{l}\text { other } \\
\text { HNC }\end{array}$ & widowed & 1 adult & $\begin{array}{l}\text { former } \\
\text { smoker }\end{array}$ & $\begin{array}{c}\text { former } \\
\text { heavy } \\
\text { drinker }\end{array}$ \\
\hline
\end{tabular}

Table 4.2

Quality of Life of Participants: Hospital Anxiety and Depression Scores

\begin{tabular}{|l|c|c|l|l|c|c|}
\hline Participant & $\begin{array}{c}\text { HADS- } \\
\text { depression }\end{array}$ & $\begin{array}{c}\text { HADS- } \\
\text { anxiety }\end{array}$ & & Participant & $\begin{array}{c}\text { HADS- } \\
\text { depression }\end{array}$ & $\begin{array}{c}\text { HADS- } \\
\text { anxiety }\end{array}$ \\
\hline Sue Ellen & N/A & N/A & & Kiki & 1 & 8 \\
\hline Annie & 2 & 2 & & Lou & 1 & 2 \\
\hline Amelia & 9 & 9 & & Pooh & 8 & 11 \\
\hline Julie & N/A & N/A & & Lady & 5 & 4 \\
\hline Penny & 11 & 11 & & Kitty & 9 & 7 \\
\hline
\end{tabular}


Table 4.3

Quality of Life of Participants: FACT-HN Scores

\begin{tabular}{|l|c|c|c|c|c|c|}
\hline Participant & $\begin{array}{c}\text { FACT-HN } \\
\text { Total }\end{array}$ & $\begin{array}{c}\text { FACT-HN } \\
\text { Physical }\end{array}$ & $\begin{array}{c}\text { FACT- } \\
\text { HN } \\
\text { Social }\end{array}$ & $\begin{array}{c}\text { FACT-HNC } \\
\text { Emotional }\end{array}$ & $\begin{array}{c}\text { FACT-HN } \\
\text { Functional }\end{array}$ & $\begin{array}{c}\text { FACT-HN } \\
\text { H\&N } \\
\text { Subscale }\end{array}$ \\
\hline Sue Ellen & N/A & N/A & N/A & N/A & N/A & N/A \\
\hline Annie & 97 & 25 & 28 & 18 & 26 & N/A \\
\hline Amelia & 89 & 11 & 27 & 16 & 12 & 23 \\
\hline Julie & N/A & N/A & N/A & N/A & N/A & N/A \\
\hline Penny & 86 & 25 & 9 & 17 & 13 & 22 \\
\hline Kiki & 115 & 21 & 28 & 20 & 27 & 19 \\
\hline Lou & 123 & 28 & 23 & 23 & 27 & 22 \\
\hline Pooh & 96 & 20 & 14 & 21 & 18 & 23 \\
\hline Lady & 136 & 28 & 28 & 20 & 28 & 32 \\
\hline Kitty & 111 & 24 & 26 & 16 & 20 & 25 \\
\hline
\end{tabular}

The ways in which women cope, receive support, and experience stigma are described by this study. Throughout the interviews, women describe the experience of HNC by sharing the physical and emotional impacts of cancer treatment, the ways in which they coped, their experience with stigma, and the impact on their close relationships.

\section{RQ1: Experience of Living with Head and Neck Cancer}

All the participants were frank in discussing their journey from diagnosis, treatment, adjustment, and in many cases recovery. As outlined by Lazarus and Folkman, this part of the $\mathrm{HNC}$ journey describes the appraisal phase of stress and coping. The women learned about their disease and treatment options, and then considered their physical and emotional resources to move forward in their journey. The will to survive $\mathrm{HNC}$ outweighed the risk of foregoing treatment. Many provided descriptions of waking up from surgery and undergoing drastic changes in their physical and mental health. Nearly all underwent radiation therapy. Many have ongoing problems with their speech and eating because of surgery and treatment. Adjustments in the mechanics and social 
ritual of eating, role changes, looking different, and grieving their former professional and personal lives are common themes. Just as there were physical and emotional implications in having $\mathrm{HNC}$, the adjustments described addressed physical and psychological changes made by the women to attempt to gain some normalcy in their lives. Most described having to make modifications to their food and the way they eat, whether it be a long-term feeding tube or changes in diet. Many struggled with their appearance being changed and made creative attempts at adjusting their appearance to improve their confidence. Adjustments were also necessary in their relationships. Intimacy and roles in the relationships changed and the women have had to reevaluate their personal needs and priorities. When describing the experience of HNC, the women shared the physical impact of the disease, which included treatment and side effects, changes in communication, eating, and appearance.

\section{Treatment and Side Effects}

All the women underwent intense treatment for their cancer, with all of them having surgery. The physical and emotional burden described by the women about treatment and side effects sheds light on the experience.

Women with $\mathrm{HNC}$ reported extreme fatigue from radiation therapy and felt the treatment would kill them faster than the disease. Radiation therapy was most often mentioned by the women as a grueling part of treatment. Many felt exhausted and in pain from the treatment, experiencing tightening of their skin and having a burning sensation in their mouths. For those who underwent chemotherapy, they also felt challenged throughout the course of treatment. The women talked about how they felt determined to get through treatment, but that the treatment team had not adequately 
prepared them for the challenges they would face. Kitty shared how undergoing treatment was extraordinarily taxing for her, saying,

"I had to go through radiation, and they said I have to go through chemo. And it liked to killed me because I thought one treatment is going to be enough, but I had both of them. It just devastated me."

Not only was treatment grueling, but some participants felt the treatment team could not relate to the difficult of being treated. Pooh poignantly described her experience with radiation like this,

"I don't think the doctors think about it, but every time you lay down for that treatment, you're being poisoned. And I felt like every day I was dying a little bit more." Surgery is another example of the physical impact of HNC. For many of the women, the surgeries not only changed their appearance, but also the way the speak and eat. The women understood that having surgery could save their lives, but also suffered from the treatment. Penny shared what it was like to wake up from her surgical procedure,

"So, I had 100 tubes coming in and out of my body, and I couldn't talk, and that scared me. I wish they would have explained in detail how many tubes was going to be coming out of my body, and what the scars would be because they didn't go into that. They just said, "Oh, it's easy. We just put something there, take a little skin off of there." They didn't explain it to me in detail, and I wish they would have because that's the one thing. When a person wakes up from surgery, they didn't show me a mirror. I just saw it in other people's eyes. They think you can't see it, yeah you could see it. I saw my husband's face when I woke up. He was shocked, and I couldn't say what's wrong, you 
know what I mean? That I knew that it was a shock that whoever walked in and saw me, they knew it was a shock. They didn't expect to see that."

Most of the surgeries described involved removal of a significant amount of tongue muscle and it being replaced with a free flap, usually from the thigh. Surgery often included removal of many, if not all, of the women's teeth. Lymph nodes were removed from many of their necks. The women thought the surgery was hard to live through but focused on the fact that they are alive.

\section{Communication}

The women described periods of time, most right after surgery or near the conclusion of radiation therapy, when they were completely unable to speak. All were able to recover their voices, and many underwent speech therapy. Only one participant in this study reported having minimal problems with her voice, but she had the least evasive surgery.

Impairment in communication went beyond merely being unable to talk. Many experienced changes in the function of their facial muscles, causing difficulties with smiling and other expressions. This inability to express themselves increased feelings of being disconnected from their loved ones, isolation, and despair. Many of the women shared that being unable to communicate made them feel powerless. In one instance, being unable to talk escalated feelings of victimization during a situation when one of the participants was unable to question and report a physical examination during her hospitalization that involved resident physicians examining her lower body, that had been completely uninvolved in her surgery. Many described that challenges with 
communication caused them to feel like a different person. Pooh shared how her voice impairment impacted her:

“... I wish I could still communicate. I wish I was still as happy. And I wish I could sing again.”

Many of the women shared that being unable to participate in lively conversations and the changes in how their mouths worked were hard to accept. They noticed that they did not have the stamina to hold extended conversations. This limited their ability to get support and to enjoy an activity that had previously been taken for granted.

Annie shared the extensive nature of her surgery and the myriad of feelings she had about her HNC treatment and recovery:

"Well, they removed part of my tongue and they took a graft from my thigh and used it to construct a flap. And so therefore that's what I have now, it's been very successful. I'm very, I'm conscious of it still, I feel like there's something in my mouth that doesn't belong there, and it has changed my speech somewhat. And that was really the only thing I was afraid that I might not be understandable. And so that was one concern I had I felt pretty confident that the cancer was gone, but then I was concerned about what people had to realize what I'm saying, but I have not found that to be true. I some words or some sounds are not as clear as I would like, I am going to have some speech therapy, upcoming to perhaps help me to enunciate a little bit better or get all the sounds out. But other than that, I'm very happy with what has happened."

To the researcher, most of the women were easily understood when they spoke. The ones who had the most extensive surgeries were more difficult to understand, but also were cognizant of the need to articulate their words. One had paper and pen on 
hand, and graciously offered to write down the things the researcher was having trouble understanding. Their speech may have been impaired, but the message rang clear.

\section{Eating}

People with $\mathrm{HNC}$ have pronounced changes in their ability to chew and swallow. This study provided perspective on this experience. All the women shared frustration with changes in the mechanics of eating. These included preferring to use a fork instead of a spoon for more control of getting food in their mouths or needing extra napkins because it is difficult to keep food in their mouths. The woman disclosed that the communal act of sharing a table was more important than the physical act of eating. In addition, this study found that the traditional role of women as the cooks of the family, especially during holidays, created some additional pressure on the women to keep traditions as intact as possible. Many explained that they still cooked for their families and enjoyed the normalcy of that act. In fact, a few of the women shared that their sense of smell had increased since being treated for HNC, so they enjoyed the smells of food preparation more than in the past. Being able to smell the food was comforting because in many cases the ability to taste food had been dulled. Needing to have food cut into small pieces and be mashed to make it easier to eat became part of the food preparation process. Pooh summarized the challenges of eating by saying this,

"It's a totally different lifestyle. If we get something from a restaurant, we have to bring it home so that I can modify it. And it's like having to work for every meal. I can't just go by and grab a cookie. At the counter. I can't do any of that. Everything has to be very planned." 
For those loved ones sharing a meal, this modification has become part of the ritual of food. The women expressed concern about making their companions wait for them to make accommodations, but found it deeply satisfying to sit at the table with them during meals. One participant, who is completely dependent on tube feedings for her nutrition, makes a point to cook for her family and join them at the table.

It seems the communal nature of sharing mealtime was significant in creating a feeling of being supported and accepted, despite their challenges. This experience demonstrates relational coping, because not only must the women adjust to their new physical functioning, but they are also concerned with the emotional impact on family members witnessing the changes. In turn, the family members are concerned with the women's inability to eat as she had done before cancer.

\section{Appearance}

The expectation of female beauty was commonly discussed by the women, with the observation that having scars is not perceived by others to be as acceptable as it is for men. Many of the women no longer felt attractive. They were self-conscious about the differences in their skin because of having grafts and the scars from surgery. Several women described nerve damage that made their faces numb, and in some cases, they were unable to move their upper lip. The experience of swelling in the neck caused by the removal of lymph nodes caused a couple of the women to describe themselves as having "turkey gobblers." Those who had partners wondered if the men in their lives would still find them attractive. Only one woman, who interestingly described herself as someone who had always been called beautiful, was not bothered by the changes in her appearance. She felt that being good-looking had always been a barrier to being taken 
seriously. In fact, she reported going to an all-female college so that she could be appraised on her academic achievements only. For her, she felt more able to be her "authentic self" without the burden of expectations based on looks.

Sue Ellen, the youngest participant in the study, shared her experience of looking different,

"And it doesn't bother me. I mean, sometimes. Sometimes it doesn't bother me. I did have an instance where I went out to a bar with some of my friends, and my husband, and we were all having a get together and one of the girls looked at me. She goes, "Oh, your scar looks fine. It just looks like you have a butt-crack chin." She goes, "And a lot of people have that." And so people do say things and they do ask when you're not ready for it, because sometimes you just don't want to deal with it. Like, "Yeah, I have a big ugly scar on my face and sometimes I do lisp a little bit," and you just don't want to deal with it. Because the whole, I think, persona of ... especially a woman, you're supposed to be like delicate. Scars aren't as cool on women, I feel. Scars are not as cool on women, and it's not as pretty for them to look unsymmetrical, which I do."

Women reported having asymmetrical faces, which was not only noticeable to others, but impacted the way the women viewed themselves. For some, they viewed the changes in their appearance as accelerated aging and impacting their emotional wellbeing. Penny said,

"I've changed a whole lot. I got more wrinkles. No teeth, a scar on my neck. I am totally different. My looks, everything. So, it affects you in so many ways. I lost my confidence. I'm going through therapy right now trying to get some of my depression 
down because I'm going through a lot of depression. So, it's hard to get back up from this when you're my age. I feel older than I am. I'm 56.” - Penny

Undergoing treatment, having changes in communication, eating, and appearance are part of the physical impact of HNC.

\section{Emotional Stress of HNC}

A variety of emotional impacts were reported by the women in this study. There were reports of fear of reoccurrence, feeling worried or anxious, depression, and grief. However, not all the emotional impacts were negative. Nearly all the women felt a sense of gratitude, for being alive and for their relationships. Increased self-confidence and feelings of self-efficacy to handle a hardship like cancer was also common among the women.

\section{Fear of reoccurrence}

Reoccurrence of the cancer was mentioned by all the women in this study, either because their disease had already come back after the initial diagnosis or because they worried it would return. This fear was not discussed directly as a fear but manifested in vigilance with getting health screenings at the first signs of any symptom that could be the return of cancer. They shared that before follow-up scans or surveillance appointments, having a sense of dread and worry about the results.

The women also questioned whether they would be willing to go through another round of treatment because of the suffering they endured during the first round of cancer. Despite feelings of anxiety that the possibility of their HNC returning, the women felt that their desire to live would override their hesitancy to go through another course of treatment. Kitty shared her worry by clearly articulating, 
“... a day don't go by that I still worry about getting cancer. Because I pray every night for the Lord not to give it back to me."

Sue Ellen was more poetic when she talked about her fear of reoccurrence. She shared the story of Dionysus to explain her experience. She has had three occurrences of her $\mathrm{HNC}$ and feels her life is in good order right now; however, the worry lingers.

“There is a Greek story, allegory, I don't know what you would want to call it, but involves a man and the god, Dionysus. And this guy, more or less, he has all these riches, he has all these great things, and then Dionysus somehow ... It's taken away from him. He's dealt with this idea of death. And Dionysus says, "Okay, I'm going to give you back ... You've went through this horrible time, I'm going to give you back everything that you've had, but the issue is you don't know when it's going to be taken away again."

However much the women worried about the reoccurrence of their cancer, they were also fierce advocates for themselves. They insist upon medical screening at the slightest indication a new cancer may be growing, usually scheduling biopsies right away.

\section{Worry and Anxiety}

While some of the anxiety experienced by the women was linked to fear of reoccurrence, the women also worried about their physical vulnerability. Being physically weakened by their $\mathrm{HNC}$, the women expressed the most worry about requiring help from others. Some lived alone, so they felt particularly worried about their safety when they were home by themselves. The sources of worry were not consistent, but the feeling of being vulnerable was notable throughout the study population. Amelia, who lives alone shared this, 
"I was afraid to be by myself. My friend next door would come over and visit with me, I'd dread when she'd leave because I just felt, I was scared. I don't know why, I mean she was right there, but just being alone I was just petrified. That eventually as I got better, went away."

For Kitty, her worry was more focused on maintaining her health.

“Oh! I worry every day. A day doesn't go by that I don't think about cancer. I talk to my girlfriend and my sister-in-law. They both had breast cancer and they said the same thing. Anytime they get a little twinge or a little pain, they think the same thing, oh, their cancer is growing back."

Worry was also talked about in terms of facing their own mortality. Many of the women stated they were unafraid to die but were not ready. They worried about dying and leaving their loved ones. Lady had given more thought to her end of life wishes and completed advance directives, because she worried about what her death would be like if she did not express her preferences.

"When can you say enough is enough? I mean, if I was not awake, and it looked like this might be forever and ever, amen, go ahead and put me away."

$\mathrm{HNC}$ was the source of worries the women felt would not be present in their lives under different circumstances.

\section{Depression}

Living through $\mathrm{HNC}$ caused some of the women in this study to feel that they were in a dark space, dealing with feelings of depression. The physical and emotional strain of HNC took a psychological toll from which some of the women are still trying to 
overcome. Many of the women in this study reported feeling hopeless and powerless during treatment. Many women choose to self-isolate because they had low energy and were self-conscious about their appearance, ability to communicate, and eating challenges. The depression experienced by the women was part of what several described as the emotional roller coaster of having cancer. Kitty's adult son died unexpectedly a few years before her HNC diagnosis. She poignantly described her struggle with feeling depressed about her diagnosis.

"I can't say I hadn't thought about it (dying), but I don't want to die. No, I'm not ready to. When my son passed away, I thought he wants me up there with him. I thought no, I'm not ready to go up there with him. I'll worry about that when the time comes." Penny shared she had been diagnosed with bipolar disorder long before she got HNC. She was insightful about attending to her mental health but felt other people did not always understand her struggles.

"Well, I'm a mom, but a grandma and recovering from cancer. So, my scars are my battle wounds and there's nothing I can do about them, or then show them with pride. I know to most of my family members, they feel since I'm not in treatment anymore, "Oh, she's fine. Everything's going to be fine." Well, it does not work that way. You have to constantly struggle and fight and want to do things and make yourself do things. And I don't know... My morale has been lowered so low. You know what I mean? Some days I don't want to get up."

Despite many of the women expressing they had experienced symptoms of depression, many also stated that these feelings began to lessen as they moved through treatment. 


\section{Grief}

A common philosophy in the oncology world is that cancer creates a "new normal." Having a new way of life was a source of sadness and adjustment for many of the women. They grieved the loss of their former independence, appearance, and way of life. For some of the women, their family and friends treated them as if they are now more fragile. While the women appreciate being cared for, it is difficult for them to accept the idea that they are delicate.

Sue Ellen, who works as a nurse, noticed a difference in her co-workers and she wished the relationships with them would be like it had been before her cancer.

"Definitely at first, I think people were all a lot more fragile with me. Not so much nicer, but like people didn't want to ... like at work, they didn't want to joke around as much, or like, "Oh, are you okay?" I mean, they are still like, "Sue Ellen, you've worked a 12-hour shift, you shouldn't be working 12-hour shifts." I'm like, "I'm fine."

Several of the women have been divorced and they shared how they were able to make a good life for themselves as independent women. Getting cancer caused them to rely on help, which was difficult because for many years they were able to stand on their own. Losing her sense of independence was difficult for Amelia, as described here,

"I have been very independent all my life. I've always hated to ask people for help, I've always had trouble doing that. I tend to depend on other people so much because right now I'm really like lightheaded and weak and so I don't feel comfortable driving to get to my doctors' appointments because God forbid that I would get on the road and hurt somebody, if I had a dizzy spell or something. So, people drive me wherever I go. I do have my groceries delivered to my house because I'm scared to death 
to get the COVID because of my immune system. So, yeah I've had to let go of a lot of things that used to be really important to me."

Looking different was a source of grief for nearly every woman in this study. Some commented that they knew that as they aged, they expected to look different, but having $\mathrm{HNC}$ seemed to them to accelerate the process. Even those who said they had never considered themselves to be pretty, grieved for the changes in their appearance. Pooh described feeling disconnected from her own identity and described it by saying,

"I was looking in the mirror. I couldn't see me. And I was shocked when one day during that summer after the surgery, I looked in the mirror and I actually saw a glimmer of myself. What I used to look like."

Throughout the interviews the women were able to share honestly about the difficulties they have faced because of $\mathrm{HNC}$ but were also able to share positive emotional impacts from the experience.

\section{Gratitude}

Having $\mathrm{HNC}$ was challenging for all the women; however, a deep sense of gratitude was shared through their stories. Many times, during the interview process the women reframed their own troubles by considering their own situation in comparison to others who "had it worse". Whether it was witnessing more extensive disfigurement in the waiting area of their doctor's office or knowing they had support when others may not, the women found ways of being thankful for their lives. Gratitude could be considered a coping mechanism, however in this case it was an emotional impact of having cancer because the women cited examples of gratitude they had not felt before being diagnosed. 
Kiki, who described herself as someone who is typically optimistic, felt thankful for everyone who was part of her HNC journey. She also expressed feeling relieved that she feels she can be her true self, because HNC has freed her to stop worrying about others' opinions.

"I found all of the doctors, and the nurses, and the caretakers to be really wonderful. I was so grateful for what they did." In response to being asked how she is different since having HNC, Kiki replied,

"Being authentic all the time, not holding back, because of what other people are thinking... And continuing to appreciate every moment of every day."

For Lou, she and her son had an experience at the medical office that gave them perspective on her challenges.

"But you know, my son went to the doctor with me. He commented that I didn't look as bad as others we saw there.... And then I made peace." - Lou

Being alive and able to continue sharing their lives with other people helped the women achieve a sense of gratitude through the HNC experience. There was a widespread feeling that although life was drastically different, there is always something for which to feel happy.

\section{Self-Efficacy}

Many reported feeling proud of themselves for managing HNC. This emotional impact was unexpected but welcomed. In a later discussion about Covid-19, the women were particularly opinionated about how their cancer has made them feel more capable of handling difficult situations. 
Annie, an octogenarian who divorced her husband in the midst of her cancer treatment explained her experience of self-efficacy,

"I think that well, I'm proud of myself. I think that beating this, as I consider I have done so far, has given me a feeling of well-being and a pride that I went through it without falling apart."

For Sue Ellen, who voiced many feelings of self-consciousness about her appearance and reduced stamina since her cancer, there was also an experience of emerging confidence because of surviving her HNC.

“. . a part of me wonders did I also become more confident? Because now I'm like, 'Oh, it is what it is. I guess if you don't like it, sorry, but I can't make it go away.' I'm slowly becoming more confident."

Living with $\mathrm{HNC}$ impacted the emotional well-being of the women in this study in difficult and positive ways. The women had insight into their feelings and mental health because of having HNC. Their insight provided solid footing as they developed coping skills to help them through their cancer journey.

\section{RQ2: Coping with HNC}

Notwithstanding the toll $\mathrm{HNC}$ had on the physical and emotional well-being of the women, they found ways to cope with cancer. The strategies employed were used as individuals and in partnership with their loved ones, bringing to life Transactional Stress and Coping Model and Relational Coping Theory. Taking control, seeking and receiving support, having faith in the Divine, expressing emotions, making adjustments, caregiving 
for others, seeking mental health care, and resilience were the coping strategies identified in this study.

\section{Asserting Control}

The ability to advocate for their needs with the treatment team, being actively involved in making treatment decisions, and planning for the future by discussing advance directives, financial plans, and designating a power of attorney were commonly discussed as a means for gaining a sense of control in their lives.

Amelia is a divorced woman, with an only adult daughter and granddaughter. It was important for her piece of mind to complete her estate planning. Her HNC surgery and recovery were difficult for her and she worried that if she had to be treated again, she may not be able to manager her affairs.

"Well, some of it I got done before I was sick. The rest of it, I had some financial things that I didn't realize I needed more information. I mean I had a durable power with attorney, but I had like money in Fidelity and their own durable power with attorney that we had to fill out. So, I had my daughter, she had to do that and then get notarized and then I had an annuity that I didn't realize she wouldn't be able to access so I went and got that all taken care of. So, she's able ... Just even if I don't pass away, but if I get sick or incapacitated, she has access to my money. So yeah.”

The participants seemed to be aware of their bodies and the need to seek medical attention. Advocating for their healthcare needs and exhibiting a sense of self-efficacy were ways to cope and manage their cancer-related stress. 
Julie has had chronic illness her entire life. She reported being comfortable questioning doctors and advocating for her needs. Although $\mathrm{HNC}$ was not her only health concern, she felt that taking control of her situation helped her cope with being sick.

"Well, there are good doctors and bad doctors. In fact, there was one doctor and I just... I guess he was learning to be a doctor. He was a resident maybe, and he and I just weren't hitting it off. And I told my doctor, I said, "I don't want him in here again. I don't want him. He just doesn't understand." I was having back surgery at the time and he wasn't accustomed, I guess, to having a transplant patient because I would say, "Well, I can't do that," or "I can't take that." And he'll be like, "Oh yes, you can." It's like, "No, I can't." So, I just got rid of him.”

The women shared a desire for honest information about the intensity of treatment and having their concerns heard were valuable ways of harnessing control in a time when many aspects of their lives were out of their control, such as changes in how they look and communicate. A sense of control not only feeds the pragmatic nature of these women, but also provides an avenue to manage expectations for themselves and their loved ones.

\section{Seeking and Receiving Support}

This study described the benefits of social support that extended outside of marital relationships. Although half of the women in this study were married, all of them reported having strong support networks that helped them combat feelings of sadness, helplessness, and isolation. The women in this study received various types of support, 
including emotional, physical, material, spiritual, and supportive care from the treatment team.

\section{Emotional Support}

For these women, emotional support was described as having friends or relatives allowing them to honestly talk about their hopes and fears about their $\mathrm{HNC}$ journey. Adult children and the women's siblings were often the source of the best support.

Lady and Annie named their daughters as their greatest support. Being in daily contact with their daughters brought a sense of comfort and reduced their feelings of isolation.

"My daughters are great resilient daughters and helpful. We talk just about every single day. I talk to at least one every single day.”

"You know, sometimes just being there to talk to me, that was all it took. Just seeing her (daughter) seeing her come up the driveway was a big help. That's all it takes. But, as I say, we talk a lot and if she doesn't get over here, we talk on the phone and she's a great sense of support. And I say that I would not have made it with her. “

Close friends, who many described as being more like members of the family, were also instrumental in providing emotional support.

Annie was appreciative of friends who supported her by trying to maintain a sense of normalcy in the relationship, despite the medical challenges.

"They tried to treat me the same. I know they were worried. A friend was able to come and see me when I was in the hospital, and then I had to go to a place for a while for rehabilitation. And so, she saw me frequently and really, I know she was worried, but 
she tried not to show it. She tried to be just the same just as talkative and she was good at it too". - Annie

Having friends who bolstered her self-esteem was important to Amelia. She knew her cancer was hard for them to cope with, and she appreciated their emotional support.

"You know I've never considered myself a vain person. But I mean everybody likes to look nice when they go out. I just feel like my friends, they're going to tell me what makes me feel good. But you know they tell me, Amelia it's not that bad, because they did the second time around did an amazing job on my reconstruction. So, it really didn't affect my face at all, it's more down here [gesturing to her neck and collarbone area]."

The women found that having a confidante helped them negotiate the myriad of emotions experienced during their HNC journey. Great affection and appreciation for the emotional support that was given to the women was palpable as they shared their stories.

\section{Material Support}

Material support was often provided in the context of having meals delivered to the women, getting rides to medical appointments, and in some cases, help with housing. Two of the women had unsolicited help with housing during their treatment. Sue Ellen reported that her landlord simply did not charge rent for several months while she underwent treatment. Kitty reported her brother asked her to pick out a house for him to buy, which he then rented to her for a rate significantly less than what she had been paying. 
"He (brother) offered to do a lot of things for me. He said, after a while, "Do you need to go to the doctor?" I'd say, "No. I don't need to go this time." He'd say, "Well call and let me know." There wasn't anything else that he could have done. He lives five minutes away. Yeah. And so is his father-in-law. So, if anything happens to them, I can be over there. If anything happens to me, they can be over here. Him and his father-inlaw both have a key to my house, and I have the code to their house. So really, in the long run everything's really turned out good."

Kitty's situation demonstrates relational coping, as she describes a relationship of mutual caregiving with her brother and his father-in-law. The family looks of for one another, benefitting all involved parties. In the instance of housing assistance, both Sue Ellen and Kitty were grateful for this help and felt that they were better able to cope with the other stresses of having cancer.

\section{Physical Support}

$\mathrm{HNC}$ is physically taxing and getting physical assistance was common for the women in this study. In some cases, the need for physical assistance was appreciated, but was a source of discomfort for the women because it was different from the pre-existing dynamic in their relationships. Overall, receiving physical care was viewed positively.

The men in Penny and Lou's lives provided considerable physical support to the women as they recovered from surgery and treatment. Penny's husband was there to attend to her every need.

"He (husband) had to help me get up and go to the bathroom. He had to make sure I can walk without falling because ...I don't know what happens when you lay in bed all that time, and you're trying to get up, and you just get all disabled, you know what I 
mean? Unsteady. So, he helped with getting in and out of the bathtub and stuff like that. And when I couldn't raise my arms above my head, he was helping me get dressed."

Lou's husband is a funeral director and had to return to work not long after her surgery. He helped her at night, but a large part of her physical care was taken over by her eldest son.

"My son did most of it. Because my husband had to go back to work. And my son was independent and then this happened to me. And he took really good care of me. He stayed with me at the hospital. If he wouldn't have stayed with me, I could have died two times, and then at the nursing home, because my sugar went down. He took good care of me. And I had a PICC (Peripherally inserted central catheter) and at home, they taught him how to do that. And he cleaned it. He put medicine in there."

Accepting physical care was difficult for the women because they had been accustomed to caring for themselves independently. However, allowing their loved ones to care for them was appreciated and helped the women to recover from their cancer and treatment.

\section{Supportive Care}

Feeling supported by the treatment team was not consistently experienced by the women in the study but made a significant impact on some of the participants. There were also some differences between the regard felt by the participants in the two medical centers. One treatment team is all-female and the women under their care reliably reported feeling that not only did they receive excellent medical care, but they also felt cared about as a person. In contrast, women treated at another location felt they only received good medical care and were not thought of as a person, but a diagnosis. 
Sue Ellen was treated by an all-female medical team and felt it was beneficial for her.

"As a woman, that has also helped me greatly, especially with all this. That going ... as we were talking about, the coping with the afterwards. Like, "Hey, how you doing? How is your son? How have you been feeling? Are you upset? Are you this?" A lot. I'm not saying men doctors don't, but I feel like there's more openness with having an all-women team. They were very concerned about me as a mother going through this, me as a wife going through it. You know, that whole separate identity that you have."

In contrast, Pooh felt her treatment team was competent in providing her medical care, but had no emotional connection with them.

"No, I think I got good care. But they don't address the emotional part of it."

Although the idea of support being helpful to those with HNC is not novel, this study gives a deeper look into the kind of support women with HNC received. This endorsement for having a support network demonstrated that women wanted to feel loved, that they were still needed in their relationships, and have a sense of unconditional regard with their loved ones. Support came from a variety of sources for the women partners, friends, adult children, and their treatment team. Not only did the women find comfort in receiving support, but they also experienced positive feelings by allowing others to care for them.

\section{Spiritual Support}

Spiritual support was frequently reported by the women in this study. Many stated they were women of Christian faith and felt that a relationship with God and the prayers they received helped them to recovery from their cancer and treatment. One 
woman, despite her own differing views about the nature of the Divine, still expressed her gratitude for offered prayers. She felt this was one of the highest expressions of love.

Pooh and Kitty both felt that prayer was essential to their well-being. It was a source of strength and comfort in their HNC experience.

"I've had my faith and a lot of prayers that's helping me through. If I had not had that I would've ended it. I would've probably stopped treatment. I don't know if I would've gone to suicide though."

“Pray. Don't give up. Like they say, they always have signs up, don't give up. I tell them don't give up and believe in God because he helped me through this. I'd tell them it's going to get rough, but take a day or two, feel sorry for yourself and then just get back up and do it again. The only thing you can do. You can't give up. You have to try."

Spirituality or faith in God/The Divine was often described as a source of coping for the women. Not only did they find comfort in their own relationship with a Higher Power but encouraged newly diagnosed women to embrace faith to help them through the cancer journey.

\section{Expressing Authentic Feelings}

The women gave themselves grace and advised newly diagnosed women to allow themselves to feel a range of emotions. Being on an emotional roller coaster and feeling whatever feeling bubbled up in the moment was important to the women.

In this study, no one explained the emotional roller coaster more clearly than Penny. She shared this, 
"If you got to scream, scream. If you got to cry, cry. If you got to beat something ... Me and my husband ... This is a funny story. We had this old couch outside that we were going to burn, and when we found out that I had cancer, I said, "I just want to hit something. I want to hit something really bad." You know how Sally Fields says in Steel Magnolias? I just want to hit something. I want to hit it real bad. I didn't realize I was saying that, and we went outside, and we took the biggest sticks we could find and start beating the shit out of this couch. We look like two mad people just beating the shit out of this couch, but it got the anger out. We were both angry, and we both beat the crap out of that couch, and then we burned it. It's something that can't hurt me. But no, it felt really liberating just to beat the shit out of that couch, and scream, and then I said, "Now it's time to get it on." You know what I mean? Time to just fight. So that's how I did it. It got the madness out of me. "

Although more subtle, Amelia also shared experiencing several emotions during her cancer experience. She is a soft-spoken woman, but when talking about her feelings, the anger was palpable in her voice.

"But I mean I've tried to be upbeat throughout all this, and at times I was just really upset but I think it took me this long to where I'm at, at this point. Where now I'm angry and I'm really upset and I'm tired of fighting it. Not that I won't, but I'm just tired. I've been doing this for over two years, and it never seems to get ... I mean luckily I just had a scan and I'm clear but they said it's a really aggressive cancer and it could come back at any time."

Living in a state of constant positivity and happiness is unrealistic in any circumstance and even more absurd in the context of living with cancer. The women in 
the study understood the value of allowing themselves to experience all their emotions. Rather than fight the less pleasant feelings, the emotions were identified and processed. This emotional range in the women proved to help them cope.

\section{Making Adjustments}

There was a desire to have a sense of normalcy in daily activities or creating some semblance of life before cancer. Managing the expectations that they placed upon themselves and setting boundaries with others helped the women to accept the limitations they have because of their illness. These adjustments made by the women in terms of intimacy, appearance, and eating served as valuable coping skills in facing HNC.

\section{Intimacy}

There were struggles with adjustments in the women's intimate relations. A sexual relationship is a basic desire for humans, but anxiety, shame, and loss of sensation as experienced by women living with $\mathrm{HNC}$ can be problematic. Not all the women shared difficulties with their intimate relations, but for those who did, they were candid about the challenges they experienced. Patience and strong communication with their partners have helped improved their sex lives.

Penny offered to share her intimate challenges, being unsure if the cancer or her age was more to blame for her lack of desire. From a relational coping standpoint, she and her husband have found ways to renegotiate how they express intimacy.

"Yeah. It's rough. It's rough on a woman. I don't have any sex desire, nothing like that. Well, it kind of works for both of us because we're both ... He has problems anyway. So it kind of works out for both of us. I think it's a little of both. Plus menopause. I've been through that, and I just don't have the inkling anymore. We kiss a lot and hug, show 
intimacy. But as the sex part, we don't deal. Yeah. There's a certain part, like this part of my mouth, I can't feel a lot of. It's just numb. But yeah, he's very passionate with me (by showing affection on a daily basis in non-sexual ways like holding hands). I think more now than he was before because of what I've been through."

For 28-year-old Sue Ellen, her struggles with sexual intimacy with her husband were shared without prompting. This part of their marriage was important to her and she stated that she wished her treatment team would have prepared her for challenges. However, she justified the lack of conversation around sexuality by saying that under normal circumstances sex is a taboo topic, and in the context of cancer, surviving takes priority over her sex life.

"But, intimately, that was very scary for me during the first time that I had a cut on my neck, because I was like, "Oh, my goodness, I look ugly." He's scared that he's going to hurt me or harm me, and I'm scared that he thinks I look like Frankenstein. We had two different ... Before we really talked about it, we were having two different mentalities. I'm thinking, "Oh, my God, he thinks I'm disgusting," and he's thinking, "Oh, my God, I don't want to hurt her. I want to feel intimate with her, but I don't want to harm her."”

For the women who made adjustments in their sexual interactions, fostering conversations with their partners and slowly easing into sexual encounters helped build a new, healthy intimate relationship.

\section{Appearance}

Changes in appearance are a physical impact of $\mathrm{HNC}$ and the women were creative in how they adjusted to these changes. The women were clear that they never 
considered themselves vain, but simply wanted to look as "normal" as possible. Some talked about wearing turtlenecks for a long period of time after surgery to hide their scars. Many also wear scarves for the same reason. Hiding scars on their necks seemed easier to manage than camouflaging facial scars and asymmetry. Many reported growing their hair longer and wearing jewelry to draw attention away from their faces. Some described situations when they quickly engaged another person in conversation by giving a compliment to keep the interaction focused away from the women with HNC.

In particular, Lady and Kitty shared they were growing their hair long to hide the scars on their necks from having lymph nodes removed. For Lady, this was a drastic change from the short bob or pixie cut that she wore before getting HNC.

"I did have short hair and then slowly I grew it, and I think it's been a little bit longer than this, but this is about the longest I've had it. Really, I haven't had it this long except about 1982. Here you are, 20 or 30 or 40 years later, I've got longer hair.”

Kitty described her hair as being different after HNC treatment. She usually wore her hair around shoulder length but has decided to let it get even longer to camouflage her scars. She also asserted that she has been wearing scarves to cover her neck but thought her hair would be more a more practical disguise in the warmer weather.

"I'm trying to let my hair grow longer so the long hair will cover up that scar, maybe. Yeah. One time I was keeping my hair short, but on the radiation, they said the chemo would let... I didn't lose my hair. They said the chemo wouldn't cause me to lose my hair. But the radiation... Then my hair, I got so thin. My hair's always been thin, but especially no. I mean, you can see my scalp. But I'm letting my hair grow out long so hopefully I can kind of cover it around my neck to hide that scar." 
Women are commonly held to a standard of beauty that is unobtainable for most but having facial damage from $\mathrm{HNC}$ and treatment adds an unfair burden. However, in this study, most found ways of adjusting how they present themselves, either by changing their hair, clothing, or accessories to distract attention away from their scars.

\section{Eating}

Eating is another feature of $\mathrm{HNC}$ that is both physically impacted by the disease and an area that requires adjustment for the women to achieve an acceptable quality of life. Many of the women refuse to eat in public and share meals with close friends and family in the privacy of their own homes. Just like addressing changes in appearance, the women in this study were creative in how they managed the changes in their ability to chew and swallow their food.

Describing several challenges at once, Sue Ellen summarizes the kinds of adjustments many of the women made in their eating practices.

"I always have a straw with me in the car. Always have a straw with me. I always have plenty of napkins, because I can't feel over here, so if I have something on my face, I'm not going to know. So constantly have to dab and check, and my teeth, you don't think about it, but when you have more motion in your lips and your tongue and whatnot, you can get that stuff out of your teeth. I have stuff everywhere, so I have to look at myself and try to clean things off."

Women living with HNC are both resilient and vulnerable. Survival instincts are tempered with an ability to adapt to the challenge of treatment and long-term management of physical and emotional changes. Being able to cope with changes that 
accompany this diagnosis is more manageable when there is a realistic expectation of limitations and possibility for improvement in functioning.

\section{Caregiving for Others}

Lazarus and Folkman's Transactional Coping and Stress Model explain the process of assessing a stressor and appraising the resources available to address the stressor, as explained earlier in this manuscript. Relational coping states that women cope in context of their close relationships. Both of these theories become clear in how women have coped with their own HNC by reflecting on their own experiences of serving as a caregiver. They often cited difficult, but fond memories of caring for their aging and ailing parents. They described a closer relationship with the people for whom they cared and stated they would have regretted it had they not provided support. In turn, not only did the women appreciate the help they received, but they also felt good about sharing that kind of caregiving connection. By reframing their need for help into an avenue toward deepening the connection with their caregiver, the women felt supported without feeling like a burden.

Lou, a self-described Christian woman, blushed as she shared how difficult was for her to allow her son to help her with physical care. However, she reframed this by remembering the importance of caregiving for her father and allowed her son to help her.

"I think the hardest part, I was embarrassed to have my son see me naked. I think that was the hardest part and then I remember I took care of my dad. I saw my dad and that my dad needed help. So that's how it was with me." 
These women shared stories about hardships in their lives besides having HNC, but also formed a steely resolve to cope with their cancer. In some cases, the women stated they had not lived through their past difficulties to succumb to cancer.

\section{Seeking Mental Health Care}

Despite the numerous cancer-related stresses, very few of the participants engaged in formal mental health interventions. Some were unaware of such resources available to them or because they did not see a psychosocial oncology professional, such as a social worker or psychologist, in their doctor's office. Some knew that therapy and other supportive services were an option, but they felt too exhausted from treatment or lived too far away to make another trip to the clinic for care. However, for the women who did utilize mental health care, it provided tools for coping.

Therapy has benefitted Sue Ellen and her family. Before having cancer, she states that she often internalized her feelings. Although she described a good relationship with her spouse and family before getting $\mathrm{HNC}$, she felt therapy helped her and her family cope.

"And so, my thing was, is I actually thought that's a really good point, so my coping was seeing this therapist. I'm very open now, more so with my family, about how I'm feeling and what I'm going through, because I use them a lot to go through my emotions. So now I'll talk to my husband."

Penny was deeply insightful about her struggles with depression and could easily identify coping strategies that helped her deal with the blues she felt, particularly in relation to her $\mathrm{HNC}$. 
"I write down things. I got workbooks and all kinds of things that I used to help me cope. But yeah, I definitely like having my therapist. She helps with a lot."

While Sue Ellen and Penny provided examples of the benefits of mental health care, others mentioned taking anti-anxiety medications helped them cope. In most of those instances, they took benzodiazepines to help with sleep and stress during radiation treatments. Mental health care appears to be an underutilized coping strategy in this sample population.

\section{Demonstrating Resilience}

Interestingly, most women in this study gave examples of personality traits that they possessed prior to having cancer as a source of coping. They report an innate propensity to "take things as they come" and often gave credit to their parents for raising them to be capable of handling adversity. They were very matter of fact when explaining this coping mechanism and took no credit for their practical approach to problem solving. For example, Pooh very plainly stated,

"Well, I mean the family that I came from - my parents were World War II generation. So, we were raised to pick yourself up and keep going."

Similarly, Amelia credited her father with helping her feel like a capable person. She feels she has modeled her own behavior after his.

"My best friend she said, "There's no way I could have done what you did." I said,

"Yes you could, if you had to, you'd do it." She said, " I don't know how you do it." I said," Well I'm the daughter of a Marine and I saw my father the way he was and that's 
the way I am." He did not give in. So, I think of him and say," What would dad say to me." You know?"

Julie was also direct when she gave credit to her family for shaping her practical sensibility, saying:

"I think it started the day I was born. We did what we had to do. My family was always behind me and now my husband, so just being in the right family."

Kiki described her views about cancer treatment being described as a battle and demonstrated her personality, which she described as "zany" and "very spiritual, but not religious". She described taking an active role in her treatment but relinquishing the idea that she has ultimate control of the outcome. She talked about feeling in synch with pacifist viewpoints when she said,

"It's so male. It's so testosterone driven. The concept of going to war to create peace has always seemed so oxymoronic to me to the point of insanity. Are you crazy? You're going to war to create peace? It doesn't make sense. And I think when people say, "You can win this battle!" I'm not in a battle. I've never been in a battle with this. To me, war is a willful act, you make a choice and that somehow you have control in the outcome. But cancer doesn't feel like you have control of the outcome. You can certainly do all the things that we know medically can help, but you can't necessarily control the outcome. So, for me, I always feel conflicted hearing that verbiage.”

Penny describes herself as a strong woman who is determined to set boundaries for healthy relationships. She shared she is a survivor of domestic violence and how that experience colors her view of tackling cancer. 
"I had my life with my kids and my husband, and then we got out of the military, and the abuse kept happening to me. So, I got out of the relationship. It was very unhealthy. I should years before, but no. I couldn't leave my kids when they were that young. You know what I mean? But when we moved back home, which Ohio is our home, I made the choice to get out of the marriage because it was unhealthy....Oh, I've been through a lot. My therapist is like, "Oh my god." I was like, "Yeah. Well, I'm a fighter that's for damn sure." Because soon after I moved home, my mom passed away, and then just five years ago my dad passed away. So, ever since I've been home, it's something negative, you know what I mean? But I've dealt with it."

As described by Lazarus and Folkman, the women referred to their emotional resources to consider how they could manage difficulties in their lives. The scenarios they shared brought this resilience to light and helped the women cope with their HNC.

\section{RQ3: Role of Stigma}

Throughout this study, the women shared experiences of stigma associated with their HNC. Women experienced social stigma because of their appearance, need for suction machines to manage side effects, changes in the way they have to manage their lifestyle, judgements about the cause of their cancer, and disclosing their diagnosis. Self-stigma was related to their appearance and guilt about past health behaviors such as smoking.

\section{Social Stigma}

The primary way this was experienced was in the response of others to their appearance by being stared at, both by strangers and loved ones. The staring was both embarrassing and a source of frustration. The women did not necessarily report feeling 
judged, but instead felt like members of a "sideshow" or objects of horror. However, one participant had several experiences of being laughed at and asked if she is contagious.

She was angered by this and stated that she let the other person "sweat it" as to whether she was contagious.

In another instance, Pooh shared that she does not go out in public very often because she must take a portable suction machine to help her manage excess secretions that are a result of her surgery. She reported that people are noticeably repulsed by this action and are rude to her. She shares this memory,

"I have this kind of small suction machine. If I have to put that machine on and use it- people hit the ceiling. But I can't go for long periods of time without that suction machine. Yeah, and so I have to carry it in the stores. And if I have to use it people get upset. So that's an issue too."

Pooh describes not only feeling like an outsider in public, but also with her siblings because of the cancer-related changes in her lifestyle. She was sad as she explained she feels her siblings make her feel the most unaccepted of any of her relationships. She said,

"I think with my siblings... They don't understand how I have to live now. Yeah. They live in Alabama. I can't travel. Of course, I have to modify my food. I have to massage my neck for the edema. And I cannot sleep flat. I sleep in the recliner. I can't lay flat. I get chocked. Of course, I can't go out to eat. So, they don't understand. It would be very hard for me to travel... That's another reason why I don't really want to go home. I don't want to be a sideshow to some family members." 
Strangers and family members were not the only people to cause the women to feel stigmatized. For some of the participants, their doctors made presumptuous statements about the cause of HNC that left the women feeling judged. For example, some were shocked when asked by their doctors how long they had been using chewing tobacco. Kiki shared one such experience,

"The one doctor asked me how many years I had been chewing tobacco. I said, "Never."

He said, "Well, that's how you get this type of cancer."

In this study, only one woman reported occasionally using chewing tobacco; however, her doctor was not one to question her past health behaviors. The stereotypical persona of people with $\mathrm{HNC}$ was captured by one physician while expressing his surprise that his patient neither smoked nor drank alcohol. Lady shared this encounter that she had with her physician,

“...'People I see that have this... ("he didn't mean like me, but yes he did") ...live under the overpass.' And I'm thinking he's probably got homeless people that are alcoholics."

Not only was it difficult to deal with accusations of self-inducing the cancer diagnosis through risky health behaviors, some women found it challenging to disclose their HNC diagnosis. Kitty worried about being pitied, which felt uncomfortable. She shared her views about telling her friends about her diagnosis for the first time,

“... When I first got diagnosed, admitting that I had cancer and getting up the courage to tell my close friends- hey, guess what? I've got cancer. Because I didn't know 
what their reaction would be and I didn't want them ... You know, you don't want anybody feeling sorry for you. That was hard to tell people that I had it."

The experience of social stigma was experienced by several women in this study. Surprisingly, the shaming attitudes were projected by strangers, family members, and medical professionals.

\section{Self-Stigma}

Most of the feelings of stigma came from within the women, because they felt self-consciousness about their appearance and knowing they look different than they had before surgery. For most of the other women in the study, encounters with loved ones viewing their disfigurement were experienced differently than with strangers. In contrast to Pooh's situation of social stigma, most of the women wanted to protect their loved ones from seeing them "this way." Women shared stories of waking from surgery knowing they must look different than before treatment, despite not being given a mirror in the hospital. They could tell by the reactions of their loved ones that they did not look like themselves. There was sadness when the women described witnessing their loved ones viewing them. Sue Ellen shared how she felt it was important to keep her son, who was three years old at the time of her surgery, from seeing her immediately after surgery. She describes self-stigma and feeling different in this passage,

"This past surgery was the hardest, because it was the most physically exhausting and physically changing. I didn't let my son see me for the first two ... He didn't see me for about almost three weeks to a month, because I did not want him ... My parents took care of him. Probably a week and a half, I came back from the hospital after my surgery. I had the trach, I had the NG tube. I didn't want him to see me with all that. I feel it'd be 
very traumatizing for him. He was three. It would be traumatizing for me. I didn't want him to see me like that. I didn't sleep well for those first two and a half, three weeks. I had the trach, it was uncomfortable. It looks gross."

For the women who did smoke, they expressed regret about their behavior, much like Kitty's,

"... Now I wish I hadn't done any of it, I think I would have had a better chance of not getting it (HNC). Yeah. Because it (smoking) just overall destroys your body.”

The stigma felt by the opinions of others was deemed more hurtful by the women. The self-stigma that was expressed seemed to form out of a sense of guilt for exposing other people to the hardship of their HNC.

\section{RQ4: Impact on Relationships}

All the women reported having at least one support person, with many describing a support network that included their adult children, parents, close friends, and the treatment team. In nearly every instance, living through $\mathrm{HNC}$ and treatment brought the women closer to the people in their support network. Many also allowed family members to help them make medical treatment decisions.

\section{Increased Closeness in Relationships}

Overwhelmingly, the women described their close relationships as better than before their cancer diagnosis. Women described increased closeness with their friends, partners, siblings, and children. Many women attribute the increased closeness to sharing vulnerability and being grateful for the emotional and physical care, such as Amelia, who said, 
"So, in that respect that really helped my relationships. All the people I mean, I couldn't believe people that hardly even knew me in my neighborhood, were sending me cards and saying, we're praying for you. When I came home the first time from the hospital, one of my friends had put a big welcome home sign in the front yard. Everybody has been so kind, and they brought me food. I think they just wanted to help. They felt bad like they couldn't do anything. So, I really saw the good side of people which is nice considering the way this world is quite now. You know that there's a lot of really caring people out there. That is one of the best things (getting closer to people). I've just gotten so much closer to my daughter I think because, she had a child now there's more, connection there. Then with my friend Sally next door, I swear I've never ... She was there every step of the way. She's probably the only person that knows exactly how bad it was and what I went through. My brother has just been phenomenal and my daughter and all my friends. It's just the support, the love and everything, has been the best part. I appreciate people so much more because of everything. But I still miss my independence."

Amelia had a broad network of people in her life, including her brother, from whom she had been estranged for many years prior to her diagnosis. She shared that he apologized for the falling out they had while their mother was ill and dying. He regretted how things had happened and did not want HNC to take Amelia before he could make amends. The two are now remarkably close and talk nearly every day.

For Penny, her husband has not only witnessed her strength to get through cancer, but he has also taken on more household responsibility to take the burden off of her. 
"Oh yeah. We work together as a team. If he knows I'm not feeling good that day, he will take initiative and do stuff for me, because I got my up days and I got my down days. Yesterday was one of my down days. I stayed laying around all day. I didn't want to do nothing yesterday."

More than any other type of relationship, the mother-daughter relationship seemed to flourish under the pressure of HNC. Many of the participants shared examples of how much love and support they have gotten from their daughters, as well as feeling that they are closer to their daughters now. For example, Annie beamed while talking about her daughter,

"My daughter is in my mind, total lifeline. She moved in with me as soon as I was diagnosed, and she never left me when I went to the hospital. She lived in the hospital day and night. I just... she was wonderful. She is wonderful. And now she lives across the street for me".

Lady shared a similar experience with her oldest daughter, stating,

"We are closer... Yeah, so she was with me in the very beginning, and that was wonderful. And she was with me at the very end, and that was wonderful, so they each (all of the daughters) had their little things that they knew to do to take care of me."

Kiki also has daughters and felt their relationships were better than before her cancer, at which point she felt it was great. She said,

'I think the girls appreciate life more. My daughters, they've made an effort to connect with me, and we have a once a week Zoom meeting, which is wonderful. And for 
Christmas last year, they gave me a daughter day, with each of them, once a week. And I thought that was wonderful."

For Sue Ellen, her entire family grew closer because of her cancer journey. She is the youngest of all of the participants, and the only one with a child under the age of 18 years. This likely factors into her family unit included her parents, her parents-in-law, friends, and her husband. She described the changes in their relationships like this,

"I would definitely say that we're all a lot closer. So much closer. Both my immediate family and my husband and my son, but also my parents and my in-laws, because my in-laws and my parents are very different types of people in all of this. Because they have all worked together to help us out so much, they have become closer. I mean, I see my family a lot... Which, I saw them a decent amount before, but now I'm so much more family oriented. I feel that I enjoy family a lot more. And even my husband has become a lot closer to my dad, because my dad is not a lovey person, and it took a very long time for my dad. My husband and I have been together since we were 15, and up until 2018 my dad didn't really give my husband the time of day. And now he's like, "Hey, love you man." That's huge. That is absolutely huge! All of our relationships are so much better. And me and my husband have gotten a lot closer, which we were already very close, but it also helps that my husband is very good at communicating. Just the whole communication has gotten a lot better between everyone."

\section{Shared Decision-Making for their Healthcare}

For some of the participants, the proposed treatment plan for $\mathrm{HNC}$ was daunting. Family members provided encouragement for the women to undergo treatment, despite the women's hesitancy. The women expressed gratitude for their loved ones providing 
this support, because without treatment the women would have died. Amelia and Kitty both leaned on family members for support and encouragement while making treatment decisions. Both women had been fiercely independent before being diagnosed with HNC. Neither woman is married, and instead of choosing a friend to advise them in their treatment decisions, they collaborated with their daughter and brother, respectively. Amelia shared,

"But anyway, my daughter was in the doctor's office when they told me I had it and I have to go through it again. I said, 'No. I'm not doing it.' She got all upset and she said, 'Mom you have to.' I said, 'Do you have any idea what that entails, for me to go through that again?' But eventually, I mean it wasn't an option. So, I finally said okay, get it done."

Kitty repeatedly mentioned throughout the interview how glad she was to have her brother in her life. Like Amelia, she had been estranged from her brother for several years. The two had reconciled before her cancer diagnosis, when her adult son died unexpectedly. Kitty shared this about her brother,

"He was trying to take care of me. Anything I needed, a drink or anything else, he goes, 'Just tell me what you need, Kitty.' But my brother kept tabs on me and our friend did, too. I have a couple of sisters-in-law that are good friends. They all kept in touch with me. But my brother pulled me through it because I was going to quit and he said, 'Just try for one more week.' He goes, 'You can always quit again.'"

Throughout these interviews, the participants exemplified grace under fire. Despite being vulnerable from their cancer, these women were able to describe their experience of life with HNC. The stereotype of woman as caretaker and nurturer is 
challenged when these women must rely on physical and emotional support from others to manage their illness. These women experience changes in how they communicate, often losing their literal and figurative voices, creating a sense of powerlessness. The ability to be understood is critically important. Working to regain their voices is an oftenfrustrating undertaking for both the women and their loved ones. Role reversal with adult children and intimate partners allows for care needs to be met but is a source of cognitive discomfort. However, allowing themselves to be shown the same love and care that they have often provided to others fosters a deeper sense of connection to their loved ones. The increased closeness that comes from this experience allows these women space to honestly express a range of emotions that are common in the HNC journey. Women with $\mathrm{HNC}$ can get through the disease and treatment with grit and grace.

\section{Distance in their Relationships}

While most of the women experienced a positive impact of the cancer on their relationship, in two cases, women felt their relationships experienced distancing. Pooh felt that because she was physically unable to talk about her feelings with her spouse, the closeness of their relationship was hard to describe, stating,

"In some ways we're closer. But, in some ways we're farther apart because I can't really speak that much.”

Penny reported having an already strained relationship with her adult children, which did not improve after her cancer diagnosis. She said,

"No, not really because my girls, they're all older. They got their own families, and they got the kids. They're stuck at home with them (due to the Covid-19 pandemic). 
But no, it's just me and my husband, my doctors, my therapist. I don't really bother my kids with it because I don't know. They don't seem to give a shit."

The results of this study identified many strengths in women with HNC. They endure physical and emotional impacts of this disease, strengthened by a variety of coping strategies. The experience of stigma, although bothersome, is taken in stride. They are supported by their families and friends, many of whom have become more connected by the experience of $\mathrm{HNC}$,

The next chapter will discuss how the findings of this study add to the existing body of knowledge about women with $\mathrm{HNC}$ and the implications for this information. 


\section{CHAPTER V: DISCUSSION AND IMPLICATIONS}

This study set out to answer the following research questions: (1) How do women describe the experience of having HNC? (2) How do women describe coping with HNC? (3) What role does stigma play in the HNC experience of women? (4) How do women perceive the impact of HNC on their close relationships? Prior to this study, the literature clearly articulated that living with $\mathrm{HNC}$ is a strenuous physical and emotional journey; however, this was viewed through the lens of a predominately male population. Many of

this study's findings agree with existing knowledge about living with $\mathrm{HNC}$, however, this narrative was told from women's points of view. Their experience of intense challenges with adjustment to their new identities, both physical and within the context of their relationships is not novel in the psychosocial oncology literature; however, within the specialized domain of $\mathrm{HNC}$ this is new information.

This chapter will discuss the findings related to the women's perceived stresses, their experience with stigma, and ways that they coped. The findings will also be discussed within the context of the COVID-19 pandemic. Finally, limitations and implications of the study for social work practice and future research will be discussed. 


\section{Stressors Related to Living with HNC}

\section{Treatment and Side Effects}

Radiation therapy is reported to be related to increased rates of fatigue and depression in patients with head and neck cancer (Chan et al., 2011; Chiou, et al., 2013; Howeren et al., 2013; Sawada et al., 2012; Zeller et al., 2006). The women in this study endorsed the experience described in the literature. Many felt relieved when the course of treatment was completed and noted that it took a long time to regain their strength after treatment.

Problems with communicating after HNC treatment is common (Hutcheson et. al, 2012; Kraaijenja, et. al, 2016; Ouyoung, et. al, 2015). The literature described loss of vocalization and changes in voice. This is consistent with the findings of this study. The women described periods of time, most right after surgery or near the conclusion of radiation therapy, when they were completely unable to speak. All were able to recover their voices, and many underwent speech therapy.

Speaking is not the only physical challenge detailed in the literature. Studies about eating after $\mathrm{HNC}$ diagnosis and treatment highlight the psychosocial challenges. This study's findings coincide with the existing literature, which mentions changes in the

physical ability to eat and considerations for food preparation (Locher et al., 2010). That study explored how relationships are affected when there are changes in how food must be prepared. The relationships between patients and their loved ones were changed 
because preparing food for another person was often seen as an act of caring. The changes in the ritual of food sharing caused people to feel disconnected from others. This study also documents meal preparation and sharing mealtimes as an important way the women found connection with their loved ones, retained a sense of normalcy, and took control of their situation to help them cope with having HNC.

Body image is consistently an issue described in the literature.(Fingeret et al., 2012; Konradsen et al., 2012; Konradsen, et al., 2009). Being embarrassed by the changes in their appearance and seeing the reactions of others to their appearance was also described in this study (Fingeret et al, 2012; Konradsen et al., 2012). The literature reports that men and women become self-conscious about their physical appearance after HNC. This study is consistent with those findings and provides further detail about this part of the experience. The women in this study reported their physical changes with a sense of grief and sadness. This attitude about appearance was mentioned by some of the participants to be in reaction to the standard of beauty that is placed on women. For many, they were unsure they ever met that standard, but having HNC made them feel certain they could never meet current beauty standards. In this way, the findings of this study are different from those already described in the literature.

One stressor that has been reported in the research literature are delays in women getting a diagnosis of HNC (Joseph, et. al, 2015). The women in this study did not share that there was a delay. The difference in this study's sample may be that all of the women noted "knowing something was not right" and quickly sought medical care. In a few 
instances, medical professionals were unsure about conducting diagnostic testing, but the women insisted on biopsies. Because of their strong self-advocacy, the women did not experience a delay in diagnoses. The literature also reported that women were less likely to undergo chemotherapy (Park, et. al, 2019). This finding is similar to the study population. Most had surgery and radiation, with a couple getting immunotherapy, and two having chemotherapy. The literature documented challenges with free flap surgery in women (Loupatatzi, et. al, 2014). Many of the women in this study had free flap surgeries to reconstruct their tongues. None reported losing the graft (having the vascular system and tissue fail to function in the area in which was transplanted; therefore, having the graft die), but they did feel the surgery was extensive and required a long recovery period.

There is some agreement in the reporting of the treatment effects of $\mathrm{HNC}$ and the description presented by the women. The study sample appears to be healthcare savvy, or at least strong-willed enough to insist upon cancer screening. In this way the findings of this study differ from the literature. The experience of the treatments does not appear to differ from the existing literature.

\section{Stigma}

The concept of stigma has been discussed in the literature and was found in this study to be part of the experience of women living with HNC. Studies have found that those who are disfigured by their disease report greater incidents of feeling judged or shame, with women be especially exposed to this experience (Hagedoorn \& Molleran, 
2006; Lebel et. al, 2013). Similar findings were found in this study. Some of the women were self-conscious of their appearance and noted the horrified expressions of those who were staring at them. In addition to appearance, some of the women commented about reactions to the action of suctioning to clear their airways. Suctioning involves using a medical device that is a type of vacuum with a tube that is swabbed inside the mouth to removed excess saliva and phlegm. Those who require suctioning reported other people being disgusted by this act, despite it being necessary for the women to breathe. This finding introduces a new facet of stigma experienced by women with HNC.

People with $\mathrm{HNC}$ reported feeling negatively about themselves when they were described as a "cancer patient" (Wong et. al, 2013). For the women in this study, some were uncomfortable sharing their diagnosis with loved ones. In some instances, the women were protective of their loved ones and did not want to cause them emotional upset when sharing the diagnosis. More often, the women wanted to be treated as they always had been in their relationships, without being pitied or feeling like a burden. This is not to say that they did not have realistic expectations about their physical limitations or changes. Relational coping involves maintaining one's identity in the context of a relationship. By accepting the identity of "cancer patient", the relationship would be changed because the women with HNC would be viewed as "other", a characteristic of stigma. Instead, the women wanted their adjustment focused on maintaining as much of their prior identity as possible. 
Another way stigma presented in this study and the literature, is the assumption that the women with HNC had done something to cause their cancer (Hamann et. al, 2013; Lebel et. al, 2013; Brown \& Cataldo, 2012). Smoking is the most harshly judged behavior that is assumed to be the reason for HNC (Hamann et. al, 2013). Medical professionals were included making this assumption in the literature and this study (Brown \& Cataldo, 2012). Most of the women included in this study were non-smokers. Only one participant thought she may have been told the cause of her cancer was HPV, but she could not remember specifically. Most were unsure of the cause of their cancer. Interestingly, most of the women did not experience judgement as it related to smoking or drinking behaviors from their families or friends. Instead, it was members of the treatment team that made assumptions about the women's lifestyle and cause of their HNC. The premise of stigma theory is demonstrated throughout this study through the examples given by the women. The experience of stigma primarily in relation to appearance and physical abilities are a variation of the existing knowledge and contributes to what is known about the experience of women with HNC.

\section{Psychological Symptomology}

In the psychosocial oncology literature, people with $\mathrm{HNC}$ experience higher rates of depression, anxiety, and suicide than the general population and other oncology populations (Chan et al., 2011; www.cdc.gov; Pandey et al., 2007; Zeller, 2006). Those people with mental health diagnoses before being diagnosed with cancer were reported to 
be at higher risk of more severe depression and more likely to be diagnosed with depression after diagnosis (Chan et al., 2011; Zeller, 2006).

Consistent with previous research on HNC patients, women in this study reported symptoms of depression such as feeling hopeless and powerless and experiencing fatigue during treatment. (However, fatigue can be a side effect of the treatment and not a symptom of depression). Another finding supported by previous research, was the selfisolation that many women choose to do because they had low energy and were selfconscious about their appearance, ability to communicate, and eating challenges.

Not only did the women struggle with depression and anxiety in the context of treatment, but many expressed feelings of sadness around the idea of their lives' being forever changed by HNC. The women grieved the loss of their former independence, changes in their appearance and professional lives. Despite being grateful to be alive, many of the women expressed sadness about what they had lost from having cancer.

Fear of reoccurrence impacts around half of people with cancer (Ghazali et al., 2013). This was described by all the women in this study, either because their disease had already come back after the initial diagnosis or because they worry it will return. This fear was not discussed directly as a fear but manifested in vigilance with getting health screenings at the first signs of any symptom that could be the return of cancer. The women also questioned whether they would be willing to go through another round of treatment because of the suffering they endured during the first round of cancer. Despite 
feelings of anxiety that the possibility of their HNC returning, the women felt that their desire to live would override their hesitancy to go through another course of treatment. the women felt that their desire to live would override their hesitancy to go through another course of treatment.

\section{Coping, Support and Close Relationships}

There are robust findings in the psychosocial literature about the positive impact support has in helping women cope with cancer. To offset feelings of depression, the DeLeeuw et al (2000) found social support to be critical in decreasing cancer-related distress (De Leeuw et al., 2000). Although this may be common knowledge, this study advances our knowledge about the kind of support women with $\mathrm{HNC}$ received and found helpful. Also, it provides information on the person from whom they received helpful support.

To offset feelings of depression, previous research has found social support to be critical in decreasing this distress (De Leeuw et al., 2000). Married people, in particular, have lower rates of depression in the context of HNC (Chan et al., 2011). Half of the study population was married or in a long-term committed relationship. The women in this study felt that having a committed partner was helpful for their overall well-being. It is not surprising that the women did not only seek support from a spouse but nearly all the women received emotional support from adult children, in particular their daughters, siblings, and close friends. Previous research has found that women are likely to turn to friends and other family members (daughters, siblings, mothers) when husbands are not 
capable of providing emotional support. This is consistent with the women in the sample. Not only did the women look for support in other relationships but one participant shared that she divorced her husband because of his inability to support her during her treatment.

In contrast with the existing literature, some of the divorced or widowed women felt that they were coping better than if they were still married. They believed that their children and friends provided support they would have been unable to get from the spouses. The women felt deeply connected to their support network and benefitted from the emotional support they received. This study brings to light that emotional support can come from others besides partners.

Physical support can be defined as providing personal care, such as bathing and toileting, assisting with preparing meals and doing housework or helping financially (Noonan \& Tennstedt, 1997; Strawbridge et al., 1997). These types of tasks were also reported in this study. The women struggled to accept that they needed physical assistance, but nevertheless accepted it. In an example of relational coping, the women often reflected on their own experiences of serving as a caregiver. They often cited difficult, but fond memories of caring for their aging and ailing parents. They described a closer relationship with the people for whom they cared and stated they would have regretted it had they not provided support. In turn, not only did the women appreciate the help they received, but they also felt good about sharing that kind of caregiving connection. By reframing their need for help into an avenue toward deepening the connection with their caregiver, the women felt supported without feeling like a burden. 
Since giving support can be important to women coping with cancer, it was not surprising that some of the women benefitted by continuing giving care to their family as well as receiving care. The example of preparing meals for their families--even though they could not eat the meals - is indicative of this need to give support. This finding highlights the relational aspect coping.

\section{Post-Traumatic Growth}

The literature describes one type of coping as Post-traumatic growth (PTG) or simply stated, finding the silver lining in a difficult situation (Harding, et al., 2014). The literature finds that those with the most extensive diagnosis and treatment reported the highest levels of benefit finding after cancer (Harding et al., 2014). People with advanced stages of disease and higher experience of pain were less likely to experience PTG after cancer (Harding et al., 2014). The findings of this study agree with the literature. Nearly all of the women in the study said they were able to engaged in gratitude within the context of their HNC. For two of the women, this meant reconnecting with estranged siblings. Many others reported their relationships had become much closer since their diagnosis. For one participant with a weak support system and poor experience with her treatment team, she had difficulty naming any type of benefit from her cancer experience. This study found great agreement with the literature on this topic.

Throughout this study, the principles of Lazarus and Folkman's Transactional Stress and Coping model were illustrated. The women were engaged in an iterative 
process of appraising their health and relationships, as well as considering the best ways to cope with their HNC. For example, PTG was demonstrated when the women were able to appraise their own cancer and treatment, consider the positive and negative aspects of the situation, and then utilize support to manage their difficulties.

Additionally, the women consistently brought the concepts of relational coping to life. All of the women considered their relationships as resources to help them manage their cancer, which in turn, allowed the women to consider themselves, their identities, and health in concert with their loved ones.

\section{Living with HNC during the COVID-19 Pandemic}

A final topic to discuss from this study is the impact of the Covid-19 pandemic on the study's participants. The inclusion criteria for this study required that the participants be at least one-year post-diagnosis, so all of them had completed their treatment prior to the pandemic. However, many expressed that the pandemic acted as an amplifier for many of their existing worries and health practices. However, the women were also able to find a "silver lining" in the pandemic.

The women reported that they felt disappointed, sad, and at times angry about the attitude of the society at large about the pandemic. Many felt that refusing to wear masks and observe social distancing recommendations were disregarding the vulnerability people with cancer have to Covid-19. Some reported their own family members refused to wear masks around them and were therefore unwelcome at the participant's home. The 
women were unapologetic about their adherence to mask wearing, on the rare occasions they went out in public.

Surprisingly, the women felt that having cancer made them more resilient in living with the pandemic. Many were sad that they could not go out to eat, because they missed the social aspect of dining out. However, they were also relieved to have takeout in the privacy in their own homes since many had difficulties in eating. Often, eating was described as a messy undertaking so, they felt they had a way of declining dining invitations that did not focus on their cancer. The women felt having cancer also prepared them to be mindful of good hygiene and health practices prior to the pandemic. They felt they had already been living in a cancer-imposed quarantine and were mindful of their exposure to others who may be sick, so Covid-19 did not create a big change in their lifestyle. The final benefit that many of the women noted about the pandemic was wearing a mask covered their disfigurement. Many reported that while wearing their masks in public allowed them to feel like everyone else. They did not have people staring at them nor did they feel the need to explain their scars. The women simply went about their activities in an anonymous world where everyone is wearing a mask. Learning about the impact of Covid-19 on women with HNC was not one of the original study goals but has been an area of great knowledge acquisition. This knowledge adds a depth to the other categories of discovery that have been highlighted in this study. 


\section{Limitations and Future Directions for Research}

Despite the contributions of this study to the literature, there are limitations. The main area of limitation in this study is a lack of diversity in the study population. There were no women of color interviewed for this study. This is not surprising given that Black women are diagnosed at an even lesser rate than white women, which may be explained by healthcare disparities, such as reduced access to care and mistrust of the medical community (cite). According to the Centers on Disease Control and Prevention (CDCP), the prevalence of new HNC diagnoses over a span of five years is $0.016 \%$ for

Black women and $0.03 \%$ for white women. Another limitation of this study is the limited types of HNC represented. Most of the participants included in this study had tongue cancer. Types of HNC that were missing include laryngeal, sinus, and pharynx cancer. The reason for the limited kinds of cancer represented in the study is unclear. It may be that the oncologist with whom the researcher partnered sees more tongue cancer patients than the other partners in her practice. Additional HNC diagnoses representation may have illuminated different experiences. The women lived within an approximate radius of 150 miles. The experience of women in different regional cultures across the country may vary from the experience described in this study. For example, in states or regions of the country with lower rates of smoking and other unhealthy lifestyles, the attitudes about $\mathrm{HNC}$ and the women diagnosed may be less forgiving than in this study. Future studies may wish to integrate purposive sampling criteria to attract a more diverse 
population of women that includes more types of HNC diagnosis and racial/ethnic backgrounds.

There are two recommendations for further illuminating the experience of women with $\mathrm{HNC}$ and the impact on their close relationships. The first is to conduct a replication study with women of varied races, economic statuses, and a wider variety of HNC diagnoses. An extended period of time to recruit women with different kinds of $\mathrm{HNC}$, from more medical practices may attract a more diverse study population. As mentioned, conducting this study in various regional cultures would deepen the understanding of women with HNC.

The second recommendation is to conduct a similar descriptive study of the close relations of the women with HNC including the women's intimate partners. This kind of study will add to the existing literature by advancing our knowledge about the impact of $\mathrm{HNC}$ on close relationships and how couples cope together with the cancer-related stress.

\section{Implications}

This dissertation study highlighted similarities between the existing psychosocial literature about $\mathrm{HNC}$ and the experience of women with this disease. Prior studies found that women often suffer severe emotional impacts from cancer and this study confirmed that finding. This study also gave context and description to the types of physical suffering that is experienced for women with HNC. Not only were the challenges of women with HNC brought to light, but this study was also able to illuminate the benefits 
of specific kinds of support and showcase the tenacity of women with HNC. The findings of this study have research, methodological, and practice implications.

\section{Research Implications}

This study provides a foundation on which to build further studies about psychosocial needs of women with HNC. Future research would include additional qualitative inquiries to better understand dyadic coping. This is important to understand because support has been identified as an essential component of living with HNC. Support from the treatment team was also identified as crucial to women with HNC. Studies about the attitudes of HNC medical professionals about the care needs of women with HNC may be beneficial to close the gap between good medical care and great emotional support.

To build upon the existing HNC literature, qualitative studies that compare psychological symptomology and coping can be conducted to explore if differences exist between the needs of men and women with HNC. Studies of family functioning and relationship satisfaction within the context of $\mathrm{HNC}$ could also build upon the existing literature.

\section{Methodological Implications}

The goal of QD studies is to provide description of a phenomenon and does not seek findings that are generalizable to the entire population impacted by it. However, from a methods standpoint, it would be interesting to conduct a replication of this study in different domestic and international study populations. For example, the rate of HNC 
is much higher in India (Sung, et al., 2020). The status and social role of women is different in India than the United States; therefore, providing opportunity to explore the experience of women with $\mathrm{HNC}$ in that region. Not only do studies in various geographic locations and cultures provide an opportunity to increase knowledge, it more importantly gives women a voice when they may otherwise be unheard.

\section{Practice Implications}

This study can be used to inform training for healthcare providers who practice with this specialized population. Social workers in this arena can use this study to guide psychosocial assessments with women with $\mathrm{HNC}$, allowing the women to be better prepared for the cancer experience through the connection with supportive services and information. Mental health therapists can also benefit from information learned to tailor interventions in individual and family or couples' therapy.

A patient-centered agenda for psychosocial interventions can also be informed by this study. The women in this study were succinct in voicing the unmet needs of women with HNC. They suggested that an educational booklet be developed to give newly diagnosed women a more accurate picture of the course of treatment and potential side effects. This booklet would also include tips for addressing the physical and emotional challenges, and how to prepare loved ones for the experience of HNC. An alternative to a written booklet may be the development of video tutorials or cell phone-based messaging to provide education about the diagnosis and treatment of HNC. This messaging could be personalized by the patient entering her treatment plan and appointment dates. A 
curriculum could be developed to coincide with the patient's treatment timeline, thus preventing an overload of information before the patient is ready to receive it. Links for resources to address many psychosocial challenges could be included in the platform, such videos by dieticians with cooking demonstrations, speech therapy exercises, and relaxation videos for stress management.

A second intervention suggested by this study's participants is the creation of video tutorials for women who have been disfigured by their $\mathrm{HNC}$ and treatment to learn makeup and skin care skills. The suggestion was made by the women to have videos available on a platform such as YouTube, to allow women to practice cosmetic skills to camouflage their scars, facial asymmetry, and ultimately, build self-esteem. Both interventions would be well-suited to be developed using community-based participatory research (CBPR). This kind of education could be linked with the web or phone-based messaging previously mentioned.

\section{Conclusion}

The narratives of women with $\mathrm{HNC}$ are filled with grit and vulnerability. The women who participated in this study experienced many of the same things currently described in the psychosocial literature. However, women voiced a depth of suffering that was related to physical changes, adjustment to their new functional abilities, emotional adjustment to role changes, grieving the loss of their feminine beauty and challenges in establishing normalcy in their daily routines and relationships. This study encapsulates the toughness of mind, body, and spirit of women to evolve and survive. 
The lived experience of women with HNC seeks to not only survive cancer but to have a life they enjoy living.

The study's results mostly supported existing findings in the research literature on HNC. However, this study brought to light the nuance of how women experience cancer in relation with other people. In no instance did any woman report going through her cancer alone. Women experience the physical and emotional impacts of cancer in partnership with others. Women cope with HNC in relationship with other people. Stigma is experienced in connection with how others relate to the women as being different. Relationships are deepened and redefined in conjunction of the women and their families and friends. This study's findings add to the existing knowledge about HNC and in many ways pioneer the understanding of women with HNC. 


\section{REFERENCES}

Archer, J., Hutchinson, I., Korszun, A. (2008). Mood and malignancy: head and neck cancer and depression. Journal of Oral Pathology Medicine, 37, 255-270.

Baxi, S.S., Shuman, A.G., Corner, G.W., Shuk, E., Sherman, E.J., Elkin, E.B., Hay, J.L. and Pfister, D.G. (2013), Sharing a diagnosis of HPV-related head and neck cancer: The emotions, the confusion, and what patients want to know. Head Neck, 35: 1534-1541. https://doi.org/10.1002/hed.23182

Bernard, L. L., \& Guarnaccia, C. A. (2003). Two Models of Caregiver Strain and Bereavement Adjustment: A Comparison of Husband and Daughter Caregivers of Breast Cancer Hospice Patients. The Gerontologist, 43(6), 808-816. doi:10.1093/geront/43.6.808

Bjelland I, Dahl AA, Haug TT, Neckelmann D. (2002). The validity of the Hospital Anxiety and Depression Scale. An updated literature review. Journal of Psychosomatics. 52, 69-77.

Björklund, M., Sarvimäki, A., \& Berg, A. (2010). Living with head and neck cancer: A profile of captivity. Journal of Nursing and Healthcare of Chronic Illness, 2, 2231. https://doi.org/10.1111/j.1752-9824.2010.01042.x 
Bodenmann, G., Meuwly, N., \& Kayser, K., (2011). Two conceptualizations of dyadic coping and their potential for predicting relationship quality and individual wellbeing. A comparison. European Psychologist, 16(4), 255-266.

Bodenmann, G. (1995). A systemic-transactional view of stress and coping in couples. Swiss Journal of Psychology, 54, 34-49.

Bond, S. M., Hawkins, D. K., \& Murphy, B. A. (2014). Caregiver-reported neuropsychiatric symptoms in patients undergoing treatment for head and neck cancer: A pilot study. Cancer Nursing, 37(3), 227-235. doi:10.1097/NCC.0b013e31829194a3

Bowman, K. F., Rose, J. H., \& Deimling, G. T. (2006). Appraisal of the cancer experience by family members and survivors in long-term survivorship. PsychoOncology, 15(9), 834-845. doi:10.1002/pon.1039

Boyd, C.O. 2001. Phenomenology the method. In Munhall, P.L. (Ed.), Nursing research: A qualitative perspective (3rd. ed., pp. 93-122). Sudbury, MA: Jones and Bartlett.

Brown, C and Cataldo, J.(2013). Explorations of lung cancer stigma for female longterm survivors. Nursing Inquiry 20: 352-362.

Cannon, T.L., Lai, D.W., Hirsh, D., Delacure, M., Downey, A., Kerr, A.R., Bannan, M., Andreopoulou, E., Safra, T., \& Muggia, F. (2012). Squamous cell carcinoma of the oral cavity in nonsmoking women: A new and unsusual complication of chemotherpay for recurrent ovarian cancer. The Oncologist, 17, 1541-1546.

Carton M, Barul C, Menvielle G for the ICARE Study Group, et al Occupational exposure to solvents and risk of head and neck cancer in women: a population-based case-control study in France 
BMJ Open 2017;7:e12833. doi: 10.1136/bmjopen-2016-012833

Cella D.F., Tulsky D.S., Gray G., Sarafian B., Linn E., \& Bonomi, A. (1993). The functional assessment of cancer therapy scale: Development an validation of the general measure. Journal of Clinical Oncology, 11, 570-579.

Chan, J. Y. K., Lua, L. L., Starmer, H. H., Sun, D. Q., Rosenblatt, E. S., \& Gourin, C. G. (2011). The relationship between depressive symptoms and initial quality of life and function in head and neck cancer. The Laryngoscope, 121(6), 1212-1218. doi:10.1002/lary.21788

Charmaz, K. C., Bogdan, R., Taylor, S. J., \& Fletcher, C. (1977). Introduction of Qualitative Research Methods: A Phenomenological Approach to the Social Sciences. Contemporary Sociology, 6(1), 114. doi:10.2307/2062788

Charma,K. (2014). Constructing grounded theory (Second edition). Thousand Oaks, CA: Sage.

Chiou, W. Y., Lee, M. S., Ho, H. C., Hung, S. K., Lin, H. Y., Su, Y. C., \& Lee, C. C. (2013). Prognosticators and the relationship of depression and quality of life in head and neck cancer. Indian Journal of Cancer, 50(1), 14-20. doi:10.4103/0019509X.112279

Cong Bui, T., Thi-Hai Tran, L., Markham,C.M., Thi-Thu Huynh, T., Thi Tran, L., ThiTuong, V.P.,Minh Tran,Q., Hieu Hoang, N., Hwang, L., Madison Sturgis, E. (2015). Self-reported oral health, oral hygiene, and oral HPV infection in at-risk women in Ho Chi Minh City, Vietnam,. Oral Surgery, Oral Medicine, Oral Pathology and Oral Radiology, 120(1), 34-42. 
Cormio, C., Romito, F., Viscanti, G., Turaccio, M., Lorusso, V., \& Mattioli, V. (2014). Psychological well-being and posttraumatic growth in caregivers of cancer patients. Frontiers in Psychology, 5.

Creswell, J. W. (2013). Qualitative Inquiry \& Research Design: Choosing among Five Approaches (3rd ed.). Thousand Oaks, CA: SAGE.

D'Antonio, L.L., Long, S.A., Zimmerman, G.J., Peterman, A.H., Petti, G.H. and Chonkich, G.D. (1998), Relationship between quality of life and depression in patients with head and neck cancer. The Laryngoscope, 108: 806-

811. https://doi.org/10.1097/00005537-199806000-00006

Dedoose Version 8.3.47, web application for managing, analyzing, and presenting qualitative and mixed method research data (2021). Los Angeles, CA: SocioCultural Research Consultants, LLC www.dedoose.com.

de Graeff, A., de Leeuw, J.R.J., Ros, W.J., Hordijk, G.-J., Blijham, G.H. and Winnubst, J.A. (2000), Long-Term Quality of Life of Patients With Head and Neck Cancer. The Laryngoscope, 110: 98-106. https://doi.org/10.1097/00005537-200001000$\underline{00018}$

De Leeuw, J. R. J., De Graeff, A., Ros, W. J. G., Hordijk, G. J., Blijham, G. H., \& Winnubst, J. A. M. (2000). Negative and positive influences of social support on depression in patients with head and neck cancer: A prospective study. PsychoOncology, 9(1), 20-28. doi:10.1002/(SICI)1099-1611(200001/02)9:1<20::AIDPON425>3.0.CO;2-Y

Derks, W., de Leeuw, J., Hordijk, G. and Winnubst, J. (2005), Differences in coping style and locus of control between older and younger patients with head and neck 
cancer. Clinical Otolaryngology, 30: 186-192. https://doi.org/10.1111/j.1365$\underline{2273.2004 .00938 . x}$

Dodd, RH, Forster, AS, Marlow, LAV, Waller, J. Psychosocial impact of human papillomavirus-related head and neck cancer on patients and their partners: A qualitative interview study. Eur J Cancer

Care. 2019; 28:e12999. https://doi.org/10.1111/ecc.12999

Dukes, S. (1984). Phenomenological methodology in the human sciences. Journal of Religion and Health, 23(3), 197-203.

Ebersole, B., Soni, R.S., Moran, K., Lango, M., \& Davarajan, K., (2017). The role of occupational voice demand and patient-rated impairment in predicting voice therapy adherence. Journal of Voice, 32(3), 325-331.

Egestad, H, Emaus,N. (2014). Changes in health related quality of life in women and men undergoing radiation treatment for head and neck cancer and the impact of smoking status in the radiation treatment period. European Journal of Oncology Nursing, 18(4), 339-346.

Ellis,J., Lloyd, W.M., Wagland, R., Bailey, C., \& Molassiotis, A. (2013). Coping with and factors impacting upon the experience of lung cancer in patients and primary carers. European Journal of Cancer Care, 22: 97-

106. https://doi.org/10.1111/ecc. 12003

Espie,C.A., Freedlander, E. Campsie, L.M, Soutar, D.S. \& Robertson,A.G. (1989). Psychological distress at follow-up after major surgery for intra-oral cancer. Journal of Psychosomatic Research, 33(4), 441-448. 
Faller, H., Koch, U., Brähler, E. (2016) Satisfaction with information and unmet information needs in men and women with cancer. Journal of Cancer Survivorship, 10, 62-70. https://doi.org/10.1007/s11764-015-0451-1

Fingeret, M. C., Yuan, Y., Urbauer, D., Weston, J., Nipomnick, S., \& Weber, R. (2012). The nature and extent of body image concerns among surgically treated patients with head and neck cancer. Psycho-Oncology, 21(8), 836-844. doi:10.1002/pon.1990

Folkman, S., \& Greer, S. (2000). Promoting psychological well-being in the face of serious illness: When theory, research and practice inform each other. PsychoOncology, 9(1), 11-19. doi:10.1002/(SICI)1099-1611(200001/02)9:1<11::AIDPON424>3.0.CO;2-Z

Foxwell, K.R. \& Scott, S.E. (2011). Coping together and apart: Exploring how patients and their caregivers manage terminal head and neck cancer. Journal of Psychosocial Oncology, 29, 308-326.

Garfield, L., (2020). Head and neck cancers: Update 2020. Reinsurance Group of America, Incorporated. https://www.rgare.com/knowledgecenter/media/articles/head-and-neck-cancers-update-2020.

Gaudet, M., Hamm, J., Aquino-Parsons, C. (2014). Incidence of ano-genital and head and neck malignancies in women with a previous diagnosis of cervical intraepithelial neoplasia. Gynecologic Oncology, 134, 523-526.

Genero, N. P., Miller, J. B., Surrey, J., \& Baldwin, L. M. (1992). Measnring perceived mutuality in close relationships: Validation of the Mutual Psychological Development Questionnaire. Journal of Family Psychology, 6, 36-48. 
Ghazali, N., Cadwallader, E., Lowe, D., Humphris, G., Ozakinci, G., \& Rogers, S. N. (2013). Fear of recurrence among head and neck cancer survivors: Longitudinal trends. Psycho-Oncology, 22(4), 807-813. doi:10.1002/pon.3069

Gil, F., Costa, G., Hilker, I., \& Benito, L. (2012). First anxiety, afterwards depression: Psychological distress in cancer patients after diagnosis and after treatment. Stress and Health: Journal of International Society for the Investigation of Stress. $28(5), 362-367$.

Giorgi, A. (2009). The descriptive phenomenological method in psychology: A modified Husserlian Approach. Pittsburgh, PA: Duquesne University Press.

Glaser, B. G., \& Strauss, A. L. (1967). The discovery of grounded theory. Chicago: Aldine.

Goffman, E. (1963). Stigma Englewood Cliffs. NJ: Spectrum.

Gourin, C. G. (2014). Outcomes Measurement in Patients with Head and Neck Cancer. Current Oncology Reports, 16(3), 376. doi:10.1007/s11912-013-0376-7

Hagedoorn, M. \& Molleman, E.(2006). Facial disfigurement in patients with head and neck cancer: the role of social self-efficacy. Health Psychology, 25, 643-647.

Hamann, H.A., Howell, L.A., \& McDonald, J.L. (2013). Casual attributions and attitudes toward lung cancer. Journal of Applied Social Psychology, 43, E37 - E45.

Hampton, M.R., \& Frombach, I. (2000). Women's experience of traumatic stress in cancer treatment. Health Care for Women International. 21(1), 67-76.

Harding, S., Sanipour, F., \& Moss, T. (2014). Existence of benefit finding and posttraumatic growth in people treated for head and neck cancer: a systematic review. PeerJ, 2, e256. doi:10.7717/peerj.256 
Hashim, D., Sartori, S., La Vecchia, C., Serraino, D., Dal Maso, L., Negri, E., Smith, E., Levi, F., Boccia, S., Cadoni, G., Luu, H.N., Lee, Y.A., Hashibe, M., \& Boffetta, P. (2017). Hormone factors play favorable role in female head and neck cancer risk. Cancer Medicine , 6(8): 1998-2007.

Helgeson, V.S. (2011), Survivor centrality among breast cancer survivors: implications for well-being. Psycho-Oncology, 20: 517-524. https://doi.org/10.1002/pon.1750

Hennink, M. M., Kaiser, B. N., \& Marconi, V. C. (2017). Code Saturation Versus Meaning Saturation: How Many Interviews Are Enough? Qualitative Health Research, 27(4), 591-608. https://doi.org/10.1177/1049732316665344

Hodges, L. J., \& Humphris, G. M. (2009). Fear of recurrence and psychological distress in head and neck cancer patients and their carers. Psycho-Oncology, 18(8), 841848. doi:10.1002/pon.1346

Howren, M. B., Christensen, A. J., Karnell, L. H., \& Funk, G. F. (2010). Health-related quality of life in head and neck cancer survivors: Impact of pretreatment depressive symptoms. Health Psychology, 29(1), 65-71. doi:10.1037/a0017788

Hutcheson, K. A., Lewin, J. S., Barringer, D. A., Lisec, A., Gunn, G. B., Moore, M. W., \& Holsinger, F. C. (2012). Late dysphagia after radiotherapy-based treatment of head and neck cancer. Cancer, 118(23), 5793-5799. https://doi.org/10.1002/cncr.27631

Isaksson, J., Salander, P., Lilliehorn, S., \& Laurell, G. (2016). Living an everyday life with head and neck cancer $2-2.5$ years post-diagnosis - A qualitative prospective study of 56 patients. Social Science \& Medicine, 154, 54-61. doi:10.1016/j.socscimed.2016.02.031 
Ichikura, K, Yamashita, A, Sugimoto, T, Kishimoto, S, Matsushima, E. Patterns of stress coping and depression among patients with head and neck cancer: A Japanese cross-sectional study. Psycho-

Oncology. 2018; 27: 556- 562. https://doi.org/10.1002/pon.4549.

Jack, D. C. (1991). Silencing the self: Women and depression. Cambridge, MA: Harvard University Press.

Joseph, L.J., Goodman, M., Higgins, K., Pilai, R., Ramalingam, S.S., Magliocca, K., Patel, M.R. El-Deiry, M., Wadsworth,J.T., Owonikoko,T.K, Beitler, J.J., Khuri, F.R., Shin, D.M., \& Saba,N.F. (2015). Racial disparities in squamous cell carcinoma of the oral tongue among women: A SEER data analysis. Oral Oncology, 51(6), 586-592.

Jordan, J.V. (1991). The meaning of mutuality. In J.V. Jordan, A.G. Kaplan, J.B.Miller, I.P. Stiver \& J.L. Surrery (Eds.), Women's growth in connection: Writings from the Stone Center (pp. 81-96). New York: Guilford.

Katz, M.R., Irish, J.C., Devins, G.M., Rodin, G.M. and Gullane, P.J. (2003), Psychosocial adjustment in head and neck cancer: The impact of disfigurement, gender and social support. Head Neck, 25: 103-

\section{2. https://doi.org/10.1002/hed.10174}

Kayser, K., Sormanti, M., \& Strainchamps, E. (1999). Women coping with cancer: The impact of close relationships on psychosocial adjustment. Psychology of Women Quarterly,23, 725-739. 
Kayser, K., Watson, L. E., \& Andrade, J. T. (2007). Cancer as a "we-disease": Examining the process of coping from a relational perspective. Families, Systems, \& Health, 25(4), 404-418. https://doi.org/10.1037/1091-7527.25.4.404

Kayser, K, Acquati, C, Reese, JB, Mark, K, Wittmann, D, Karam, E. A systematic review of dyadic studies examining relationship quality in couples facing colorectal cancer together. Psycho-

Oncology. 2018; 27: 13-21. https://doi.org/10.1002/pon.4339

Kissil, K., Nino, A., Jacobs, S., Davey, M., \& Tubbs, C. Y. (2010). "It Has Been a Good Growing Experience for Me": Growth Experiences Among African American Youth Coping With Parental Cancer. Families, Systems \& Health: The Journal of Collaborative Family HealthCare, 28(3), 274-289. doi:10.1037/a0020001

Kim, Y., Baker, F., \& Spillers, R. L. (2007). Cancer caregivers' quality of life: Effects of gender, relationship, and appraisal. Journal of Pain and Symptom Management, 34(3), 294-304. doi:10.1016/j.jpainsymman.2006.11.012

Kim, Y., Baker, F., Spillers, R. L., \& Wellisch, D. K. (2006). Psychological adjustment of cancer caregivers with multiple roles. Psycho-Oncology, 15(9), 795-804. doi:10.1002/pon.1013

Kim, Y., Carver, C. S., Schulz, R., Lucette, A., \& Cannady, R. S. (2013). Finding benefit in bereavement among family cancer caregivers. Journal of Palliative Medicine, 16(9), 1040-1047. doi:10.1089/jpm.2013.0049

Kim, Y., Schulz, R., \& Carver, C. S. (2007). Benefit finding in the cancer caregiving experience. Psychosomatic Medicine, 69(3), 283-291.

doi:10.1097/PSY.0b013e3180417cf4 
Kim, Y., van Ryn, M., Jensen, R. E., Griffin, J. M., Potosky, A. and Rowland, J. (2015), Effects of gender and depressive symptoms on quality of life among colorectal and lung cancer patients and their family caregivers, PsychoOncology, 24, pages 95-105, doi: 10.1002/pon.3580

Konradsen, H., Kirkevold, M., McCallin, A., Cayé-Thomasen, P., \& Zoffmann, V. (2012). Breaking the silence: Integration of facial disfigurement after surgical treatment for cancer. Qualitative Health Research, 22(8), 1037-1046. doi: $10.1177 / 1049732312448545$.

Konradsen, H., Kirkevold, M., \& Zoffmann, V. (2009). Surgical facial cancer treatment: The silencing of disfigurement in nurse-patient interactions. Journal of Advanced Nursing, 65(11), 2409-2418. doi:10.1111/j.1365-2648.2009.05102.x

Kraaijenga, S. A., Oskam, I. M., van der Molen, L., Hamming-Vrieze, O., Hilgers, F. J., \& van den Brekel, M. W. (2015). Evaluation of long term (10-years+) dysphagia and trismus in patients treated with concurrent chemo-radiotherapy for advanced head and neck cancer. Oral oncology, 51(8), 787-794. https://doi.org/10.1016/j.oraloncology.2015.05.003

Landis, J. R., \& Koch, G. G. (1977). The Measurement of Observer Agreement for Categorical Data. Biometrics, 33(1), 159-174. doi:10.2307/2529310

Lang, H., France, E., Williams, B., Humphris, G. and Wells, M. (2013), The psychological experience of living with head and neck cancer: a systematic review and meta-synthesis. Psycho-Oncology, 22: 2648-

2663. https://doi.org/10.1002/pon.3343 
Lazarus, R. S., \& Folkman, S. (1987). Transactional theory and research on emotions and coping. European Journal of Personality, 1(3, Spec Issue), 141-169. doi:10.1002/per.2410010304

Lazure, K.E., Lydiatt, W.M., Denman, D. and Burke, W.J. (2009), Association between depression and survival or disease recurrence in patients with head and neck cancer enrolled in a depression prevention trial. Head Neck, 31: 888-

892. https://doi.org/10.1002/hed.21046

Lebel, S., \& Devins, G. M. (2008). Stigma in cancer patients whose behavior may have contributed to their disease. Future oncology (London, England), 4(5), 717-733. doi:10.2217/14796694.4.5.717

Lebel, S., Castonguay, M., Mackness, G., Irish, J., Bezjak, A., \& Devins, G.M. (2013). The psychosocial impact of stigma in people with head and neck or lung cancer. Psycho-Oncology, 22, 140-152.

Lee, Y. J., Choi, Y. S., Hwang, I. C., Kim, H. M., \& Hwang, S. W. (2016). Resilience at the end of life as a predictor for postloss growth in bereaved caregivers of cancer patients: A prospective pilot study. Journal of Pain and Symptom Management, 5l(3), e3-e5. doi:10.1016/j.jpainsymman.2015.12.304

Le Guevelou, J, Lebars, S, Kammerer, E, et al. Head and neck cancer during pregnancy. Head \& Neck. 2019; 41: 3719- 3732. https://doi.org/10.1002/hed.25877

Levesque, J. V., \& Maybery, D. (2012). Parental cancer: Catalyst for positive growth and change. Qualitative Health Research, 22(3), 397-408.

doi: $10.1177 / 1049732311421617$ 
Levesque, J. V., \& Maybery, D. J. (2014). Predictors of benefit finding in the adult children of patients with cancer. Journal of Psychosocial Oncology, 32(5), 535554. doi:10.1080/07347332.2014.936646

Lincoln, Y.S.,\& Guba, E.G. (1985). Naturalistic inquiry. Beverly Hills, CA: Sage. List, M. A., D'Antonio, L. L., Cella, D. F., Siston, A., Mumby, P., Haraf, D., \& Vokes, E. (1996). The Performance Status Scale for Head and Neck Cancer Patients and the Functional Assessment of Cancer Therapy-Head and Neck Scale. A study of utility and validity. Cancer, 77(11), 2294-2301.

Locher, J. L., Robinson, C. O., Bailey, F. A., Carroll, W. R., Heimburger, D. C., Saif, M. W., ... Ritchie, C. S. (2010). Disruptions in the organization of meal preparation and consumption among older cancer patients and their family caregivers. Psycho-Oncology, 19(9), 967-974. doi:10.1002/pon.1656

Loupatatzi, A., Stavrianos, S.D., Karantonis, F.F., Machaira, A., Rapidis, A.D., Kokkalis, G., \& Papadopoulos, O., (2014). Are females predisposed to complications in head and neck cancer free flap reconstruction? Journal of Oral Maxillofacial Surgery, 72, 178-185.

Maguire, R., Hanly, P., Balfe, M., Timmons, A., Hyland, P., O'Sullivan, E., . . Sharp, L. (2017). Worry in head and neck cancer caregivers: The role of survivor factors, care-related stressors, and loneliness in predicting fear of recurrence. Nursing Research, 66(4), 295-303. doi:10.1097/NNR.0000000000000223

Manne, S. and Badr, H. (2010), Intimacy processes and psychological distress among couples coping with head and neck or lung cancers. Psycho-Oncology, 19: 941954. https://doi.org/10.1002/pon.1645 


\section{Marshal, C., \& Rossman, G.B.. (2010). Designing qualitative research (5ht ed.).}

Thousand Oaks, CA: Sage.

Mayre-Chilton, K. M., Talwar, B. P., \& Goff, L. M. (2011). Different experiences and perspectives between head and neck cancer patients and their care-givers on their daily impact of a gastrostomy tube. Journal of Human Nutrition and Dietetics, 24(5), 449-459. doi:10.1111/j.1365-277X.2011.01165.x

McCaughan, E., Prue, G., Parahoo, K., McIfatrick, S., McKenna, H. (2012). Exploring and comparing the experience and coping behavior of men and women wih colorectal cancer after chemotherapy treatment: A qualitative longitudinal study. Psycho-Oncology, 21(1), 64-71.

Mcguirt, W.F. (1983), Head and neck cancer in women - a changing profile. The Laryngoscope, 93: 106-107. https://doi.org/10.1288/00005537-198301000-00018

McPhail, C., Dwyer, J. J. M., Hanemaayer, R., \& Preyde, M. (2017). The experience of parental cancer among emerging adult university students. Journal of Psychosocial Oncology, 35(2), 202-219. doi:10.1080/07347332.2016.1275918

Michalowska, S., Samochowiec, A., \& Matusewicz, S. (2019). Coping and anxiety in cancer patients. Archives of Psychiatry and Psychotherapy, 21(2), 28-32.

https://doi-org.echo.louisville.edu/10.12740/APP/103093

Miller, J.B. (1984). The development of women's sense of self. (Work in Progress No. 12). Wellesley, MA: Stone Center Working Paper Series.

MOORE, R. J., CHAMBERLAIN, R. M., \& KHURI, F. R. (2004). Communicating suffering in primary stage head and neck cancer. European Journal of Cancer Care, 13(1), 53-64. 
MORTON, R.P. (1995), Life-satisfaction in patients with head and neck cancer. Clinical Otolaryngology \& Allied Sciences, 20: 499-503. https://doi.org/10.1111/j.13652273.1995.tb01588.x

Moschopoulou, E., Hutchison, I., Bhui, K. et al. Post-traumatic stress in head and neck cancer survivors and their partners. Support Care Cancer 26, 3003-3011 (2018). https://doi.org/10.1007/s00520-018-4146-9

Moubayed, S. P., Sampalis, J. S., Ayad, T., Guertin, L., Bissada, E., Gologan, O. E., . . . Christopoulos, A. (2015). Predicting depression and quality of life among longterm head and neck cancer survivors. Otolaryngology--Head And Neck Surgery: Official Journal Of American Academy Of Otolaryngology-Head And Neck Surgery, 152(1), 91-97. doi:10.1177/0194599814557772

Mosher, C. E., \& Danoff-Burg, S. (2005). Psychosocial impact of parental cancer in adulthood: A conceptual and empirical review. Clinical Psychology Review, 25(3), 365-382. doi:http://doi.org/10.1016/j.cpr.2004.12.003

Moustakas, C. (1994). Phenomenological research methods: Sage.

Nakarada-Kordic, I., Patterson, N., Wrapson, J. (2018). A systematic review of patient and caregiver experiences with a tracheostomy. Patient 11, 175-191. https://doi.org/10.1007/s40271-017-0277-1

National Association of Social Workers. (2017). NASW code of ethics. Retrieved December, 10, 2020, from https://www.socialworkers.org/About/Ethics/Code-ofEthics/Code-of-Ethics-English 
Noonan, A. E., Tennstedt, S. L., \& Rebelsky, F. G. (1996). Making the best of it: Themes of meaning among informal caregivers to the elderly. Journal of Aging Studies, 10(4), 313-327. doi:http://dx.doi.org/10.1016/S0890-4065(96)90004-3

Nund, R. L., Rumbach, A. F., Debattista, B. C., Goodrow, M. N. T., Johnson, K. A., Tupling, L. N., ... Porceddu, S. V. (2015). Communication changes following non-glottic head and neck cancer Wmanagement: The perspectives of survivors and carers. International Journal of Speech-Language Pathology, 17(3), 263-272. doi:10.3109/17549507.2015.1010581

Onakoya, P. A., Nwaorgu, O. G., Adenipekun, A. O., Aluko, A. A., \& Ibekwe, T. S. (2006). Quality of Life in Patients with Head and Neck Cancers. Journal of the National Medical Association, 98(5), 765-770.

Ouyoung, L.M., Swanson, M.S., Villegas, B.C., Damodar, D., Kokot, N. and Sinha, U.K. (2016), ABCLOVE: Voice therapy outcomes for patients with head and neck cancer. Head Neck, 38: E1810-E1813. https://doi.org/10.1002/hed.24322

Pandey, M., Devi, N., Thomas, B.C., Vinod Kumar, S., Krishnan, R. and Ramdas, K. (2007), Distress overlaps with anxiety and depression in patients with head and neck cancer. Psycho-Oncology, 16: 582-586. https://doi.org/10.1002/pon.1123

Park, A., Alabaster, A., Shen, H., Mell, L.K. and Katzel, J.A. (2019), Undertreatment of women with locoregionally advanced head and neck cancer. Cancer, 125: 30333039. https://doi.org/10.1002/cncr.32187

Perry, A., Casey, E., \& Cotton, S. (2015). Quality of life after total laryngectomy: Functioning, psychological well-being and self-efficacy. International Journal of 
Language \& Communication Disorders, 50(4), 467-475. doi:10.1111/14606984.12148

Polkinghorne, D.E. (1989). Phenomenological research methods. In R.S. Valle \& S. Halling (Eds.), Existential-phenomenological perspectives in psychology (pp. 41-60). New York: Plenum

Reis, H. T., \& Rusbult, C. E. (Eds.). (2004). Close relationships: Key readings. Taylor \& Francis.

Sawada, N., Paula, J., Sonobe, H., Zago, M., Guerrero, G., \& Nicolussi, A. (2012). Depression, fatigue, and health-related quality of life in head and neck cancer patients: a prospective pilot study. Supportive Care in Cancer, 20(11), 2705-2711. doi:10.1007/s00520-012-1390-2

Schenck, D. P. (2002). Ethical Considerations in the Treatment of Head and Neck Cancer. Cancer Control, 9(5), 410-419. doi:10.1177/107327480200900506

Sharp, L, Redfearn, D, Timmons, A, Balfe, M, Patterson, J. Posttraumatic growth in head and neck cancer survivors: Is it possible and what are the correlates? PsychoOncology. 2018; 27: 1517-1523. https://doi.org/10.1002/pon.4682

Siegel, R. L., Miller, K. D., \& Jemal, A. (2020). Cancer statistics, 2020. CA: a cancer journal for clinicians, 70(1), 7-30. https://doi.org/10.3322/caac.21590

Siegel, R. L., Miller, K. D., \& Jemal, A. (2018). Cancer statistics, 2018. CA: A Cancer Journal for Clinicians, 68(1), 7-30. doi:10.3322/caac.21442

Snaith R. P. (2003). The Hospital Anxiety ans Depression Scale. Health and quality of life outcomes, 1, 29. https://doi.org/10.1186/1477-7525-1-29 
Starks, H., \& Trinidad, S. B. (2007). Choose your method: A comparison of phenomenology, discourse analysis, and grounded theory. Qualitative Health Research, 17(10), 1372- 1380

Stern A. F. (2014). The hospital anxiety and depression scale. Occupational medicine (Oxford, England), 64(5), 393-394. https://doi.org/10.1093/occmed/kqu024

Strawbridge, W.J., Wallhagen, M.I., Shema, S., \& Kaplan, G. (1997). New burdens or more of the same? Comparing grandparent, spouse, and adult-child caregivers. The Gerontologist, 37(4), 505.

Sung,H., Ferlay, J., Siegel, R.L., Laversanne, M., Soerjomataram, I., Jemal, A., \& Bray, F. (2021). Global cancer statistics 2020: GLOBOCAN estimates of incidence and mortality worldwide for 36 cancers in 185 countries. CA Cancer J Clin. 2020. https://doi.org/10.3322/caac.21660

Tedeschi, R. G., \& Calhoun, L. G. (1996). The Posttraumatic Growth Inventory: Measuring the positive legacy of trauma. Journal of Traumatic Stress, 9(3), 455472. doi: $10.1002 /$ jts. 2490090305

van Manen, M. (1990). Researching lived expereince. New York: State University of New York Press.

Vigneswaran, N., \& Williams, M. D. (2014). Epidemiologic trends in head and neck cancer and aids in diagnosis. Oral and maxillofacial surgery clinics of North America, 26(2), 123-141. doi:10.1016/j.coms.2014.01.001

Wertz, F.J. (2005). Phenomenological research methods for counseling psychology. Journal of Counseling Psychology, 52(2), 167-177 
Wong, J.C., Payne, A.Y.M., Mah, K., Lebel, S., Lee, R.N., Irish, J., Rodin, G., \& Devins, G.M. (2013). Negative cancer stereotypes and disease-specific self-concept in head and neck cancer. Psycho-Oncology, 22(5), 1055-1063

www.cancer.gov/types/head-and-neck-fact-sheet\#what-causes-cancers-of-the-head-and-

$\underline{\text { neck }}$

www.cancer.net

www.cancer.org

www.cdc.gov/cancer/headneck/index.htm

Www.seer.cancer.gov/report_to_nation

Zeller, J. L. (2006). High suicide risk found for patients with head and neck cancer.

JAMA, 296(14), 1716-1717. doi:10.1001/jama.296.14.1716

Zigmond AS, Snaith RP. The Hospital Anxiety and Depression Scale. Acta Psychiatr

Scand $1983 ; 67,361-370$. 


\section{Appendix A}

\section{Interview Guide}

Goals: The study hopes to understand the experience of women with head and neck cancer. In particular, this study is interested in how women view themselves and their relationships during cancer treatment and beyond.

\section{Background of Illness}

A. Please tell me about your journey with cancer?

1. When were you diagnosed?

2. Were there recurrences or metastases?

B. Please tell me about when you were diagnosed with cancer.

3. What was going on in your life at the time? (working, family, etc.)

4. Where there any delays in getting a diagnosis (or a misdiagnosis)?

5. Tell me about your treatment.

6. What do you think caused your cancer?

7. Are you cancer free now?

II. Identity

A. How would you describe yourself to yourself?

B. Is the way you see yourself difference since the diagnosis?

a. How is it different?

b. What were the turning points?

C. Do you like who you are?

D. What has been the most important change in your life since the diagnosis?

a. Do you physically look different because of your cancer or treatment?

E. What has been the hardest thing to cope with since being diagnosed with cancer?

a. How did you cope with that?

F. Have your views about yourself changed since getting cancer?

III. Impact on Family Relationships

A. What has been the most important change for your family since being diagnosed? 
a. Did you notice differences in how people treated you once you were diagnosed?

B. In what ways has the illness affected your relationship with your spouse or partner? (if you have one)

C. Can you tell me about what kinds of things you do for recreation?

a. Has the amount of time you spend doing recreational/social activities changed?

\section{Support}

A. Who was your primary caregiver?

a. In what ways did your caregiver help you?

b. Could your partner have helped more?

c. In what ways could they have been more helpful?

B. Who provided you the best help?

V. Changes in Meaning of Life
A. How do you see yourself changing in the future?
B. What advice would you give to a woman who is just beginning her cancer journey?
C. What else do you want me to understand about you and your cancer? 


\section{Appendix B - Consent \\ THE LIVED EXPERIENCE OF WOMEN WITH HEAD AND NECK CANCER \& THE IMPACT ON RELATIONSHIPS}

Date

Dear

You are being invited to participate in a research study to investigate what it is like to be a woman with head and neck cancer and how that experience has impacted your relationships. You will be asked to participate in two interviews (each will take about 60 minutes) and complete a brief questionnaire that will take approximately 10 minutes. There are no known risks for your participation in this research study. The information collected may not benefit you directly. The information learned may be helpful to others by increasing the understanding of women with head and neck cancer and what kind of support is helpful. This information will be used to help women with this disease. Your recorded interview will be stored on a password protected computer. Your completed surveys will be stored in a locked file cabinet in the researchers' office on the University of Louisville campus. You will receive $\$ 20.00$ after completing each interview. This study is conducted by Georgia Anderson, a Doctoral Candidate, under the supervision of Dr. Karen Kayser at the University of Louisville.

Individuals from the Department of Social Work, the Institutional Review Board (IRB), the Human Subjects Protection Program Office (HSPPO), and other regulatory agencies may inspect these records. In all other respects, however, the data will be held 
in confidence to the extent permitted by law. Should the data be published, your identity will not be disclosed.

Taking part in this study is voluntary. By participating in the interview and answering survey questions you agree to take part in this research study. You do not have to answer any questions that make you feel uncomfortable (or prosecutable by law; if appropriate). You may choose not to take part at all. If you decide to be part of this study, you may stop at any time. If you decide not to be in this study or if you stop taking part at any time, you will not lose any benefits for which you may qualify.

If you have any questions, concerns, or complaints about the research study, please contact: Karen Kayser (502-852-1946) or Georgia Anderson (513-417-1725).

If you have any questions about your rights as a research subject, you may call the Human Subjects Protection Program Office at (502) 852-5188. You can discuss any questions about your rights as a research subject, in private, with a member of the Institutional Review Board (IRB). You may also call this number if you have other questions about the research, and you cannot reach the research staff, or want to talk to someone else. The IRB is an independent committee made up of people from the University community, staff of the institutions, as well as people from the community not connected with these institutions. The IRB has reviewed this research study.

If you have concerns or complaints about the research or research staff and you do not wish to give your name, you may call 1-877-852-1167. This is a 24 -hour hot line answered by people who do not work at the University of Louisville. 
Sincerely, 
Appendix C

\section{Fieldnotes Template}

$\underline{\text { Identifier: }}$

Date:

\section{Current Events:}

Time Begin:

Duration:

Location:

General Comments: General impressions of setting, participant. Participant reaction

observation/observer.

Evaluation Comments: Analytic, theoretical notes (interpretation of activities reported,

behavior observed). 
Methodological Notes: Notes regarding methods, thoughts about approach being used, the need for modification, addition or deletion of strategies in the future.

Technical Notes: Suggestions for future work

Personal Notes: Personal notes, impressions, reactions, feelings, related to the experience, concerns about the self as researcher, reflexive thoughts, judgement, bias. 


\section{Appendix D}

\section{Participant Information}

Participant Code:___ Participant

Age:

Type of

Cancer:

Diagnosis Date:

Cancer

Stage:

Type of treatment:

Surgery

Radiation

Chemotherapy

- Other

Relationship Status:

Married

Partnered

Divorced

Single

Widowed
Race:

American Indian or Alaska Native Asian

Black

Hispanic or Latino

Native Hawaiian or other Pacific Islander

White
Employment Status:

Working full-time

Working part-time

Disabled

Retired

Unemployed, not seeking work

Unemployed, seeking work
Highest Level of Education Received:

Less than High School

High School Diploma or GED

Some college

College degree

Graduate degree

Other: 


\section{Appendix E}

\section{Inclusion Criterion}

- Adult women (18 years of age and older) with a diagnosis of any of the following head and neck cancers: oral cavity, tongue, pharynx (throat), larynx (voice box), salivary glands, nasal and paranasal sinuses, and nasopharynx, at any stage of disease (I, II, III, or IV), with any prognosis;

- Head and neck cancer diagnosis was received within the past 1-4 years;

- Received treatment (surgery, chemotherapy, radiation therapy, any combination therein, or received non-curative treatment (palliative focused treatment);

- Ability to speak in English. 


\section{Appendix F}

Hospital Anxiety and Depression Scale (HADS)

Tick the box beside the reply that Is closest to how you have been feeling in the past week.

Don't take too long over you replies: your Immediate Is best.

\begin{tabular}{|c|c|c|c|c|c|}
\hline D & $\mathrm{A}$ & & $\mathrm{D}$ & $\mathrm{A}$ & \\
\hline & & I feel tense or 'wound up": & & & | feel as if I am slowed down: \\
\hline & 3 & Most of the time & 3 & & Nearly all the time \\
\hline & 2 & A lot of the time & 2 & & Very often \\
\hline & 1 & From time to time, occasionally & 1 & & Sometimes \\
\hline & 0 & Not at all & 0 & & Not at all \\
\hline & & & & & \\
\hline & & $\begin{array}{l}\text { I still enjoy the things I used to } \\
\text { enjoy: }\end{array}$ & & & $\begin{array}{l}\text { I get a sort of frightened feeling like } \\
\text { 'butterflies' in the stomach: }\end{array}$ \\
\hline 0 & & Definitely as much & & 0 & Not at all \\
\hline 1 & & Not quite so much & & 1 & Occasionally \\
\hline 2 & & Only a little & & 2 & Quite Often \\
\hline \multirow[t]{9}{*}{3} & & Hardly at all & & 3 & Very Often \\
\hline & & & & & \\
\hline & & $\begin{array}{l}\text { I get a sort of frightened feeling as } \\
\text { If } \\
\text { something awful Is about to } \\
\text { haooen: }\end{array}$ & & & I have lost Interest in my appearance: \\
\hline & 3 & Very definitely and quite badly & 3 & & Definitely \\
\hline & 2 & Yes, but not too badly & 2 & & I don't take as much care as I should \\
\hline & 1 & A little, but it doesn't worry me & 1 & & I may not take quite as much care \\
\hline & 0 & Not at all & 0 & & I take just as much care as ever \\
\hline & & & & & \\
\hline & & $\begin{array}{l}\text { I can laugh and see the funny side } \\
\text { of thini: } 1 \mathrm{~s} \text { : }\end{array}$ & & & $\begin{array}{l}\text { I feel restless as I have to be on the } \\
\text { move: }\end{array}$ \\
\hline 0 & & As much as I always could & & 3 & Very much indeed \\
\hline 1 & & Not quite so much now & & 2 & Quite a lot \\
\hline 2 & & Definitely not so much now & & 1 & Not very much \\
\hline \multirow[t]{8}{*}{3} & & Not at all & & 0 & Not at all \\
\hline & & $\begin{array}{l}\text { Worrying thoughts go through my } \\
\text { mind: }\end{array}$ & & & $\begin{array}{l}\text { I look forward with enjoyment to } \\
\text { things: }\end{array}$ \\
\hline & 3 & A great deal of the time & 0 & & As much as I ever did \\
\hline & 2 & A lot of the time & 1 & & Rather less than I used to \\
\hline & 1 & From time to time, but not too often & 2 & & Definitely less than I used to \\
\hline & 0 & Only occasionally & 3 & & Hardly at all \\
\hline & & & & & \\
\hline & & 1 feel cheerful: & & & aet sudden feelinQs of oanic: \\
\hline 3 & & Not at all & & 3 & Very often indeed \\
\hline 2 & & Not often & & 2 & Quite often \\
\hline 1 & & Sometimes & & 1 & Not very often \\
\hline \multirow[t]{7}{*}{0} & & Most of the time & & 0 & Not at all \\
\hline & & & & & \\
\hline & & I can sit at ease and feel relaxed: & & & $\begin{array}{l}\text { I can enjoy a good book or radio or TV } \\
\text { program: }\end{array}$ \\
\hline & 0 & Definitely & 0 & & Often \\
\hline & 1 & Usually & 1 & & Sometimes \\
\hline & 2 & Not Often & 2 & & Not often \\
\hline & 3 & Not at all & 3 & & Very seldom \\
\hline
\end{tabular}

Please check you have answered all the questions.

Scoring: Total score: Depression (D) __ Anxiety (A)_ $\quad 0-7=$

Normal, 8-10= Borderline abnormal (borderline case), 11-21 = Abnormal (case) 


\section{Appendix G}

\section{FACT-H\&N (Version 4)}

Below is a list of statements that other people with your illness have said are important. Please circle or mark one number per line to indicate your response as it applies to the past 7 days.

\begin{tabular}{|c|c|c|c|c|c|c|}
\hline & PHYSICAL WELL-BEING & $\begin{array}{l}\text { Not } \\
\text { at all }\end{array}$ & $\begin{array}{l}\text { A little } \\
\text { bit }\end{array}$ & $\begin{array}{c}\text { Some- } \\
\text { what }\end{array}$ & $\begin{array}{l}\text { Quite } \\
\text { a bit }\end{array}$ & $\begin{array}{l}\text { Very } \\
\text { much }\end{array}$ \\
\hline GP1 & I have a lack of energy & 0 & 1 & 2 & 3 & 4 \\
\hline GP2 & 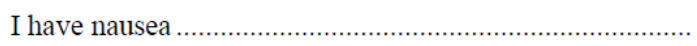 & 0 & 1 & 2 & 3 & 4 \\
\hline GP3 & $\begin{array}{l}\text { Because of my physical condition, I have trouble } \\
\text { meeting the needs of my family } \ldots \ldots \ldots \ldots \ldots \ldots \ldots \ldots \ldots \ldots \ldots \ldots \ldots \ldots \ldots \ldots \ldots \ldots \ldots \ldots\end{array}$ & 0 & 1 & 2 & 3 & 4 \\
\hline GP4 & I have pain ....... & 0 & 1 & 2 & 3 & 4 \\
\hline GPS & I am bothered by side effects of treatment ...................... & 0 & 1 & 2 & 3 & 4 \\
\hline GP6 & I feel ill ... & 0 & 1 & 2 & 3 & 4 \\
\hline GP7 & 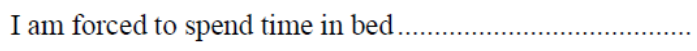 & 0 & 1 & 2 & 3 & 4 \\
\hline & SOCIAL/FAMILY WELL-BEING & $\begin{array}{l}\text { Not } \\
\text { at all }\end{array}$ & $\begin{array}{l}\text { A little } \\
\text { bit }\end{array}$ & $\begin{array}{c}\text { Some- } \\
\text { what }\end{array}$ & $\begin{array}{l}\text { Quite } \\
\text { a bit }\end{array}$ & $\begin{array}{l}\text { Very } \\
\text { much }\end{array}$ \\
\hline GS1 & I feel close to my friends ........... & 0 & 1 & 2 & 3 & 4 \\
\hline GS2 & 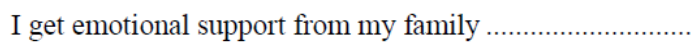 & 0 & 1 & 2 & 3 & 4 \\
\hline GS3 & I get support from my friends..... & 0 & 1 & 2 & 3 & 4 \\
\hline GS4 & My family has accepted my illness .............................. & 0 & 1 & 2 & 3 & 4 \\
\hline GSS & 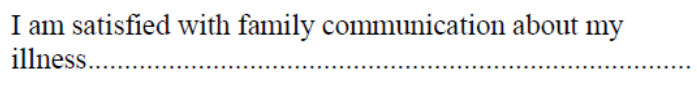 & 0 & 1 & 2 & 3 & 4 \\
\hline GS6 & 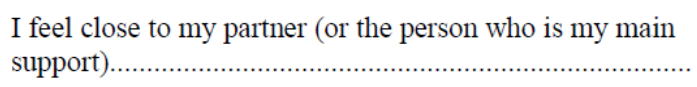 & 0 & 1 & 2 & 3 & 4 \\
\hline Q1 & $\begin{array}{l}\text { Regardless of your current level of sexual activity, please } \\
\text { answer the following question. If you prefer not to answer it, } \\
\text { please mark this box } \square \text { and go to the next section. }\end{array}$ & & & & & \\
\hline GS7 & 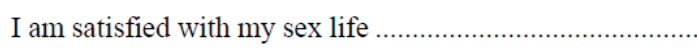 & 0 & 1 & 2 & 3 & 4 \\
\hline
\end{tabular}




\section{FACT-H\&N (Version 4)}

Please circle or mark one number per line to indicate your response as it applies to the past 7 days.

\begin{tabular}{|c|c|c|c|c|c|c|}
\hline & EMOTIONAL WELL-BEING & $\begin{array}{c}\text { Not } \\
\text { at all }\end{array}$ & $\begin{array}{c}\text { A little } \\
\text { bit }\end{array}$ & $\begin{array}{c}\text { Some- } \\
\text { what }\end{array}$ & $\begin{array}{c}\text { Quite } \\
\text { a bit }\end{array}$ & $\begin{array}{l}\text { Very } \\
\text { much }\end{array}$ \\
\hline GE1 & 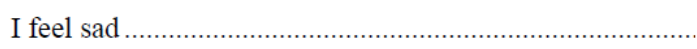 & 0 & 1 & 2 & 3 & 4 \\
\hline GE2 & I am satisfied with how I am coping with my illness........... & 0 & 1 & 2 & 3 & 4 \\
\hline GE3 & 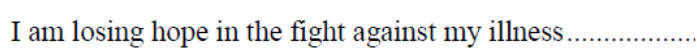 & 0 & 1 & 2 & 3 & 4 \\
\hline GE4 & I feel nervous............................ & 0 & 1 & 2 & 3 & 4 \\
\hline GES & I worry about dying & 0 & 1 & 2 & 3 & 4 \\
\hline GE6 & I worry that my condition will get worse & 0 & 1 & 2 & 3 & 4 \\
\hline & FUNCTIONAL WELL-BEING & $\begin{array}{l}\text { Not } \\
\text { at all }\end{array}$ & $\underset{\text { bit }}{\text { A little }}$ & $\begin{array}{c}\text { Some- } \\
\text { what }\end{array}$ & $\begin{array}{c}\text { Quite } \\
\text { a bit }\end{array}$ & $\begin{array}{l}\text { Very } \\
\text { much }\end{array}$ \\
\hline GF1 & 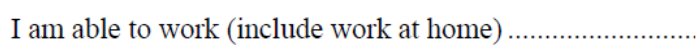 & 0 & 1 & 2 & 3 & 4 \\
\hline GF2 & 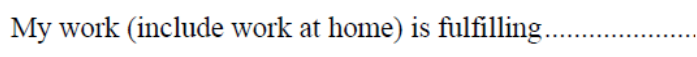 & 0 & 1 & 2 & 3 & 4 \\
\hline GF3 & I am able to enjoy life.. & 0 & 1 & 2 & 3 & 4 \\
\hline GF4 & 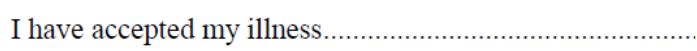 & 0 & 1 & 2 & 3 & 4 \\
\hline GF5 & 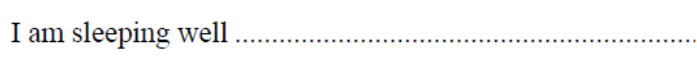 & 0 & 1 & 2 & 3 & 4 \\
\hline GF6 & 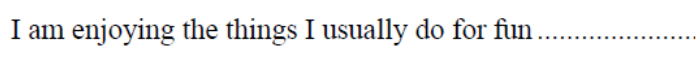 & 0 & 1 & 2 & 3 & 4 \\
\hline GF7 & I am content with the quality of my life right now................. & 0 & 1 & 2 & 3 & 4 \\
\hline
\end{tabular}




\section{FACT-H\&N (Version 4)}

Please circle or mark one number per line to indicate your response as it applies to the past 7 days.

\begin{tabular}{|c|c|c|c|c|c|c|}
\hline & ADDITIONAL CONCERNS & $\begin{array}{c}\text { Not at } \\
\text { all }\end{array}$ & $\begin{array}{c}\text { A little } \\
\text { bit }\end{array}$ & $\begin{array}{c}\text { Some- } \\
\text { what }\end{array}$ & $\begin{array}{l}\text { Quite } \\
\text { a bit }\end{array}$ & $\begin{array}{l}\text { Very } \\
\text { much }\end{array}$ \\
\hline $\mathrm{H} \& \mathrm{~N} 1$ & I am able to eat the foods that I like .................. & 0 & 1 & 2 & 3 & 4 \\
\hline $\mathrm{H \& N} 2$ & 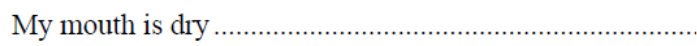 & 0 & 1 & 2 & 3 & 4 \\
\hline HEN3 & I have trouble breathing....................... & 0 & 1 & 2 & 3 & 4 \\
\hline H\&N4 & My voice has its usual quality and strength $\ldots \ldots \ldots \ldots \ldots \ldots \ldots \ldots \ldots \ldots \ldots \ldots \ldots$ & 0 & 1 & 2 & 3 & 4 \\
\hline H\&N5 & 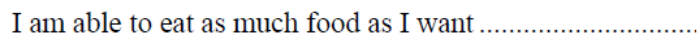 & 0 & 1 & 2 & 3 & 4 \\
\hline H\&N6 & I am unhappy with how my face and neck look.................. & 0 & 1 & 2 & 3 & 4 \\
\hline $\mathrm{H \& N} 7$ & 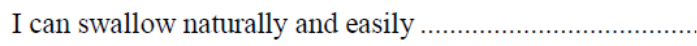 & 0 & 1 & 2 & 3 & 4 \\
\hline H\&NS & 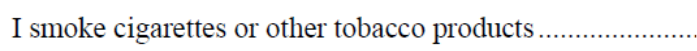 & 0 & 1 & 2 & 3 & 4 \\
\hline H\&N9 & I drink alcohol (e.g. beer, wine, etc.)........ & 0 & 1 & 2 & 3 & 4 \\
\hline $\begin{array}{c}\text { H\&N } \\
10\end{array}$ & 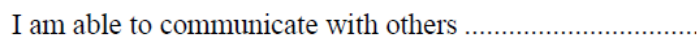 & 0 & 1 & 2 & 3 & 4 \\
\hline $\begin{aligned} H \& N \\
11\end{aligned}$ & I can eat solid foods................ & 0 & 1 & 2 & 3 & 4 \\
\hline $\begin{array}{c}\mathrm{H} \& \mathrm{~N} \\
12\end{array}$ & I have pain in my mouth, throat or neck. & 0 & 1 & 2 & 3 & 4 \\
\hline
\end{tabular}




\section{Appendix H - FACT-HN Scoring}

FACT-H\&N Scoring Guidelines (Version 4) - Page 1

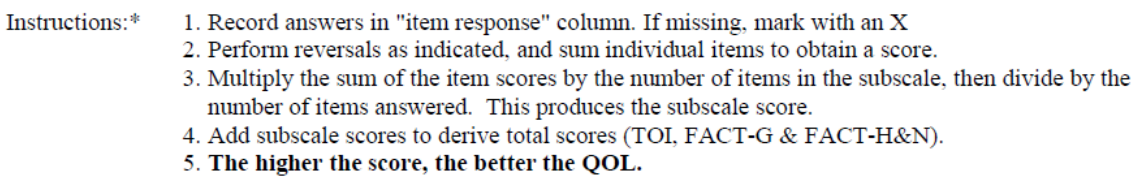

Subscale

PHYSICAL

WELL-BEING

(PWB)

Score range: $0-28$

\section{$\underline{\text { Item Code }} \underline{\text { Reverse item? Item response }}$}

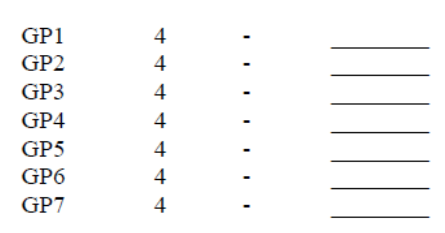

\section{$\underline{\text { Item Score }}$}

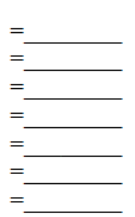

Sum individual item scores: Multiply by 7: Divide by number of items answered: $=\underline{\text { PWB subscale score }}$

SOCIAL/FAMILY WELL-BEING

(SWB)

Score range: $0-28$

GS1

GS2

GS3

GS4

GS5

GS6

EMOTIONAL
WELL-BEING
(EWB)

Score range: $0-24$

GE1

GE2

GE2

GE4

GE5

GE6

0
0
0
0
0
0
0

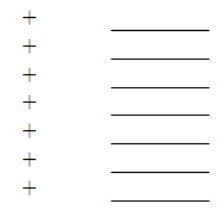

Sum individual item scores:

Multiply by 7:

Divide by number of items answered:

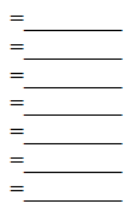

-

$\begin{array}{lll} & & \\ & & \\ \text { FUNCTIONAL } & \text { GF1 } & 0 \\ \text { WELL-BEING } & \text { GF2 } & 0 \\ \text { (FWB) } & \text { GF3 } & 0 \\ & \text { GF4 } & 0 \\ \text { Score range: } 0-28 & \text { GF5 } & 0 \\ & \text { GF6 } & 0 \\ & \text { GF7 } & 0\end{array}$

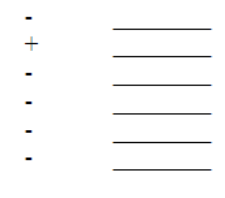

Sum individual item scores: Multiply by 6 : Divide by number of items answered:

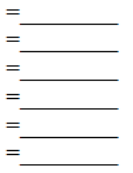
$=\underline{\text { SWB subscale score }}$

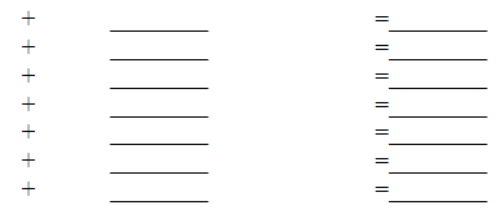

Sum individual item scores:

Multiply by 7:

Divide by number of items answered $=\underline{ }=$ B subscale score 
FACT-H\&N Scoring Guidelines (Version 4) - Page 2

\begin{tabular}{|c|c|c|c|c|}
\hline$\underline{\text { Subscale }}$ & Item Code & Reverse item? & $\underline{\text { Item response }}$ & $\underline{\text { Item Score }}$ \\
\hline HEAD \& NECK & $\mathrm{HN} 1$ & 0 & & $=$ \\
\hline CANCER & $\mathrm{HN} 2$ & 4 & & $=$ \\
\hline SUBSCALE & $\mathrm{HN} 3$ & 4 & & $=$ \\
\hline \multirow{2}{*}{ (HNCS) } & HN4 & 0 & & $=$ \\
\hline & HN5 & 0 & & $=$ \\
\hline \multirow[t]{8}{*}{ Score range: $0-40$} & HN6 & 4 & & $=$ \\
\hline & $\mathrm{HN} 7$ & $0+$ & & $=$ \\
\hline & HN8 & \multicolumn{2}{|c|}{ NOT CURRENTLY SCORED } & \\
\hline & HN9 & \multicolumn{2}{|c|}{ NOT CURRENTLY SCORED } & \\
\hline & $\mathrm{HN} 10$ & $0+$ & (1) & $=$ \\
\hline & HN11 & 0 & & $=$ \\
\hline & $\mathrm{HN} 12+$ & 4 & & $=$ \\
\hline & & \multicolumn{3}{|c|}{$\begin{array}{r}\text { Sum individual item scores: } \\
\text { Multiply by } 10:\end{array}$} \\
\hline
\end{tabular}

+ Item HN12 has been added to the scoring algorithm of the FACT-H\&N as of 08.25.05

To derive a FACT-H\&N Trial Outcome Index (TOI):

Score range: 0-96

$\overline{(\text { PWB score })}^{+} \overline{(\text { FWB score })}^{+} \frac{}{(\text { HNCS score })}=\underline{=}=$ FACT-H\&N TOI

To Derive a FACT-G total score:

Score range: $0-108$

$\overline{(\text { PWB score })}^{+} \overline{(\text { SWB score })}^{+} \frac{}{(\text { EWB score })}^{+} \overline{(\text { FWB score })}^{=}=\underline{\text { FACT-G Total score }}$

To Derive a FACT-H\&N total score:

Score range: $0-148$

$\overline{(\text { PWB score })}^{+} \overline{\text { (SWB score })}^{+} \overline{(\text { EWB score })}^{+} \overline{\text { (FWB score })}^{+} \overline{(\text { HNCS score })}_{-}^{=}=$FACT-H\&N Total score

*For guidelines on handling missing data and scoring options, please refer to the Administration and Scoring Guidelines in the manual or on-line at www.facit.org.

FACT-H\&N scoring template 08.25 .05 


\section{Appendix I}

\section{UMIIUESSITY of LOUISVILLE}

Human Subjects Protection Program Office

MedCenter One - Suite 200

$501 \mathrm{E}$. Broadway

Louisville, KY 40202-1798

\begin{tabular}{ll}
\hline DATE: & June 10, 2020 \\
TO: & Karen Kayser, PhD \\
FROM: & The University of Louisville Institutional Review Board \\
IRB NUMBER: & 19.1116 \\
& The Lived Experience of Women with Head \& Neck Cancer and The Impact on Close \\
STUDY TITLE: & Relationships IAA \\
REFERENCE \#: & 702891 \\
IRB STAFF & Jackie Powell, CIP 852-4101 jspowe01@louisville.edu \\
CONTACT: &
\end{tabular}

This study was reviewed and approved with changes on $04 / 14 / 2020$ by the Chair of the Institutional Review Board. The resubmitted changes were approved administratively on 06/09/2020. This study was approved through Expedited Review Procedure, according to 45 CFR 46.110(b), since this study falls under Category 7: Research on individual or group characteristics or behavior (including, but not limited to, research on perception, cognition, motivation, identity, language, communication, cultural beliefs or practices, and social behavior) or research employing survey, interview, oral history, focus group, program evaluation, human factors evaluation, or quality assurance methodologies

This study now has final IRB approval from 06/09/2020 through 06/08/2023.

This study was also approved through 45 CFR 46.116 (C), which means that an IRB may waive the requirement for the investigator to obtain a signed informed consent form for some or all subjects.

The following items have been approved:

\begin{tabular}{|c|c|c|c|}
\hline \multicolumn{4}{|l|}{ Submission Components } \\
\hline Form Name & Version & \multicolumn{2}{|l|}{ Outcome } \\
\hline Submit for Initial Review & Version 1.0 & \multicolumn{2}{|c|}{ Approved as Submitted } \\
\hline $\begin{array}{l}\text { Review Response Submission } \\
\text { Form }\end{array}$ & Version 3.0 & \multicolumn{2}{|c|}{ Approved as Submitted } \\
\hline $\begin{array}{l}\text { Review Response Submission } \\
\text { Form }\end{array}$ & Version 2.0 & \multicolumn{2}{|c|}{ Approved as Submitted } \\
\hline $\begin{array}{l}\text { Review Response Submission } \\
\text { Form }\end{array}$ & Version 1.0 & \multicolumn{2}{|c|}{ Approved as Submitted } \\
\hline IRB Study Application & Version 1.1 & \multicolumn{2}{|c|}{ Approved as Submitted } \\
\hline \multicolumn{4}{|l|}{ Study Document } \\
\hline Title & Version \# & Version Date & Outcome \\
\hline Brochure & Version 1.0 & $03 / 13 / 2020$ & Approved \\
\hline Interview Guide & Version 1.0 & $02 / 26 / 2020$ & Approved \\
\hline Demographics form & Version 1.0 & $02 / 20 / 2020$ & Approved \\
\hline FACT-HN Questionnaire & Version 1.0 & $02 / 20 / 2020$ & Approved \\
\hline
\end{tabular}




\begin{tabular}{|l|l|l|l|}
\hline HIPAA Complete waiver & Version 1.1 & $06 / 08 / 2020$ & Approved \\
\hline Study Protocol & Version 1.2 & $03 / 27 / 2020$ & Approved \\
\hline Unsigned consent & Version 1.1 & $03 / 16 / 2020$ & Approved \\
\hline
\end{tabular}

IRB policy requires that investigators use the IRB "stamped" approved version of informed consents, assents, and other materials given to research participants. For instructions on locating the IRB stamped documents in iRIS visit: https://louisville.edu/research/humansubjects/iRISSubmissionManual.pdf

Your study does not require annual continuing review. Your study has been set with a three year expiration date. If your study is still ongoing you will receive iRIS automated reminders to submit a request to continue your study prior to the expiration date above.

All other IRB requirements are still applicable. You are still required to submit amendments, personnel changes, deviations, etc... to the IRB for review. Please submit a closure amendment to close out your study with the IRB if it ends prior to the three year expiration date.

Human Subjects \& HIPAA Research training are required for all study personnel. It is the responsibility of the investigator to ensure that all study personnel maintain current Human Subjects \& HIPAA Research training while the study is ongoing.

Site Approval

Permission from the institution or organization where this research will be conducted must be obtained before the research can begin. For example, site approval is required for research conducted in UofL Hospital/UofL Health, Norton Healthcare, and Jefferson County Public Schools, etc...

Privacy \& Encryption Statement

The University of Louisville's Privacy and Encryption Policy requires identifiable medical and health records; credit card, bank account and other personal financial information; social security numbers; proprietary research data; and dates of birth (when combined with name, address and/or phone numbers) to be encrypted. For additional information: http://louisville.edu/security/policies.

Implementation of Changes to Previously Approved Research

Prior to the implementation of any changes in the approved research, the investigator must submit modifications to the IRB and await approval before implementing the changes, unless the change is being made to ensure the safety and welfare of the subjects enrolled in the research. If such occurs, a Protocol Deviation/Violation should be submitted within five days of the occurrence indicating what safety measures were taken, along with an amendment to revise the protocol.

Unanticipated Problems Involving Risks to Subjects or Others (UPIRTSOs)

A UPIRTSO is any incident, experience, or outcome, which has been associated with an unexpected event(s), related or possibly related to participation in the research, and suggests that the research places subjects or others at a greater risk of harm than was previously known or suspected. The

Full Accreditation since June 2005 by the Association for the Accreditation of Human Research Protection Programs, Inc

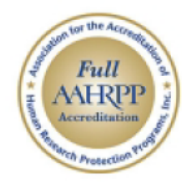


investigator is responsible for reporting UPIRTSOs to the IRB within 5 working days. Use the UPIRTSO form located within the iRIS system. Event reporting requirements can be found at:

http://louisville.edu/research/humansubjects/lifecycle/event-reporting.

\section{Payments to Subjects}

In compliance with University policies and Internal Revenue Service code, payments to research subjects from University of Louisville funds, must be reported to the University Controller's Office. For additional information, please call 852-8237 or email controll@louisville.edu. For additional information:

http://louisville.edu/research/humansubjects/policies/PayingHumanSubjectsPolicy201412.pdf

The committee will be advised of this action at a regularly scheduled meeting.

If you have any questions, please contact: Jackie Powell 852-4101 jspowe01@louisville.edu

\section{Pate $m$ alusach}

Peter M. Quesada, Ph.D., Chair

Social/Behavioral/Educational Institutional Review Board

$\mathrm{PMQ} / \mathrm{jsp}$

We value your feedback; let us know how we are doing: https://www.surveymonkey.com/r/CCLHXRP

Full Accreditation since June 2005 by the Association for the Accreditation of Human Research Protection Programs, Inc

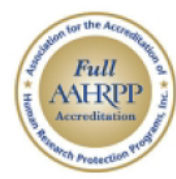




\section{Appendix J}

\section{University of \\ CINCINNATI}

Institutional Review Board

FWA \#: 000003152

\section{ACKNOWLEDGEMENT OF EXTERNAL IRB REVIEW}

March 25, 2020

Alice Tang

COM Oto H\&N Oncologic Surgery

Dear Alice Tang,

\begin{tabular}{|r|l|}
\hline Type of Submission: & IRB Site \\
\hline Title: & $\begin{array}{l}\text { Site for The Lived Experience of Women with Head and Neck Cancer } \\
\text { and the Impact on Close Relationships }\end{array}$ \\
\hline Investigator: & Alice Tang \\
\hline IRB ID: & 2020-0239-001 \\
\hline Funding: & Name: Investigator-Initiated \\
\hline IRB of Record: & University of Louisville \\
\hline
\end{tabular}

The IRB has received the above referenced submission. After review of the materials submitted, the UC IRB has determined per 45 CFR 46.114 that UC (or "Relying Institution") will rely on University of Louisville IRB for the review of this research. This determination is effective $3 / 25 / 2020$ for the aforementioned study. Study-related activities on this protocol may commence per the Designated IRB of Record's approval date.

Even though this institution is relying on the Designated IRB of Record for this research, your responsibilities as Principal Investigator include ensuring:

1. the prompt forwarding to the Designated IRB of Record noted above of any information and/or required submissions related to continuing review, unanticipated problems, investigator requests for modification of approved research or related forms (including subject consent forms), and possible deviations from IRB-approved research protocol or other concerns about the manner in which such research is being conducted, in accordance with the Designated IRB of Records' policies and procedures

2. that IRB approval is maintained for the duration of each research protocol

3. that a procedure is established by which the Designated IRB of Record will receive and review the materials for this study

4. the prompt forwarding of all continuing review approvals from the Designated IRB of Record to this institution's IRB for this study

5. that the Designated IRB of Record and this institution is notified in writing of study completion for this study;

6. full cooperation with any request from the Designated IRB of Record for information or documentation relating to the research proposal or the conduct of the research following IRB approval

7. compliance with the determinations made by the Designated IRB of Record

8. in the event that the Designated IRB of Record determines that the research must be suspended or discontinued, or that specific conditions must be met in order for the research project to commence or

Page 1 of 2 
2020-0239-001

IRB Site Acknowledgement

continue, the PI shall be responsible for implementing and enforcing that determination and notifying this institution if such a situation were to occur

9. the protection of human subjects with respect to the conduct of the research

10. safeguarding the rights and welfare of human subjects through active monitoring of the manner in which such research is conducted, including the continuing competency of employees or agents performing such research

Please note the following requirements:

CHANGES IN THE RESEARCH PERSONNEL: The investigator must immediately report to the UC IRB and the IRB of Record any changes to the research staff. The University of Cincinnati IRB is still responsible for review of Conflict of Interest and required training (e.g., CITI, FDA).

CONTINUING REVIEW: The investigator must provide documentation, in the form of an Approval Letter, of the external IRB's continuing review of the research to the IRB prior to the external IRB's expiration date. Updated Conflict of Interest forms must be provided and required training must be current for all active research personnel.

STUDY COMPLETION: The investigator is responsible for notifying the UC IRB when the research, including data analysis, is complete. The notification will occur using the Request to close submission in RAP.

\section{PI Notifications}

This acknowledgement is through the UC IRB only. You may be responsible for reporting to other regulatory officials. Please check with your institution and department to ensure you have met all reporting requirements.

\section{Statement regarding International Conference on Harmonization and Good Clinical Practices}

The Institutional Review Board is duly constituted (fulfilling FDA requirements for diversity), has written procedures for initial and continuing review of clinical trials: prepares written minutes of convened meetings and retains records pertaining to the review and approval process all in compliance with requirements defined in 21 CFR Parts 50, 56 and 312 Code of Federal Regulations. This institution is in compliance with the ICH GCP as adopted by FDA/DHHS.

Thank you for your cooperation during the review process. 


\section{Appendix K}
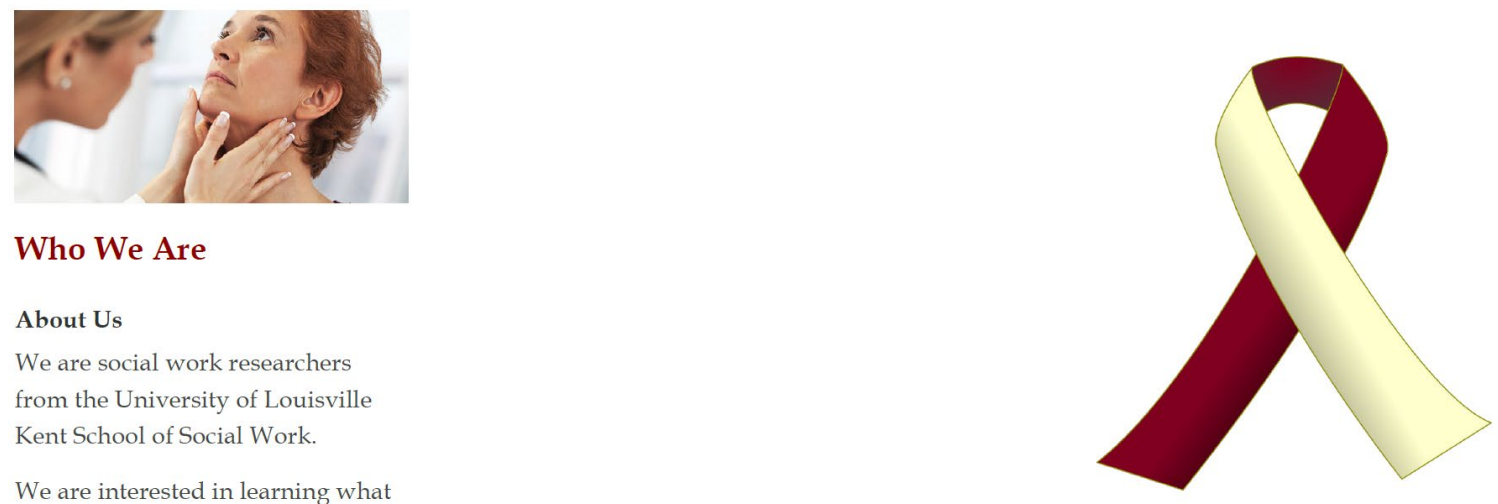

We are interested in learning what it is like to be a woman living with head and neck cancer.

Contact Us

- Phone:

- 513-417-1725 (Georgia Anderson, cell)

- 502-852-1946 (Dr. Kayser, office) You can leave a confidential message on our voicemail.

Women Living with Head \& Neck Cancer and the Impact on Relationships 


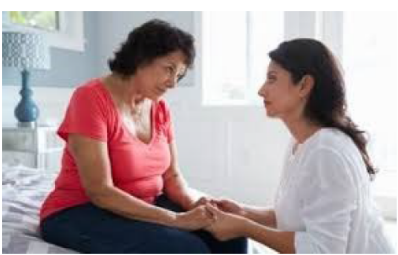

\section{Having cancer can change} everything.

Going through cancer treatment can be difficult for both you, your family and friends.
We would like to invite you to participate in a study which is designed to:

- Understand what it is like to live with head and neck cancer

- Understand how your cancer diagnosis impacted your relationships

- Identify how to best help patients

You are eligible to participate if you:

- Are a woman with head and neck cancer

- Are over 18 years old

- Can speak English

- Are able and willing to participate in 2 interviews
What will happen in this study?

- We will ask you to complete a short questionnaire before being interviewed

- You can be interviewed in clinic, hospital, or your home.

- There will be 2 in-person interviews (approximately 60 minutes each). The interviews will be about 2 weeks apart.

How long will I take part in this study?

- Your participation will be finished after completing the second interview.

- In appreciation for your participation, each of you will receive a total of $\$ 40$ when you complete the interviews ( $\$ 20$ for each interview). 


\section{Appendix L - Sample Field Notes}

Memo

February 24, 2021

Eight of my participants have adult children, five of them having daughters. I am aware that this is particularly present for me because this situation is so personal for me. My own father died in May 2020 and I provided care for him during the last couple weeks of his life. He lived out of state, so I am unsure of how much caregiving he would have allowed me to do, had we lived closer. I am revisiting my grief and also wondering how caring for a father might be different from caring for a mother.

I keep thinking of how the sons provided help with tube feedings and physical care and were sometimes able to share in their mother's emotional concerns. The daughters were described more in terms of emotional support and physical support. In three of the women's families, their daughters have babies (children under age 2) and are managing both caregiving responsibilities. In some cases, the daughters persuaded their mothers to get treatment for the cancer that the patient may not have elected without their influence.

Going further down the rabbit-hole, I think of myself as a mother and what it would be like for my children to have to provide physical care to me. Of course, my kids are still young -10 and 7. Mostly I hope that I never need them to take care of me. One the other hand, I hope they will remember the love I tried to give and will jump in to help me. One of my participants, was so candid when she told me her kids “just don't give a shit." I know relationships can be hard for a variety of reasons. I hope I can't ever relate to that either. 
It feels important that the daughters rallied around their mothers. The organized meals and schedules with other family and friends. They also talked with their mothers, really talked about the fears and victories they faced in the cancer journey. It seems like a mix of nature and nurture. Some of the sons talked too, but the descriptions from the women made me think that the conversations were not very deep. I wish I would have probed into this more, but at the time, it didn't seem as pronounced. I think it will be important for me to be mindful of my own transference about the parent-child caregiving dyad. 


\section{Appendix $\mathbf{M}-$ Coding Sample $-1^{\text {st }}$ Iteration}

Amelia:

I lost 70 pounds since this all started.

Interviewer:

Oh my goodness.

Amelia:

So once I had the surgery, they said the chemo, and the radiation didn't work. So, we can try this clinical trial which is a new therapy, it was the Opdivo and they were a little concerned because I've had problems with colitis in the past and that was a side effect of this Opdivo. Well [inaudible $00: 10: 06$ ] the second treatment [inaudible 00:10:08] and they had to take me off because I couldn't keep anything my stomach.

Interviewer:

Oh goodness.

Amelia:

I have had diarrhea since last February. I'm down to 95 pounds. Every time they put me on Prednisone and every time I get down to maybe 10 milligrams of Prednisone it flares back up again and that's what happened now. So, one of my options is to do these Remicade infusions, it's supposed to help with colitis, but the side effects scared me to death. I mean either tuberculosis, you can get cancer, all kinds of infections. I just think I'm asking for trouble. I went into an endocrinologist last week and she said, "I have at it as the Less of two evils. Be on a smaller dosage of Prednisone for a longer period of time or try the immune therapy or the remicade."

Interviewer:

Yeah.

Amelia:

So, I got to call in my doctor because I'm losing weight because I can't keep anything in my stomach. Then the radiation I had an underactive thyroid and so the radiation messed all that up because it was right there, where my pituitary gland and my thyroid and everything, so not immune therapy they're trying to get that straightened out. So that's why I'm so tired and I'm anemic and I'm getting B12 shots because I'm low on that and iron. So, it's just kind of been a roller coaster for the last two years.
Losing $70 \mathrm{lbs}$ from

illness/surgery

Being told chemo and rads didn't work

Going on clinical trial

Having to stop trial because of severe stomach problems

Losing an additional $25 \mathrm{lbs}$. (95 total)

Getting steroids to help manage colitis

Choosing between "lesser of two evils" with steroids or medications that may cause more cancer

Having complications from radiation

Aggravating thyroid and pituitary glands

Getting immunotherapy Getting B12 shots and iron Being on a rollercoaster for 2 years 
Interviewer:

It sounds like it. You've really been through a lot.

Amelia:

Yeah it's been ... There was one thought where I really didn't think I was going to make it, because I thought this was after my first surgery. My neighbor is one of my best friend, she moved in about five years ago and she's been by my side through this whole thing. I thought I was having a heart attack. I called [inaudible 00:12:44] I can't remember who called 911. I was laying down and the room was spinning and I had this horrendous headache, I was nausea. It wasn't pain but more of a heaviness in my chest.

So, when the EMTs got there, they said "Yeah I think that you are having a heart attack." So they took me to hospital. They even checked it in the ambulance and they said, "Yeah I think you are." Then I got there to the hospital and then they took another one and they said that I was just severely dehydrated which has the same effect on your body.

Interviewer:

Oh my goodness I didn't know that.

Amelia:

I think I'm going to die. It's been rough, because I live by myself, so I don't really have anybody here that helps me. I mean my family is great and my friends have all been great they've helped me out enormously but yeah it's still not the same just having somebody there with you.

Interviewer:

Yeah. Does your best friend still live with you?

Amelia:

She lives next door.

Interviewer:

Next door, okay.

Amelia:

Yeah she's still there.

Interviewer:

Okay, cool. So when you got diagnosed what was going on in
Thinking she wouldn't survive after first surgery

Needing 911 because she thought she was having a heart attack

Being severely dehydrated presented like a heart attack

Thinking she is going to die

Living alone is hard

Having great help, but also being alone

Having best friend live next door 


\section{Appendix $\mathrm{N}$ - Coding sample $-2^{\text {nd }}$ Iteration - All gerunds entered in Excel}

\begin{tabular}{|c|c|}
\hline Amelia & Being referred to oral surgeon for biopsy \\
\hline Amelia & Being a non-smoker \\
\hline Amelia & Confirming cancer diagnosis \\
\hline Amelia & Having squamous cell carcinoma \\
\hline Amelia & Describing surgery as "the most horrendous thing I've ever been through" \\
\hline Amelia & Surgery taking a long time \\
\hline Amelia & Having surgery \\
\hline Amelia & Having arm bone to make new jawa \\
\hline Amelia & Having infection in jaw \\
\hline Amelia & Getting metal plate in mouth \\
\hline Amelia & Having a graft from leg to repair arm \\
\hline Amelia & Having surgery \\
\hline Amelia & Having radiation \\
\hline Amelia & Having chemotherapy \\
\hline Amelia & Being depleted after surgery \\
\hline Amelia & Needing repeat hospitalization \\
\hline Amelia & Going to SNF for PT \\
\hline Amelia & Needing another surgery after SNF \\
\hline Amelia & Discharging home after first surgery \\
\hline Amelia & Feeling like a burden to her daughter \\
\hline Amelia & Having feeding tube \\
\hline Amelia & Daughter feeding her \\
\hline Amelia & Living with her daughter after surgery \\
\hline Amelia & Getting infection while recoving from 1st surgery \\
\hline Amelia & Having swelling "looking like a bullfrog" \\
\hline Amelia & Having infected area burst \\
\hline Amelia & Having drainage from cancer for a year \\
\hline Amelia & Getting metal plate replaced \\
\hline Amelia & Being surprised by reoccurent in her bones \\
\hline Amelia & Needing a 2nd surgery \\
\hline Amelia & Not wanting to have another surgery \\
\hline Amelia & Being told she would die without surgery \\
\hline Amelia & Dying wasn't an option \\
\hline Amelia & Getting a second opinion \\
\hline Amelia & Getting 2nd surgery \\
\hline Amelia & Replacing jawbone with leg bone \\
\hline Amelia & Having a skin graft on her neck \\
\hline Amelia & Feeding tube \\
\hline Amelia & Losing a lot of weight \\
\hline Amelia & Chemo and radiation didn't prevent reoccurence \\
\hline Amelia & Being on a clinical trail \\
\hline Amelia & Stopping trial because of severe stomach problems \\
\hline Amelia & $\begin{array}{l}\text { Choosing "lesser of } 2 \text { evils" with steroids for stomach or meds that may cause more } \\
\text { cancer }\end{array}$ \\
\hline
\end{tabular}




\section{Appendix 0 - Coding Sample $-3^{\text {rd }}$ Iteration - Grouping of ideas}

\begin{tabular}{|c|c|c|c|}
\hline $\begin{array}{l}7 \\
9 \\
7\end{array}$ & $\begin{array}{l}\text { Lou } \\
\text { Lady } \\
\text { Lou }\end{array}$ & $\begin{array}{l}\text { Wanting people to know there is more beyond life on Earth } \\
\text { Wanting to give back to the cancer center } \\
\text { Winning no matter what because she has God }\end{array}$ & $\begin{array}{l}\text { coping } \\
\text { coping } \\
\text { coping }\end{array}$ \\
\hline 6 & Kiki & Wondering if cancer is a friend to warn you about your wellbeing & coping \\
\hline $\begin{array}{l}8 \\
6\end{array}$ & $\begin{array}{l}\text { Pooh } \\
\text { Kiki }\end{array}$ & $\begin{array}{l}\text { Picking self up and keep going } \\
\text { Praying for a plan to work with the Divine }\end{array}$ & $\begin{array}{l}\text { coping } \\
\text { coping }\end{array}$ \\
\hline $\begin{array}{l}8 \\
8 \\
5\end{array}$ & $\begin{array}{l}\text { Pooh } \\
\text { Pooh } \\
\text { Penny }\end{array}$ & $\begin{array}{l}\text { Intersection of cancer and covid } \\
\text { Allowing select visitors to her home (daughter and some neighbors) } \\
\text { Avoiding holiday gatherings because of Covid }\end{array}$ & $\begin{array}{l}\text { covd } \\
\text { Covid } \\
\text { Covid }\end{array}$ \\
\hline 7 & Lou & Avoiding in-person church because of Covid & covid \\
\hline 5 & Penny & Avoiding public places because of Covid & covid \\
\hline 2 & Annie & Beating cancer empowers her to feel she could be Covid & covid \\
\hline 3 & Amelia & Being able to avoid resturants because of Covid & covid \\
\hline 3 & Amelia & Being afraid of getting Covid & covid \\
\hline 8 & Pooh & Not being able to sit and enjoy a meal & eating \\
\hline 5 & Penny & Not having company for meals & eating \\
\hline 7 & Lou & Noticing some peole are uncomfortable when she can't eat with them & eating \\
\hline $\begin{array}{l}1 \\
6\end{array}$ & $\begin{array}{l}\text { Sue } \\
\text { Ellen } \\
\text { Kiki }\end{array}$ & $\begin{array}{l}\text { Preferring a fork over a spoon } \\
\text { Still has feeding tube }\end{array}$ & $\begin{array}{l}\text { eating } \\
\text { eating }\end{array}$ \\
\hline 9 & Lady & Struggling to manager her diabets during hosptial stay & eating \\
\hline 8 & Pooh & Working for every meal- changes in lifestyle & eating \\
\hline $\begin{array}{r}1 \\
10 \\
7\end{array}$ & $\begin{array}{l}\text { Sue } \\
\text { Ellen } \\
\text { Kitty } \\
\text { Lou }\end{array}$ & $\begin{array}{l}\text { Worrying about ability to eat } \\
\text { Worrying about maintaining weight } \\
\text { Family adjusting to eating changes }\end{array}$ & $\begin{array}{l}\text { eating } \\
\text { eating } \\
\text { eating }\end{array}$ \\
\hline 1 & $\begin{array}{l}\text { Sue } \\
\text { Ellen }\end{array}$ & Acknowledging adjustment is hard & Emotions \\
\hline 7 & Lou & Acknowledging that cancer can be sad & emotions \\
\hline 7 & $\begin{array}{l}\text { Lou } \\
\text { Sue }\end{array}$ & Admitting she is sometimes upset & \\
\hline 1 & $\begin{array}{l}\text { Ellen } \\
\text { Sue } \\
\text { Ellen }\end{array}$ & $\begin{array}{l}\text { Afraid of her reaction } \\
\text { Asking for time alone to process feelings }\end{array}$ & $\begin{array}{l}\text { Emotions } \\
\text { emotions }\end{array}$ \\
\hline 8 & Pooh & Becoming distraught & emotions \\
\hline $\begin{array}{l}5 \\
7 \\
\end{array}$ & $\begin{array}{l}\text { Penny } \\
\text { Lou }\end{array}$ & $\begin{array}{l}\text { Being able to process through feelings } \\
\text { Being angry is expressed as upset }\end{array}$ & $\begin{array}{l}\text { emotions } \\
\text { emotions }\end{array}$ \\
\hline
\end{tabular}




\section{Appendix P- Developing Parent/Child Codes}

Physical Impact of HNC

\section{Control}

- Advocating for self

- Self-care

- Planning (financial, Advance Directives, funeral arrangements)

- Making treatment decisions

\section{$\underline{\text { Adjustment }}$}

- Role changes (level of independence, accepting assistance)

- Personal style (hair, makeup, jewelry, clothing)

- Eating (food choices, modifying food, tube feeding, eating as a social activity, adapting to mechanics of eating - utensils, etc.)

- Changes in self (attitude)

- Changes in lifestyle/health habits

- Seeking normalcy in daily activities

- Awareness of mortality

- Coping with Covid

\section{Support Received}

- Increased closeness

- Physical care

- Emotional support

- Having a confidante

- Material assistance/Financial help

- Prayers

- Help going to medical appointments

- Relationship with medical team
- Pain

- Changes in saliva production

- Dental problems

- Fatigue

- Memory problems

- Weight loss

- Losing voice

- Skin changes

- Nausea

- Sleep disturbances

- Skin tightening

- Choking

- Infections

- Swallowing problems

- Lymphedema/edema

- Treatment (surgery, radiation, chemotherapy, immunotherapy)

Emotional Impact of HNC

- Worry/anxiety

- Emotional rollercoaster

- Fear of reoccurrence

- Stigma/shame (self and projected from others)

- Pondering morality

- Gratitude (happy to be alive, others have it worse)

- Others' reaction to appearance/physical changes

Adverse Life Events

- Domestic violence

- Death of child

- Death of parents (caring for them at end of life)

- Medical condition predisposing cancer

- Divorce 


\section{Grieving}

- Legacy planning

- Loss of former lifestyle- life plans

- Loss of former appearance

- Distancing in personal relationships

- Unmet needs

- Fertility/family planning

\section{Coping}

- Spiritual

- Mental Health Therapy

- Family Support

- Activities (Classes, crafts, cooking)

- Maintaining normalcy (no fuss)

- Acknowledging a range of emotions

- Managing expectations

- Personality traits

- Medical intervention (antidepressants/anti-anxiety meds) 
CURRICULUM VITAE

Georgia Anderson, LISW-S

\section{Glande08@1ouisville.edu}

\section{EDUCATION:}

PhD in Social Work - University of Louisville, Louisville, KY - May 2021

Master of Social Work - University of Kentucky, Lexington, KY - May 2007

Bachelor of Liberal Arts with Psychology minor - Xavier University, Cincinnati, OH - May 2004

\section{CURRENT LICENSURE/CERTIFICATIONS:}

Licensed Independent Social Worker Supervisor - August 2010 - Present

\section{MANUSCRIPTS:}

Anderson, G., (2021) End of life care during the Covid-19 pandemic: Professional influence on a personal loss. Journal of Psychosocial Oncology.

Kayser, K., Washington, A., Anderson, G., Harris, L., Lee, H., Lajoie, A.S. (In progress). Perceived barriers and facilitators in assessing cervical cancer screening: The voices of women in a low-income urban community (Submitted for review: Family and Community Health).

LaJoie, A.S., Anderson, G., Randall, J., Smith, L., Washington, A., Kayser, K. (In progress) Evaluating the impact of health promotion and health education programs to reduce HPV and cervical cancer burden in rural communities: A systematic review. Manuscript in preparation.

Randall, J.; Anderson, G.; and Kayser, K. (In progress). Pre-hematopoietic cell transplantation psychosocial assessment practices: A national survey. Manuscript in preparation.

\section{PEER REVIEWED ORAL PRESENTATIONS:}

Kayser, K. and Anderson, G. The ECHO ${ }^{\circledR}$ Tele-mentoring Model: How Social Workers can extend best practices in health during the Coronavirus Pandemic. Society for Social Work Research Conference, January 2021 
LaJoie, A.S., Anderson, G., Randall, J., Smith, L., Washington, A., Kayser, K. Evaluating the impact of health promotion and health education programs to reduce HPV and cervical cancer burden in rural communities: A systematic review. APHA's 2019 Annual Meeting and Expo (November 2019)

Washington, A., LaJoie, A.S. Kayser, K., Anderson, G. Knowledge and attitudes related to accessing cervical cancer preventative services among African American Women in West Louisville. Research! Louisville, September 2019, 2nd Place, Health Disparities Award

\section{TEACHING/ADADEMIC EXPERIENCE:}

University of Louisville, Louisville, KY

Research Assistant to Karen Kayser, Ph.D., MSW

2016-2018

Active member of Cervical Cancer/HPV study with responsibilities including facilitating focus groups and coding focus group data

Attended ECHO Institute training (Spring 2018)

\section{Acting Administrator of Psychosocial Oncology Specialization}

MSSW Program, Kent School of Social Work (Spring Semester 2018)

Served as Acting Administrator during Endowed Chair's Sabbatical

Responsibilities included reviewing applicants to Psychosocial Oncology specialization program, student advising, planning reception for specialization students, and other administrative duties as needed.

\section{Project ECHO Administrator and IT support}

2018-2020

Responsibilities include managing session schedule, coordination of speakers and participants, coordinating Zoom sessions, troubleshooting and assisting with technology needs of all participants, managing online surveys/feedback and reporting all program data.

Cervical Cancer/HPV ECHO (September 2018)

India-USA Psycho-Oncology ECHO (Spring 2019)

Cancer Care and COVID-19 ECHO (Spring 2020)

\section{Adjunct Professor}

Field Faculty - MSSW program, online (Fall 2018, Spring 2019) 
Xavier University, Cincinnati, Ohio

Adjunct Professor

Research Methods - Required BSW curriculum (Fall 2018)

Social Work Practice III: Communities and Organizations - Required BSW curriculum (Fall 2019)

\section{PROFESSIONAL EXPERIENCE (POST-MSW):}

Cancer Support Community (formerly The Wellness Community), Cincinnati, OH 45242

Support Group Facilitator - June 2008 - present (Break Dec. 2012 - Feb. 2016)

Facilitate weekly support groups for people living with cancer and caregivers (friends and family) of people with cancer, facilitate networking groups, including Gynecologic cancers, Cancer Grads, Metastatic Breast Cancer, and Pre-Vivors (focused on genetic testing).

\section{University of Cincinnati Medical Center, Cincinnati, OH 45229}

Social Work Manager: Outpatient, OB, Office of Decedent Affairs and Palliative Care October 2012 - July 2016

Provided clinical and administrative leadership to 39 social workers and 1 community health worker in the following outpatient clinics: oncology, solid organ transplant, sickle cell, cystic fibrosis, neurology, general medicine \& subspecialties, and obstetrics (inpatient and outpatient). Provided clinical and administrative leadership to the Office of Decedent Affairs, a 24/7 social work service to support inpatient hospital units by providing bereavement support and dispositioning for all hospital deaths (adult and infant.) Provided administrative leadership and program development for the Palliative Care program and clinical supervision of the team social worker. Responsible for growing Social Work services to provide optimal support for patients and families within the UC Health system. Additional responsibilities included provision of clinical supervision to social workers seeking advanced licensure, planning Continuing Education programs for social work staff, managing the approval and reporting of Continuing Education Units for the University of Cincinnati Medical Center by the Ohio Counselor, Social Worker and Marriage \& Family Therapist Board, tracking and reporting metrics and performance improvement in each clinical area. Served on multiple committees including: Cancer Committee (representing Psychosocial Services and Palliative Care), UC Health Morbidity and Mortality Committee, Ethics, End of Life, LVAD Selection, Diabetes Now, Social Work Department Professional Development Committee, and Chairperson for Schwartz Rounds Committee. 
Oncology Social Worker- The Barrett Cancer Center

March 2008-October 2012

Provided assessment, emotional support, counseling, and referrals for people with cancer and their families. Developed and conducted pre-surgery psychosocial assessments of patients with Head and Neck Cancer. Facilitated support groups for women with cancer and people with head and neck cancer. Served as Coordinator of Psychosocial Services on Cancer Committee. Provided clinical supervision setting to social workers seeking LISW licensure. Achieved Healthcare Professional Advancement Level II in 2009 and Healthcare Professional Advancement Level III in 2010. Served as co-chairperson for Schwartz Rounds Committee and as co-chairperson of Social Work Department Professional Development Committee.

Palliative Care Social Worker

January 2011-April 2012

Provided assessment, emotional support, care collaboration and education for patients and families coping with life limiting illness in the outpatient and inpatient settings. Provided support and education to patients, families, and staff about end-of-life care. Provided education to hospital staff about palliative care.

\section{Centerpoint Healthcare, Cincinnati, OH 45227}

Outpatient Therapist

September 2007-March

Provided counseling to school-age children, adolescents, adults and families. Duties included working with people individually and in groups, assessment, treatment planning, coordinating referrals and collaborating care in a community mental health agency. Demonstrated the ability to engage with diverse client population and demonstrated a willingness to work with clients who have been treatment resistant.

\section{Greater Cincinnati Behavioral Health Services, Cincinnati, OH 45206}

Case Manager

January 2006-September 2007

Responsible for educating clients with severe mental illness and their families about diagnosis and medications, as well as independent living skills, interpersonal skills, and coping skills in a community-based setting. Duties included treatment planning, crisis intervention, and coordinating with the client and the community to access resources and benefits. All duties performed with a clinical emphasis on recovery. 


\section{PRESENTATIONS}

Schwartz Rounds: "Looking in the Mirror: When You See Yourself in the Patient" clinical presentation; University of Cincinnati Medical Center, June 2012

"Accepting Illness" clinical presentation given to Department of Social Work at University of Cincinnati Medical Center, May 2010

Expert Panel Speaker at Central States Communication Association Annual Conference on Palliative Care and Healthcare Communications; April 2010

"Frankly Speaking about Coping with the Cost of Cancer", The Wellness Community, October 2009

"Money Matters: Facing Cancer in a Stressful Economy", The Wellness Community, April 2009

"Managing the Fear of Reoccurrence: A Panel Discussion", The Cancer Support Community (formerly The Wellness Community), March 2013 \& May 2014

Invited lecturer at University of Cincinnati MSW program," Palliative Care", March 2013 \& March 2014

Guest Speaker for Leukemia \& Lymphoma Society Caregiver Connection, November 2013

Panelist, Cincinnati State, undergraduate Social Work class, November 2013

Invited lecturer at University of Cincinnati Learning Community Class; October 2014, March 2015 \& April 2015

Panelist - American Cancer Society ResearcHERS campaign launch (Cincinnati and Louisville), April 2019

Acknowledged Guest - American Cancer Society Hope Gala, Louisville, KY; September 2018

“Whole Person Care 101” Cancer Support Community Cincinnati, November 2019

\section{SCHOLARSHIPS, GRANTS \& AWARDS}

Graduate Dean's Citation, University of Louisville

May 2021

Awarded at each commencement to both masters and doctoral students recommended by their departments in recognition of superior accomplishment (e.g., publications, teaching excellence, and professional service) in their graduate studies beyond the achievement of a high grade point average. 
American Cancer Society Doctoral Training Grant for Social Work

$\begin{array}{lll}\text { Initial term } & 2018-2020 & \$ 40,000 \\ \text { Renewal } & 2020-2021 & \$ 20,000\end{array}$

University of Louisville Research Assistantship (Tuition and monthly salary) 2016-2018

Tuition and Monthly Salary

NCI-funded Psychosocial Distress Screening Project with the American Psychosocial Oncology Society and Yale School of Nursing

Member of dyad selected to participate in inaugural training program

February 2014- February 2016

Cancer Family Care Pauline Cohen Award, Cincinnati, OH

Awarded for outstanding contributions to the lives of people who are touched by cancer.

May 2012

\section{SERVICE AND MEMBERSHIPS}

Journal of Psychosocial Oncology

Reviewer, 2017-present

Cancer Support Community

Member of Education Committee, 2019 - present

Member of Psychosocial Curriculum Committee, 2019- present

Academic Judge

BSW Capstone Posters, University of Louisville, April 2017

Mistress of Ceremonies

Cancer Support Community Jokefest, November 2019 \& 2020

Practicum Field Instructor

University of Cincinnati MSW student, Regina Dunlap, 2012-13

University of Louisville MSW student, Oncology Specialization, Kelly Moore, 2013-15

Member of Association of Oncology Social Work

Member of National Association of Social Workers

Member of Ohio, Kentucky,Indiana (OKI) Social Work Leaders in Healthcare, 20142016

Member of Advance Care Planning Coalition through the Greater Cincinnati Health Collaborative, 2015 